\section{ZUSAMMENFASSUNG DER ZENTRALEN ERGEBNISSE}

\subsection{Die Biosphärenparklandschaft Österreichs}

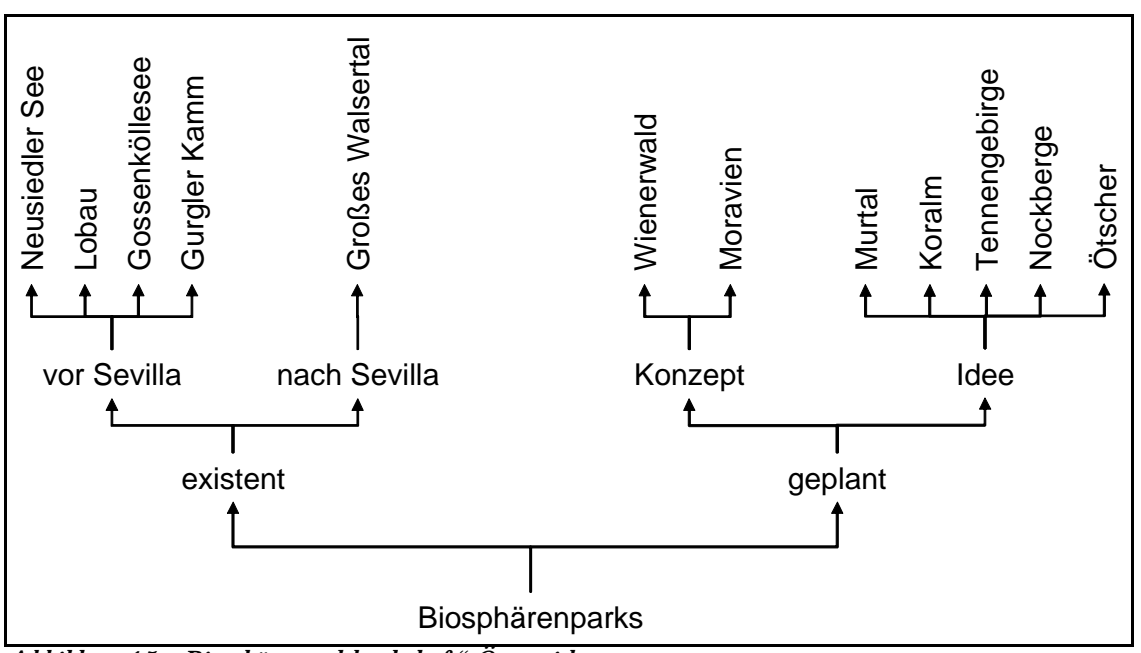

Abbildung 15: „Biogphärenparklandshaft" Östereichs

Aktuell gibt es in Österreich fünf Biosphärenparks (vergl. Abbildung 15) Neusiedler See, Untere Lobau, Gossenköllesee und Gurgler Kamm sind angeregt durch die bemühungen regionaler Forschungsinitiativen bereits vor mehr als 25 Jahren (1977) entstanden. Zu diesem Zeitpunkt wurde einer umfassenden, nachhaltigen Regionalentwicklung nicht jene Bedeutung zugemessen, die sie durch die 1995 beschlossene Sevilla-Strategie enlangte (vergl. Anhang-2). Demgegenüber steht das Große Walsertal als Biosphärenpark der „,neuen Generation“, der von den Kriterien der Sevilla Strategie maßgeblich bestimmt ist und im Jahr 2000 ins weltweite Biosphärenparknetz aufgenommen urrde.

In jüngerer Zeit wurden über ganz Österreich verteilt rege Anstrengungen untemommen, zusätzliche Biosphäremparks ins Leben zu nufen. Am weitesten fortgeschnitten ist dabei der Planungsprozess im Wienerwald, der sich in der Einnichtungsphase befindet und voraussichtlich 2005 als Biosphärenpark ausgewiesen wird (vergl. DAS LAND NIEDERÖSTERREICH; ARGE WIENERWALD, 2002). Der Planungsprozess im potenziellen Biosphärenpark Moravien wurde vorübergehend eingestellt, da die Politik der Einnichtung des Biosphärenpark Wienerwald Prionität einräumte. Eine Machbarkeitsstudie zu einem grenzüberschreitenden Biosphärenpark ist aber bereits vorhanden (vergl. MENTIL \& MAITZ, 2002). Die restlichen Biosphärenparkbestrebungen sind unterschiedlich weit gediehen, sie befinden sich jedoch alle noch in der Orientienungsphase. 
5.1.1 Kurzcharakterisierung der Biosphärenparks

\begin{tabular}{|c|c|c|c|c|c|}
\hline Biosphärenpark & Eckgrößen & $\begin{array}{l}\text { Naturraum/zentrale } \\
\text { Elemente }\end{array}$ & Wirtschaft/Landnutzung & Soziologie/Kultur & Verwaltung und Planung, sonstiges \\
\hline $\begin{array}{l}\text { Großes } \\
\text { Walsertal } \\
\text { (einger. 2000) }\end{array}$ & $\begin{array}{l}19.200 \mathrm{ha} \\
-\quad 3500 \mathrm{Ew} .\end{array}$ & $\begin{array}{l}\text { : Geschlossene Talschaft } \\
\text { : Kulturlandschaft } \\
\text { - Gebirgsökosysteme }\end{array}$ & $\begin{array}{l}\text { Landwirtschaft } \\
\text { - Forstwirtschaft } \\
\text { Tourismus }\end{array}$ & $\begin{array}{l}\text { - dünne Besiedelung } \\
\text { - hohe Bodenständigkeit } \\
\text { ldentitätsbewusstsein (die } \\
\text { "Walser") }\end{array}$ & $\begin{array}{l}\text { - eigenes Biosphärenpark-Management } \\
\text { - } \text { dreiteilige Zonierung }\end{array}$ \\
\hline $\begin{array}{l}\text { Gossenköllesee } \\
\text { (einger. 1977) }\end{array}$ & $\begin{array}{l}85 \text { ha } \\
\text { keine Ew. }\end{array}$ & Hochgebirgssee & $\begin{array}{ll}\text { - Forschungsaktivitäten } \\
\text { - gev. Skitourismus } \\
\text { gelegentlich Beweidung }\end{array}$ & $\begin{array}{l}\text { keine Besiedelung/kein } \\
\text { Dauersiedlungsraum }\end{array}$ & $\begin{array}{ll}\text { - } & \text { kein spezifisches BSP-Management } \\
\text { - Offizielle Verwaltung durch Land Tirol } \\
\text { - Koordination der Forschung: Uni Innsbruck } \\
\text { - keine Zonierung } \\
\text { - } & \text { aktuell Lifttrassenplanung }\end{array}$ \\
\hline $\begin{array}{l}\text { Gurgler Kamm } \\
\text { (einger. 1977) }\end{array}$ & $\begin{array}{ll} & 1.500 \text { ha } \\
\text { - keine Ew. }\end{array}$ & $\begin{array}{l}\text { (Hoch)gebirgsregion } \\
\text { Gletscher }\end{array}$ & $\begin{array}{l}\text { - Forschung } \\
\text { - Alpintourismus } \\
\text { - Schansiver Skitourismus }\end{array}$ & $\begin{array}{l}\text { keine Besiedelung/kein } \\
\text { Dauersiedlungsraum }\end{array}$ & $\begin{array}{ll}\text { Kein spezifisches BSP-Management } \\
\text { Verwaltung durch Land Tirol } \\
\text {. } \\
\text { Kuhegebietsbetreuer in Ausschreibung } \\
\text { angrenzend an Südtirol }\end{array}$ \\
\hline $\begin{array}{l}\text { Neusiedler See } \\
\text { (einger. 1977) }\end{array}$ & $\begin{array}{l}25.000 \text { ha } \\
\text { - keine Ew. }\end{array}$ & $\begin{array}{l}\text { Pannonische Tiefebene } \\
\text { - Steppensee } \\
\text { angrenzend: } \\
\text { Kulturlandschaft, } \\
\text { Salzlacken }\end{array}$ & $\begin{array}{l}\text { Forschung } \\
\text { - } \text { Schilfnutzung } \\
\text { - } \text { angrersport } \\
\\
\text { Wein- und Ackerbau }\end{array}$ & $\begin{array}{l}\text { Nähe zu Ungarn } \\
\text { keine Besiedelung/kein } \\
\text { Dauersiedlungsraum }\end{array}$ & 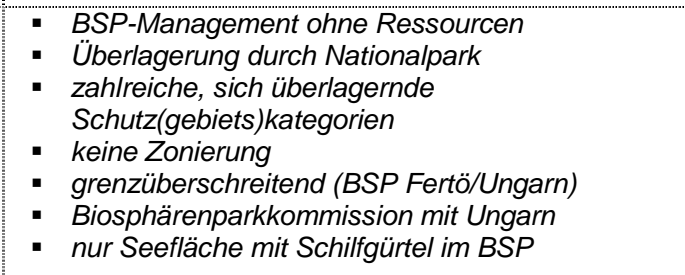 \\
\hline $\begin{array}{l}\text { Lobau } \\
\text { (einger. 1977) }\end{array}$ & $\begin{array}{l}1.203 \mathrm{ha} \\
\text { keine Ew. }\end{array}$ & $\begin{array}{l}\text { abgedämmtes } \\
\text { Auwaldgebiet } \\
\text { - ehemahliges } \\
\text { Überschwemmungs- } \\
\text { gebiet der Donau } \\
\text { - Heißländen }\end{array}$ & $\begin{array}{ll}\text { - Tagestourismus } \\
\text { - } \text { Umwweltbildungsaktivitäten } \\
\text { - Fischerei } \\
\text { - } \text { indirekt Energienutzung }\end{array}$ & $\begin{array}{l}\text { keine Besiedelung } \\
\text { - } \text { proßstadtnähe } \\
\text { Naherholungsgebiet }\end{array}$ & $\begin{array}{ll} & \text { Kein separates BSP-Management } \\
\text { - } & \text { Betreuung: MA 49/ Forstverwaltung Lobau } \\
\text { - } & \text { relativerung durch Nationalparkverwaltung Flächenausmaß } \\
\text { - } & \text { keine genaue Abgrenzung/keine Zonierung (alles } \\
& \text { Kernzone }\end{array}$ \\
\hline $\begin{array}{l}\text { Wienerwald } \\
\text { (in Planung) }\end{array}$ & $\begin{array}{l}105.370 \text { ha } \\
750.000 \mathrm{Ew} . \\
\text { (inkl. } \\
\text { Nahbereich) }\end{array}$ & $\begin{array}{ll}\text { - } & \text { ausgedehntes } \\
& \text { Buchenwaldgebiet } \\
\text { - } & \text { extensives Offenland } \\
\text { - } & \text { Voralpencharakter }\end{array}$ & $\begin{array}{l}\text { - Forstwirtschaft } \\
\text { - Fourismus } \\
\text { Ereizeit und } \\
\text { Erholungstourismus }\end{array}$ & $\begin{array}{ll}\text { - Sroßstadtnähe } \\
\text { Suburbanisationskultur } \\
\text { Naturschutzgeschichte }\end{array}$ & $\begin{array}{ll}\text { eigenes BSP-Management (Verein NO/Wien) } \\
\text { - } \begin{array}{l}\text { sktuell in Einrichtungsphase } \\
\text { Bevölkeßungszanungsgebiet und hohe }\end{array}\end{array}$ \\
\hline
\end{tabular}

Tabdle1: Biosphärenperkübersidtt- Schlagnatcharakteisieung

Hintergnundinformationen bereitstellen und die Ausgangslage darstellen.

In Tabelle 1 sind wichtige Merkmale der Biosphärenparks schlagwortartig Eine detaillierte Beschreibung der einzelnen Biosphärenparks enfolgt in der zusammengefasst. Diese Übersicht soll hinsichtlich der Analyse der Enfüllung der Sevilla-Strategie und der Forschungsaktivitäten 


\subsection{Metadatenkatalog}

\subsubsection{Analyse der Datenbankeinträge}

Mit Stand 20. Oktober 2004 befinden sich insgesamt 781 Einträge in der Datenbank. 620 Datensätze sind vollständig eingegeben (Haupttabelle METADATA) und bilden den Stand des Metadatenkataloges. Die restlichen 161 Datensätze werden ebenfalls in der Haupttabelle evident gehalten, ihnen fehlen zur vollständigen Beschlagwortung meist nur mehr Teilaspekte. Sie sind in der Tabelle durch das unausgefüllte Überprüfungsfeld (,checked“) von den vollständigen Datensätzen unterscheidbar. Nach einer weiteren Recherche zur Ergänzung fehlender Details könnten diese Datensätze ebenfalls in den Metadatenkatalog übergeführt werden.

\section{Anzahl und Verteilung der Datenbankeinträge}

\begin{tabular}{|l|r|}
\hline \multicolumn{1}{|c|}{ Biosphärenpark } & \multicolumn{1}{|c|}{ Anzahl } \\
\hline Großes Walsertal & 93 \\
Gossenköllesee & 57 \\
Gurgler Kamm & 121 \\
Neusiedler See & 124 \\
Lobau & 65 \\
Wienerwald & 117 \\
Moravien & 54 \\
BSP allgemein & 55 \\
\hline Gesamt & 686 \\
\hline
\end{tabular}

Tabdle2: Anzahl der Datenbankenträgepro Biosphärenpark.

Tabelle 2 zeigt den jeweiligen Biosphärenparks zugeordnete Einträge. Demnach sind für den Neusiedler See die meisten, für Moravien die wenigsten Metadaten vorhanden. Manche Einträge können mehr als nur einem Biosphärenpark zugeordnet werden. Daher liegt die Summenbildung (686 Einträge) auch über der eigentlichen Anzahl an Einträgen (620
Einträge). Abbildung 19 illustriert die prozentuelle Vetteilung der Datenbankeinträge.

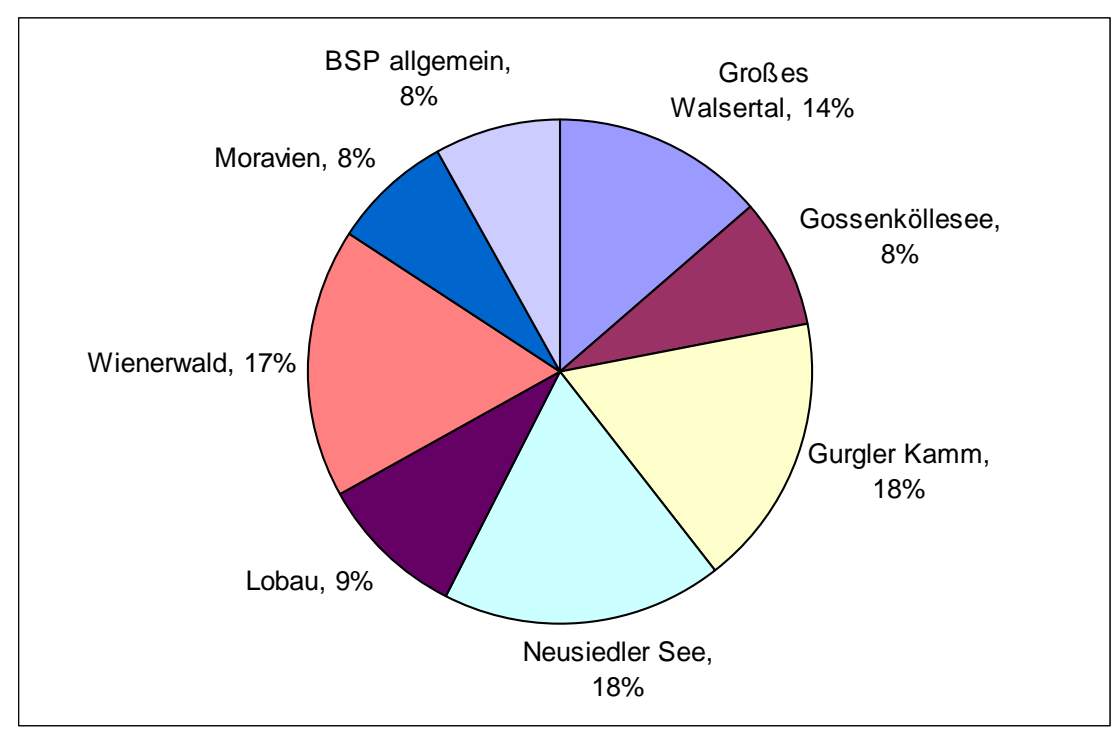

Abbildung 16: V etteilungder Datenbankeinträgepro Biosphärenpark.

\section{Anzahl und Verteilung der Einträge nach Objekttypen}

Tabelle 3 und Abbildung 17 zeigen, dass die überwiegende Mehrheit der Datenbankeinträge (mehr als 80 Prozent) der klassischen Literatur (Dokumente/ Berichte) zugeordnet werden kann. 


\begin{tabular}{|l|r|r|}
\hline \multicolumn{1}{|c|}{ Objekttyp } & \multicolumn{1}{|c|}{ Anzahl } & Prozent \\
\hline Audiovisuelle Medien & 1 & 0,16 \\
Datensammlung/Datenbank & 10 & 1,61 \\
Dienst/Anwendung/ & & \\
Informationssystem & 15 & 2,42 \\
Dokument/Bericht/Literatur & 499 & 80,48 \\
Geoinformation/Karte & 35 & 5,65 \\
Organisationseinheit/ & & \\
Fachaufgabe & 14 & 2,26 \\
Vorhaben/Projekt/Programm & 46 & 7,42 \\
\hline Gesamt & 620 & 100,00 \\
\hline
\end{tabular}

Tabdle3: Arzahl undV etailungdr Einträgenach Objkttypen

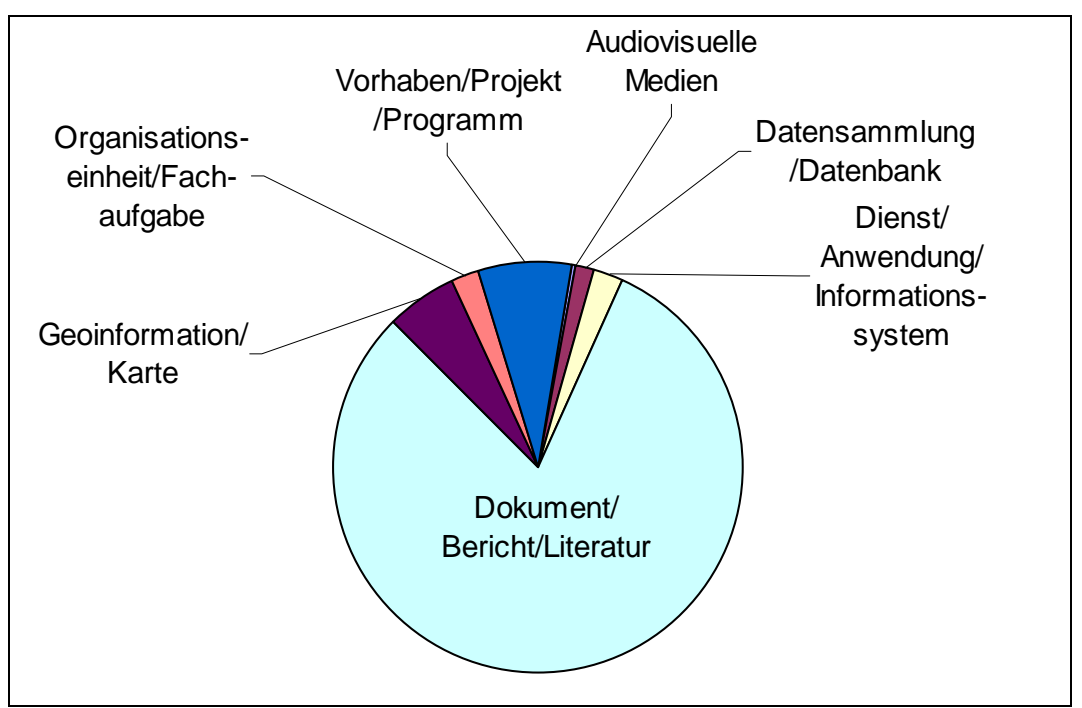

Abbildung17: Vetälungder Einträgenah Objkttypen, insgssant.

Tabelle 4 ordnet die Einträge nach Objekttypen den einzelnen Biosphäremparks zu

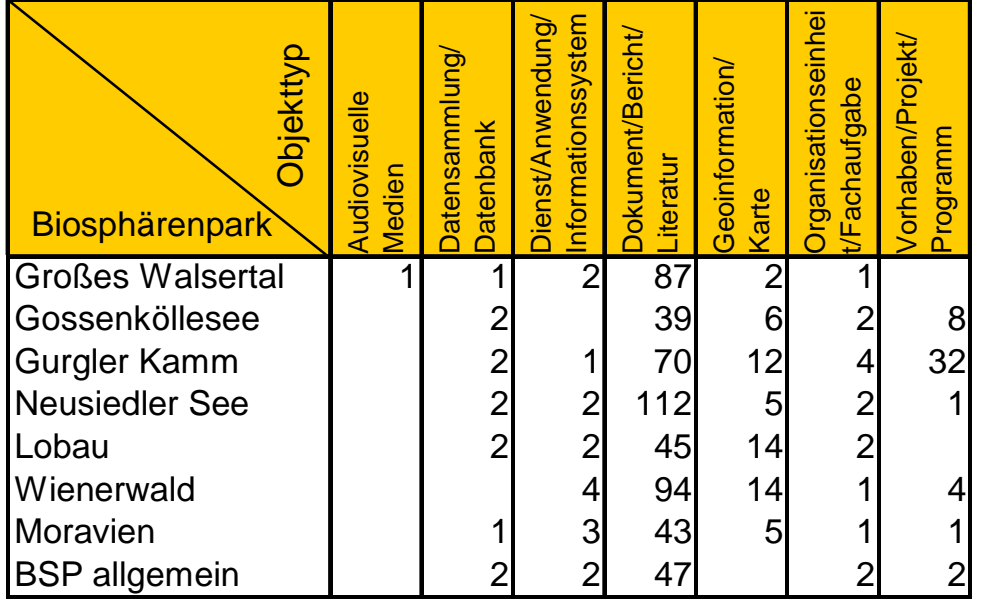

Tabdle4: Arzahl dre Einträgenach ObjkttypenproBiosphärenpark.

\section{Anzahl und Verteilung der Einträge nach Themenbereichen}

Tabelle 5 bzw. Abbildung 18 zeigen die Verteilung der verwendeten Schlagwörter nach den Themenbereichen der 1. Ordnung, einerseits pro Biosphärenpark, andererseits insgesamt (siehe auch Abbildung 9). Insgesamt wurden 4516 Schlagwörter vergeben, wobei der größte Anteil gesellschaftlichen Themen zugeordnet ist (42\%), gefolgt von den Bereichen Natur (34 \%), Wirtschaft (14\%) und allgemeine Themen (10 \%). Der hohe Anteil gesellschaftsrelevanter Themen komelient sehr gut mit den Zielsetzungen der Biosphärenparkkategonie. Aufholbedarf besteht demnach bei wirtschaftsonientierten Metadaten. Die Verteilung innerhalb der einzelnen Biosphärenparks gestaltet sich individuell, wobei sich die spezifischen Gegebenheiten nur teilweise in der Verteilung der Schlagworte niederschlagen (z.B. die hohe Relevanz der gesellschaftlichen Komponente im Biosphärenpark Großes Walsental). 


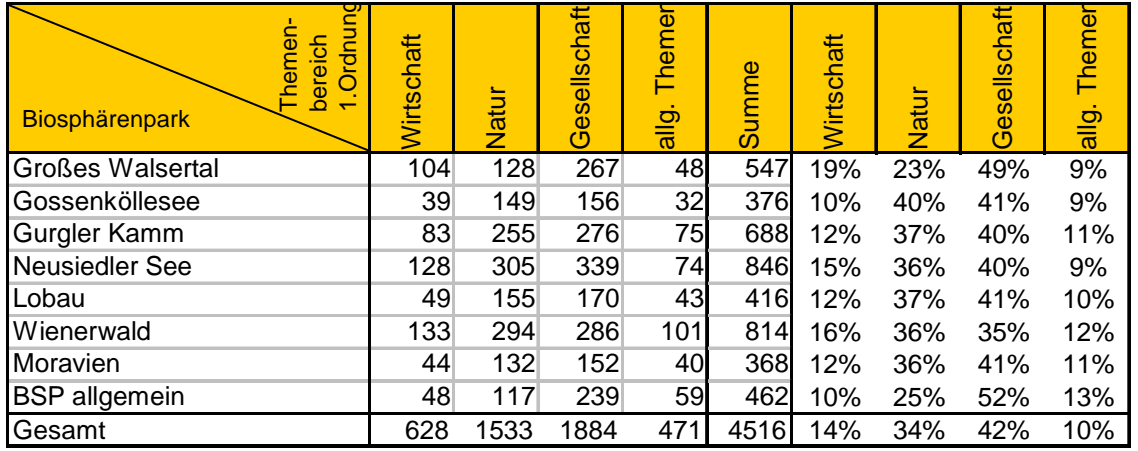

Tabdle5: Anzahl undV eteilungdre Datenbankeinträgenach Themenberichen

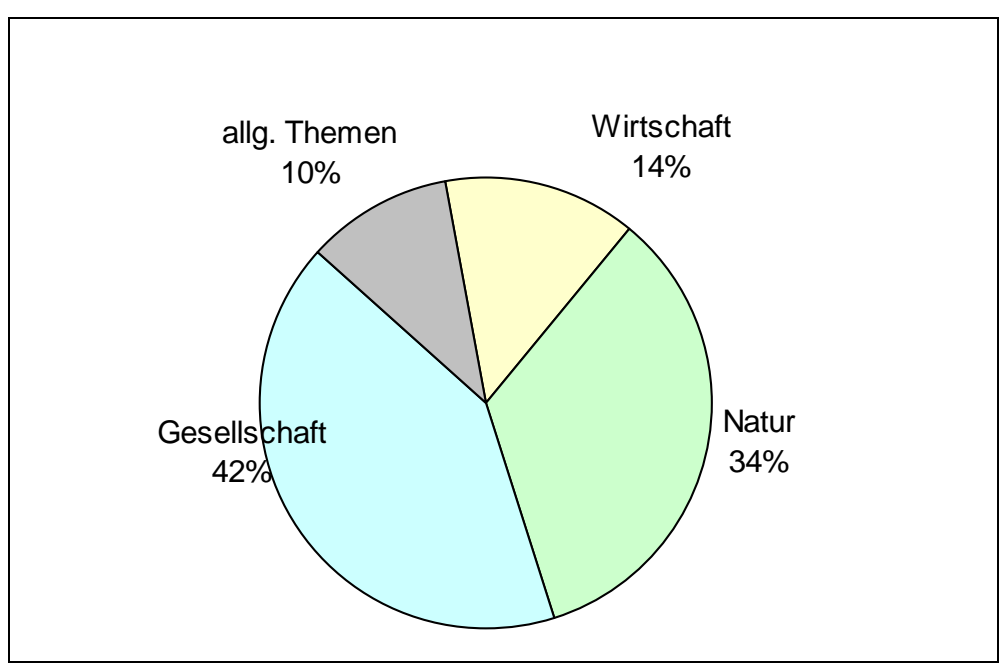

Abbildung18: Veteilungder Datenbankeinträgenach Themenbereichen, insgesant.

\section{Themenbereiche-Beziehungsmatrix}

Tabelle 6 soll die Venflechtung der Themenbereiche aller eingegebenen Datensätze anhand einer Matrix darstellen. Auffallend dabei ist vor allem die hohe Korrelation von Natur und Gesellschaft (335 Einträge) sovie
Wirtschaft, Natur und Gesellschaft (351 Einträge). Letzteres bedeutet, dass viele Datensätze ein weites Themenspektrum abdecken. Beiträge rein zur Natur, zur Wirtschaft oder Einträge zum Spannungsfeld Wirtschaft und Natur sind selten. Gemäß den Zielsetzungen der Biosphärenparkkategonie könnte hieraus der Handlungsbedarf hinsichtlich Recherche veiterer Datensätze abgeleitet verden.

\begin{tabular}{|r|c|c|c|}
\hline Einträge & Wirtschaft & Natur & Gesellschaft \\
\hline 41 & & & $\mathrm{x}$ \\
\cline { 3 - 4 } & & $\mathrm{x}$ & \\
\cline { 3 - 4 } 335 & & $\mathrm{x}$ & $\mathrm{x}$ \\
\hline 1 & $\mathrm{x}$ & & \\
\hline 92 & $\mathrm{x}$ & & $\mathrm{x}$ \\
\hline 3 & $\mathrm{x}$ & $\mathrm{x}$ & \\
\hline 351 & $\mathrm{x}$ & $\mathrm{x}$ & $\mathrm{x}$ \\
\hline
\end{tabular}

Tabdle6: ThemenbericheBeriehungrmatrix.

\section{Zitatliste}

Eine Auflistung aller vollständigen Einträge des Metadatenkataloges (Zitatliste) befindet sich im Anhang-4.

\subsubsection{Abfragedesign}

Benutzeroberfläche

Abbildung 19 soll ein Beispiel für die Erstellung einer webbasierten Benutzeroberfläche darstellen. Anhand von fünf vordefinierten Suchkategonien (Biosphärenpark, Themenbereich, Schlagwort, MABSchlagwort, Objekttyp) kann die Suche enfolgen. Mit Hilfe Bool'scher Operatoren (,und“, „oder", „und nicht" etc.) ist es möglich, die Suche einzuschränken. Folgende Zusatzfunktionen, die aufgrund der erarbeiteten Datenbankstruktur und -inhalte umgesetzt werden könnten, sollten bei der Webumsetzung in Betracht gezogen werden:

Volltextsuche: Die Volltextsuche ermöglicht dem Benutzer die Suche nach 
beliebigen Wörtem in der gesamten Datenbank

„Ranking“: Da die Schlagwörter bei der Eingabe auf ihre Relevanz hin für den Datensatz bewertet werden, kann bei der Ergebnisliste die Darstellung gereiht werden.

Zweisprachigkeit: Im Zuge des Webdesigns sind die Möglichkeiten einer zweisprachigen Umsetzung (Englisch/ Deutsch) zu klären.

Aktive Benutzereinbindung: Benutzer sollen selbst Einträge in die Datenbank vomehmen können.

Link zum Bibliothekenvedbund: Damit der Benutzer jene Datenquelle nutzen kann, die für ihn am leichtesten erreichbar ist, soll der Eintrag direkt mit der entsprechenden Seite im Bibliothekenvenbund „verinkt“ werden

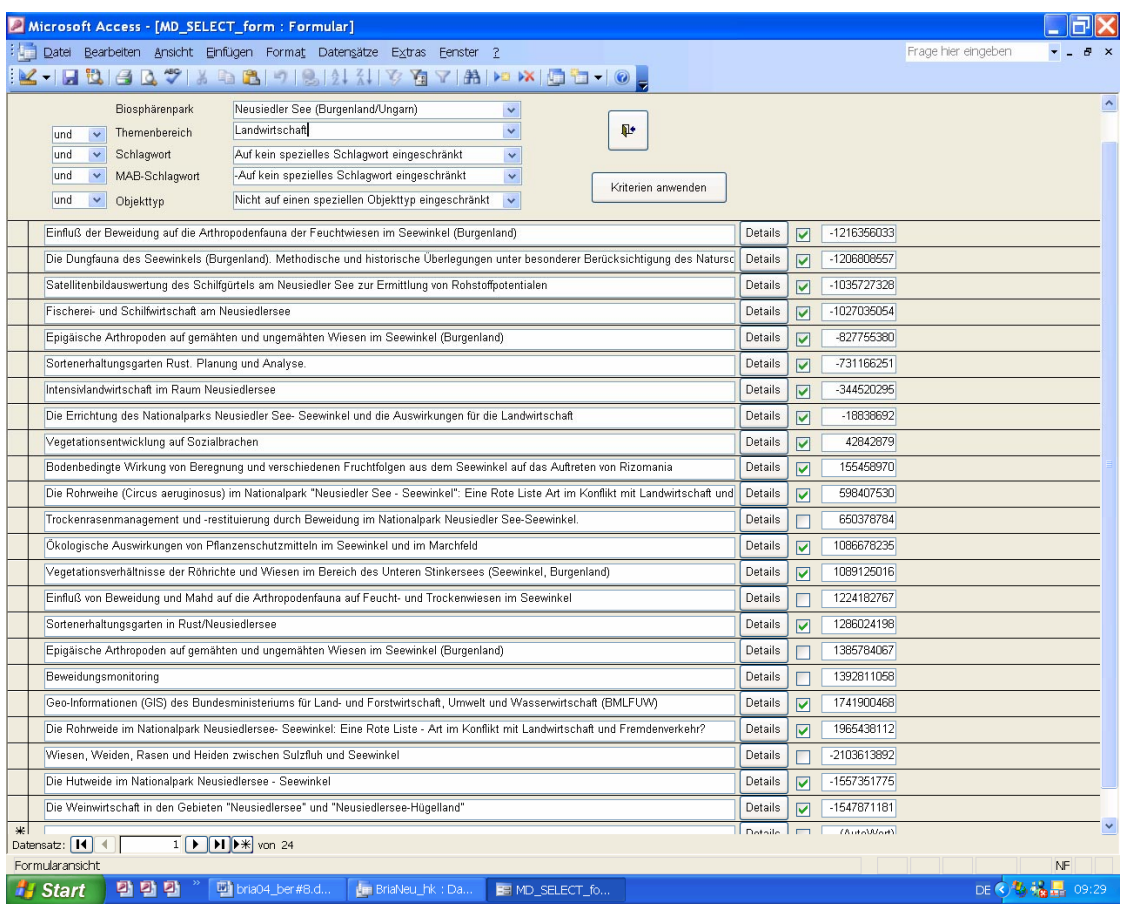

Abbildung 19: Beispid zu dan vardefinieten Suchkategrien für dieBenutzedbeflähe

\subsubsection{Weitere Betreuung}

Ein guter Metadatenkatalog verlangt intensive Betreuung. Seine Verwaltung und Aktualisienung enfordert die kontinuiediche Bereitstellung von Ressourcen. Es ist daher zu kären, in welcher Form die weitere Betreunng enfolgen kann. Gnundsätzlich sind drei Betreuungsmöglichkeiten gegeben.

MAB-Nationalkomitee: Als Koordinationsstelle für die österreichischen Biosphärenparks könnte die Metadatenbank vom Sekretaniat des Nationalkomitees gewartet werden.

E.C.O.-Institut für Ökologie: Im Zuge der Erstellung der Metadatenbank hat sich fachliches, methodisches und technisches Know-how bei E.C.O. angesammelt. Eine fachgerechte und zuvedässige Betreunng kann dadurch garantient werden

Weitere Organisation: Denkbar ist auch die Betreunng durch eine dritte Stelle, die thematisch mit Biosphärenparks vertraut sein sollte und die über entsprechende Enfahnung im Bereich Metadatenbanken venfügen sollte (z.B. Abteilung für Vegetationsökologie der Uni Wien).

Gnundsätzlich müssen die benötigten Soft- und Hardwarekomponenten der Metadatenbank bei der Wartungsstelle liegen. Der Zugniff hingegen ist über Links von jeder Homepage aus möglich (z.B. Link auf der BiosphärenparkHomepage, der auf die Domain, in der die Metadatenbank abgelegt ist, verneist).

\subsection{Stand der Forschung und Bedarfsanalyse}

Das folgende Kapitel enthält eine Übersichtsdarstellung von abgeschlossenen und aktuellen Forschungsaktivitäten in der Region der Biosphärenparks bzw. von Forschungen mit Bezug zum MAB-Programm Anhand verschiedener Beurteilungskniterien soll ein Bild der Forschungslandschaft skizziert werden. Die Ergebnisse veranschaulichen das breite Spektrum an Einsichten und Zugängen zur Forschung.

Danüber hinaus verden gnundsätzliche Enfordemisse für eine funktionierende Biosphärenpark-Forschung dargelegt. 
Detaillieste Ausfühnungen zur Analyse-Methodik sind in Kapitel 4.2 forschungsrelevante Rahmenbedingungen als Hintergnundinformation in Kapitel 3.6.3 zu finden.

\subsubsection{Status quo der nationalen MAB- Forschung}

Forschungsorganisation und Budget: Das Österreichische MAB Nationalkomitee an der Östemeichischen Akademie der Wissenschaften (ÖAW) koordiniert die von Österreich durchgeführten wissenschaftlichen Projekte im Rahmen von MAB. Mit Bezug auf die intemationale und nationale Schwerpunktsetzung enfolgt die Vergabe von Projekten nach Maßgabe der vorhandenen finanziellen Ressourcen. Das derzeitige jährliche Forschungsbudget liegt bei nund 230.000 Euro.

Forschumgsschmerpunkte: Die Zielsetzungen der MAB-Projekte in Österreich entsprechen grundsätzlich den von der UNESCO (vergl. Kapitel 3.6.3.6) vorgegebenen Projektbereichen, die der Situation Österreichs angepasst wurden

In den 1970er Jahren beteiligte sich Österreich an den EU-weiten Untersuchungen zum Einfluss des Menschen auf Hochgebirgsökosysteme (MAB-Projektbereich 6, bekannt als „MAB6-Projekt"). Im Zuge des österreichischen Hochgebirgsprogramms wurde in zahlreichen Großprojekten die Enforschung des anthropogenen Einflusses auf alpine Ökosysteme vorangetrieben. Dieser Forschungsschwerpunkt setzt sich bis in die Gegenwart fort. Themen der Forschung waren beispielsweise alpines Grasland, Almen, Karst, Schipisten oder Tounismus.

Ein weiterer Schwenpunkt liegt im Bereich der Gewässerforschung (MABProjektbereich 5), wo einige Studien zum Einfluss anthropogen venursachter Verändenungen (Eutrophienung, Wasserstau) durchgefühıt wurden.

Als einziger Vertreter des MAB-Projektbereichs 2 kann die Studie zur Hemerobie österreichischer Waldökosysteme angesehen werden, die der herausragenden Bedeutung des Waldes in Östemeich und dessen Nutzung durch den Menschen Rechnung trägt.

Als weiterer Schwerpunkt kann die Mitarbeit der österreichischen MABForschung an der Lösung spezieller MAB-relevanter Fragen der Dritten
Welt genannt werden.

Wesen der Forschung: Dem Anspruch des MAB-Programms nach interdisziplinärer Forschung (verstanden als Zusammenarbeit zwischen den wissenschaftlichen „Großdisziplinen", wie beispielsweise Naturwissenschaft und Geisteswissenschaft, im Gegensatz zu Fachdisziplinen wie beispielsweise Zoologie und Botanik) wird nur teilweise nachgekommen. Die Mehrheit der Projekte ist grundsätzlich naturwissenschaftlich ausgenichtet und besitzt häufig ökosystemaren Charakter. Dieser ganzheitlichen Herangehensweise wird durch intensive Kooperationen zwischen den einzelnen naturwissenschaftlichen Fachdisziplinen Rechnung getragen. Eingeschränkt lässt sich unter diesem Gesichtspunkt der von vielen Projekten beanspruchte interdisziplinäre Ansatz rechtfertigen. Neben dem „Musterprojekt Obergurgl“ (Band 10) spielen sozio-ökonomische, interdisziplinäre Aspekte auch in anderen Projekten mitunter tragende Rollen (vergl. Band 5, 9, 12, 19, 21).

Art der Forschung: Die nationale MAB-Forschung besitzt hauptsächlich den Charakter der Gnundlagenforschung. Dies kommt in einer hohen Anzahl von Ökosystemstudien zum Ausdruck. Inventare und Analysen werden im Zuge der Grundlagenforschungen für die Untersuchungsgebiete durchgeführt. Begleitforschung zum Management fehlt zu Gänze.

Räumlicher Bezug: Die nationale MAB-Forschung hat bis auf zwei Ausnahmen bisher keinen Bezug zur Biosphärenparkregion genommen. Wichtige Untersuchungsgebiete waren die Hohen Tauem, die Salzburger Kalkalpen, das Ennstal und die Donau bzw. ganz Östemeich. Biosphärenparkbezogene Forschung fand im Biosphärenpark Obergurgl (MAB6-Projekt Obergurgl - Band 10) und Neusiedler See (Der Einfluss des diffusen und punktuellen Nährstoffeintrags auf die Eutrophienung von Seen - Band 8/ 1) statt.

Forschumgskonzeption: Ein umfassendes Forschungsrahmenkonzept auf nationaler Ebene fehlt bisher, ist aber aktuell in Ausarbeitung. Die Schwerpunktsetzung erfolgte in unregelmäßigen Abständen primär nach den Gesichtspunkten der internationalen Vorgaben mit Bezugnahme auf die spezielle Topografie Östemeichs. Biosphärenparks wurden kaum in die Überlegungen mit einbezogen 
Forschungsalktivitäten und -programme: Seit 1973 sind im Zuge des österreichischen MAB-Programms 19 abgeschlossene Projektpakete zu verzeichnen, die in den „Veröffentlichungen des österreichischen MAB-

Programms" publizient wurden. Aktuell sind drei weitere Projekte in Ausfühnung. Projektpaket 20 war im Zuge der Recherchetätigkeit nicht eindeutig „auffindbar". Die einzelnen Forschungsprojekte sind jeweils mit einer Kurzbeschreibung in Tabelle 7 angeführt. 


\begin{tabular}{|c|c|c|c|c|c|}
\hline Nr. & Projekt & Schweqpunkt & Veröff. & Projektbereich & Kurzbeschreibung \\
\hline $\mathbf{1}$ & $\begin{array}{l}\text { Alpine Grasheide Hohe Tauem } \\
\text { Ergebnisse der Ökosystemstudie } \\
1976\end{array}$ & $\begin{array}{l}\text { Österreichisches } \\
\text { Hochgebirgsprogramm }\end{array}$ & 1977 & MAB6 & $\begin{array}{l}\text { Ziel dieser Studie war es, die Existenzbedingungen der Lebensgemeinschaft ,alpine } \\
\text { Grasheide" am Beispiel eines Krummeggenrasens (Curvuletum) umfassend } \\
\text { darzustellen und den Biomassevorrat, die Nettoprimäpproduktion sowie den } \\
\text { Energiefluss in diesem System so vollständig wie möglich zu erfassen. }\end{array}$ \\
\hline 2 & $\begin{array}{l}\text { Ökologische Analysen von } \\
\text { Almflächen im Gasteiner Tal }\end{array}$ & $\begin{array}{l}\text { Österreichisches } \\
\text { Hochgebirgsprogramm }\end{array}$ & 1978 & MAB6 & $\begin{array}{l}\text { Ziel der Studie war die Erforschung der ökologischen Verändenungen im Bereich" } \\
\text { aufgelassener Almen im Gasteiner Tal. }\end{array}$ \\
\hline 3 & $\begin{array}{l}\text { Untersuchumgen an alpinen Böden in } \\
\text { den Hohen Tauem 1974- } 1978 \\
\text { Stoffdynamik und Wasserhaushalt }\end{array}$ & $\begin{array}{l}\text { Österreichisches } \\
\text { Hochgebirgsprogramm }\end{array}$ & 1980 & MAB6 & $\begin{array}{l}\text { Diese Studie ist der Rolle der Böden im Stoffhaushalt der Hochgebirgsökosysteme } \\
\text { gevidmet. Durch Vervollständigung der Kenntnis der in den Hochgebirgsböden } \\
\text { ablaufenden Prozesse und ihrer Beeinflussung durch menschliche Eingriffe, sollen } \\
\text { die Voraussetzungen für einen planmäSigen Schutz der Hochgebirgsböden } \\
\text { geschaffen werden. }\end{array}$ \\
\hline $\mathbf{4}$ & $\begin{array}{l}\text { Bodenbiologische Untersuchumgen } \\
\text { in den Hohen Tauem } 1974 \text { bis } 1978\end{array}$ & $\begin{array}{l}\text { Österreichisches } \\
\text { Hochgebirgsprogramm }\end{array}$ & 1981 & MAB6 & $\begin{array}{l}\text { Dieser Band fasst Untersuchungen an den Konsumenten in den alpinen Biozönosen, } \\
\text { in erster Linie avertebrate Tiere, und einige Arbeiten über die } \\
\text { Bodenmikroorganismen zusammen. }\end{array}$ \\
\hline 5 & $\begin{array}{l}\text { Die Ergebnisse des MAB-Projekts } \\
\text { „Sammeralm". Ein Beitrag zur } \\
\text { sozioökonomisch gesteuerten Ver- } \\
\text { ändenumg subalpiner } \\
\text { Landschaftssysteme }\end{array}$ & $\begin{array}{l}\text { Österreichisches } \\
\text { Hochgebirgsprogramm }\end{array}$ & 1983 & MAB6 & $\begin{array}{l}\text { Die vorliegende Studie zeigt, wie der Niedergang einer seit dem Hochmittelalter } \\
\text { bestehenden alpinen Kulturandschaft mit dem Übergang zu extensiven } \\
\text { almwirtschaftlichen Betriebsformen verbunden ist. }\end{array}$ \\
\hline 6 & $\begin{array}{l}\text { Die klimatologischen } \\
\text { Untersuchumgen in den Hohen } \\
\text { Tauem von } 1874 \text { - } 1980\end{array}$ & $\begin{array}{l}\text { Österreichisches } \\
\text { Hochgebirgsprogramm }\end{array}$ & 1983 & MAB6 & $\begin{array}{l}\text { Mit diesem Teilprojekt des Hochgebirgsprogramms wird die Wichtigkeit der } \\
\text { Klimatologie im Hochgebirge unterstrichen. Ziel war neben der Behandlung der } \\
\text { eigentlichen ökoklimatischen Fragestellungen, Lücken in der Kenntnis der } \\
\text { Hochgebirgsmeteorologie zu schließen. }\end{array}$ \\
\hline 7 & MAB - Kartenband "Hohe Tauem“ & $\begin{array}{l}\text { Östemeichisches } \\
\text { Hochgebirgsprogramm }\end{array}$ & 1983 & MAB6 & $\begin{array}{l}\text { Gesammelte Kartenbände zu Untersuchungsgebieten des Hochgebirgsprogramms } \\
\text { (Vegetationskarten, geologische Karten, Sonderkarten) }\end{array}$ \\
\hline $8 / 1$ & $\begin{array}{l}\text { DerEinfluss des diffusen } \\
\text { Nährstoffeintrags auf die } \\
\text { Eutrophienumg von Seen. Teil } 1 \\
\text { Piburger See, WörtherSee und } \\
\text { MillstätterSee }\end{array}$ & Gewässerforschung & 1984 & MAB5 & $\begin{array}{l}\text { Ziel war die Verfeinerumg des Instrumentariums zur Erkennung und Quantifizierung } \\
\text { von Eurtrophierngsursachen und zu einer zugleich fachgerechten und praxisnahen } \\
\text { Beurteilung ihrer limnologischen Auswirkungen. Schwerpunkt war die Beschreibung } \\
\text { und Deutung der limnologischen Entwicklung des betreffenden Sees. }\end{array}$ \\
\hline $8 / 2$ & $\begin{array}{l}\text { Der Einfluss des diffusen und } \\
\text { punkthellen Nährstoffeintrags auf die } \\
\text { Eutrophienumg von Seen. Teil } 2 \\
\text { Neusiedler See und Attersee }\end{array}$ & Gewässerforschung & 1985 & MAB6 & Wie Band $8 / 1$ \\
\hline 9 & $\begin{array}{l}\text { Beiträge zu den Wechselbeziehumgen } \\
\text { zwischen den } \\
\text { Hochgebirgsökosystemen und den } \\
\text { Menschen }\end{array}$ & $\begin{array}{l}\text { Östemeichisches } \\
\text { Hochgebirgsprogramm }\end{array}$ & 1985 & MAB6 & $\begin{array}{l}\text { Enthält ergänzende Beiträge zu den Bänden } 1 \text { bis } 4 \text { des Hochgebirgsprogramms. Des } \\
\text { weiteren werden der Einfluss des Menschen auf alpine Ökosysteme (Verkehr, } \\
\text { Emissionen, Umweltverschmutzung) und die Einflüsse des Hochgebirgsmilieus auf } \\
\text { den Menschen untersucht. }\end{array}$ \\
\hline
\end{tabular}




\begin{tabular}{|c|c|c|c|c|c|}
\hline 10 & MAB6- Projekt Obergurgl & $\begin{array}{l}\text { Osterreichisches } \\
\text { Hochgebirgsprogramm }\end{array}$ & 1987 & MAB6 & $\begin{array}{l}\text { Als erstes MAB-Projekt in Ósterreich als interdisziplinäres (natur- und } \\
\text { humanwissenschaftlich) und transdisziplinäres Projekt (Einbindung der } \\
\text { Bevölkerung) angelegt. Es widmet sich der Frage der Verwendung wissenschaftlicher } \\
\text { Befunde für den Entscheidungsprozess. Hauptfrage war, ob die Bewohner eines im } \\
\text { dynamischen Wachstum befindlichen Ortes bereit sind, uneingeschränktes } \\
\text { Wachstum auf Grund wissenschaftlicher Erkenntnisse in Frage zu stellen. Die } \\
\text { Ergebnisdarstellung hat naturwissenschaftlichen Überhang, da das Projekt } 1979 \\
\text { wegen Geldmangel abgebrochen wurde. Humanwissenschaftliche Arbeiten waren zu } \\
\text { diesem Zeitpunkt noch nicht voll angelaufen bzw. abgeschlossen. }\end{array}$ \\
\hline 11 & $\begin{array}{l}\text { Die Vorstudie für das } \\
\text { Forschumgsobjelt „Ökosystemstudie } \\
\text { Donaustau“ }\end{array}$ & Gewässerforschung & 1985 & MAB5 & $\begin{array}{l}\text { Diese Untersuchung sollte die MAB-Relevanz, die Objektauswahl, die Material- und } \\
\text { Datensichtung, die Durchführbarkeit, die Kosten u dgl. für das Gesamtprojekt } \\
\text { untersuchen. }\end{array}$ \\
\hline 12 & $\begin{array}{l}\text { Beiträge zur Landschaftsökologie der } \\
\text { Salzburger Kalkalpen, mit besonderer } \\
\text { Berücksichtigung der } \\
\text { sozioökonomischen } \\
\text { Prozesssteuenung }\end{array}$ & Karstforschung & 1987 & MAB6 & $\begin{array}{l}\text { Durch Auswertung von Luftbildem und Beobachtung sozioökonomisch gesteuerter } \\
\text { Parameter an zwei Testflächen wird statistisch belegt, dass eine almwirtschaftiche } \\
\text { Einflussnahme auf natüniche Prozesse (Erosion, Denudation) vorliegt. Weiters } \\
\text { sollen Ursachen der Verwaldung und Verbuschung efforscht werden. }\end{array}$ \\
\hline 13 & $\begin{array}{l}\text { Strukdurund Funktion von } \\
\text { Graslandökosystemen im } \\
\text { Nationalpark Hohe Tauem }\end{array}$ & $\begin{array}{l}\text { Ósterreichisches } \\
\text { Hochgebirgsprogramm, } \\
\text { Grünlandforschung }\end{array}$ & 1989 & MAB6 & $\begin{array}{l}\text { Dieser Band nimmt Bezug auf die umfangreichen Untersuchungen zur Klärung von } \\
\text { Aufbau und Funktionsweise alpiner Graslandökosysteme des } \\
\text { Hochgebirgsprogramms und präsentieit die in den Hohen Tauem durchgeführten } \\
\text { Ökosystemstudien „Alpine Grasheide“ und „Höhentransekt“. }\end{array}$ \\
\hline 14 & $\begin{array}{l}\text { Ökosystemstudie Donaustau } \\
\text { Altenmörth. Teil 1: Veränderungen } \\
\text { durch das Donaukraftwerk } \\
\text { Altenmö̈th }\end{array}$ & Gewässerforschung & 1989 & MAB5 & $\begin{array}{l}\text { Ziel war die Sichtung von Veränderungen seit Enichtung der Staustufe (1973 - 1976) } \\
\text { im Hinblick auf Hydrologie, Limnologie, Fischerei, Klima, Ökozoologie, } \\
\text { Ökobotanik, Forstökologie und Sozioökonomie sowie auf entsprechende } \\
\text { Zusammenhänge. }\end{array}$ \\
\hline 15 & $\begin{array}{l}\text { Der Untersberg bei Salzburg. Die } \\
\text { ober- und unterirdische } \\
\text { Karstentwickdung und ihre } \\
\text { Zusammenhänge. Ein Beitrag zur } \\
\text { Trinkwasserforschung }\end{array}$ & Karstforschung & 1989 & MAB6 & $\begin{array}{l}\text { Ist als eine Ergänzung zu Teilprojekten in Band } 5 \text { zu sehen. Ziel war die Erfassung } \\
\text { des ober- und unteirdischen Karstformenschatzes und die Rekonstruktion der } \\
\text { Genese des Gesamtsystems. Dies soll als Grundlage für raumordnerische } \\
\text { Maßnahmen dienen und so helfen, die Trinkwasserversorgung der Stadt Salzburg } \\
\text { zusichem. }\end{array}$ \\
\hline 16 & $\begin{array}{l}\text { Skipistenökologische } \\
\text { Ummeltverträglichkeitsprüfung der } \\
\text { Wald-Abfahten im Gasteiner Schi- } \\
\text { Zirkus }\end{array}$ & Skipistenökologie & 1990 & MAB6 & $\begin{array}{l}\text { Ziel war eine integrierte Gesamtbeurteilung der direkten und indirekten } \\
\text { Schadenskumulation für den Schutz- und Wirtschaftswald im Schipistenbereich, } \\
\text { besonders auch hinsichtlich wirtschaftlicher und überwirtschaftlicher } \\
\text { Funktionsfähigkeit. }\end{array}$ \\
\hline 17 & $\begin{array}{l}\text { Hemerobie österreichischer } \\
\text { Waldökosysteme }\end{array}$ & Waldforschung & 1998 & MAB2 & $\begin{array}{l}\text { Ziel war die Erstellung eines Modells zur Bewertung der gesamten Waldfläche } \\
\text { Österreichs nach dem Grad des menschlichen Einflusses (Hemerobie). Der } \\
\text { Natürichkeitsgrad von Waldökosystemen bildet eine wesentliche Grundlage für } \\
\text { Entwicklungskonzepte in der Forstwirtschaft und im Naturschutz. }\end{array}$ \\
\hline 18 & $\begin{array}{l}\text { Ókosystemstudie Donaustau } \\
\text { Altenmörth Teil } 2 \text { Management und } \\
\text { Gestaltumgsmöglichkeiten }\end{array}$ & Gewässererforschumg & 2000 & MAB5 & $\begin{array}{l}\text { Auf Grundlage der Okosystemstudie Teil } 1 \text { enthält diese Studie Vorschläge für } \\
\text { Management und Verbesserungen im bestehenden Stauraum sovie Vergleiche und } \\
\text { Hinweise auf andere Stauhaltungen. }\end{array}$ \\
\hline 19 & Ökotone Donatr-March & $\begin{array}{l}\text { Gewässenforschung, } \\
\text { Land/ inland water ecotones }\end{array}$ & 2003 & MAB5 & $\begin{array}{l}\text { Die Studie wendet sich der Problematik ökologischer, aber auch sozioökonomischer } \\
\text { Veränderungen an einem großen Fließgewässer in Folge der Emichtung einer } \\
\text { Wasserkraftanlage zu. }\end{array}$ \\
\hline
\end{tabular}




\begin{tabular}{|c|c|c|c|c|c|}
\hline 20 & $\begin{array}{l}\text { Keine eindeutige Information } \\
\text { exhältlich' }\end{array}$ & & & & \\
\hline 21 & $\begin{array}{l}\text { Landschaft und Landwirtschaft im } \\
\text { Wandel - Das Grünland im } \\
\text { Berggebiet Österreichs }\end{array}$ & Grünlandforschung & i.p. & MAB2,3 und 6 & $\begin{array}{l}\text { Zentrale Frage des interdisziplinären Projektes ist die Erforschung der optimalen } \\
\text { Nutzungsintensitäten des Grünlandes und deren Bestimmungsgründe. Damit soll } \\
\text { eine nachhaltige Nutzung gesichert werden, die zum einen höchstmögliche kulturelle } \\
\text { und soziale Werte sichert, zum anderen eine akzeptable wirtschaftliche Nutzung } \\
\text { zulässt. }\end{array}$ \\
\hline 22 & $\begin{array}{l}\text { Topolfimatischer Vergleich zweier } \\
\text { Grünlanditypen }\end{array}$ & Grünlandforschung & i.p. & MAB 3 und 6 & $\begin{array}{l}\text { Mithilfe dieses Projektes soll ein Modell der Stickstoff-Flüsse und } \\
\text { Vegetationsdynamik erstellt werden, das in weiterer Folge eine Modellienung } \\
\text { möglicher Ausuirkungen von Ändenungen der Bevirtschaftungsweisen auf die } \\
\text { Biodiversität, Produktivität und ökosystemare Funktionalität von Grünland } \\
\text { emmöglicht. }\end{array}$ \\
\hline 23 & $\begin{array}{l}\text { Einfluss von Weidevieh und Wild aif } \\
\text { das alpine Grasland }\end{array}$ & Grünlandforschung & $\begin{array}{l}\text { abgeschl., } \\
\text { aber nicht } \\
\text { veröff. }\end{array}$ & MAB 3 und 6 & $\begin{array}{l}\text { Die Studie zeigt Einflüsse des Weideviehs und des Wilds auf die Vegetation der } \\
\text { alpinen und nivalen Stufe. Dabei stehen die Fragen nach der Veränderung der } \\
\text { Artenzusammensetzung vor allem in Hinblick auf Migrationserscheinungen sowie } \\
\text { die Auswirkumgen von Hervivorie auf die zukünftige Entwicklung der Vegetation im } \\
\text { Zuge der globalen Klimaveränderung im Vordergnund. }\end{array}$ \\
\hline
\end{tabular}

Tabelle7: Prgikteimnationalen MAB-Programm

\subsubsection{Status quo auf Biosphärenpark-Ebene}

Im Folgenden werden Umfang, Ziele, Inhalte und Organisation der Forschung auf Ebene der einzelnen Biosphärenparks in Österreich detaillient dargestellt. 


\subsubsection{Großes Walsertal}

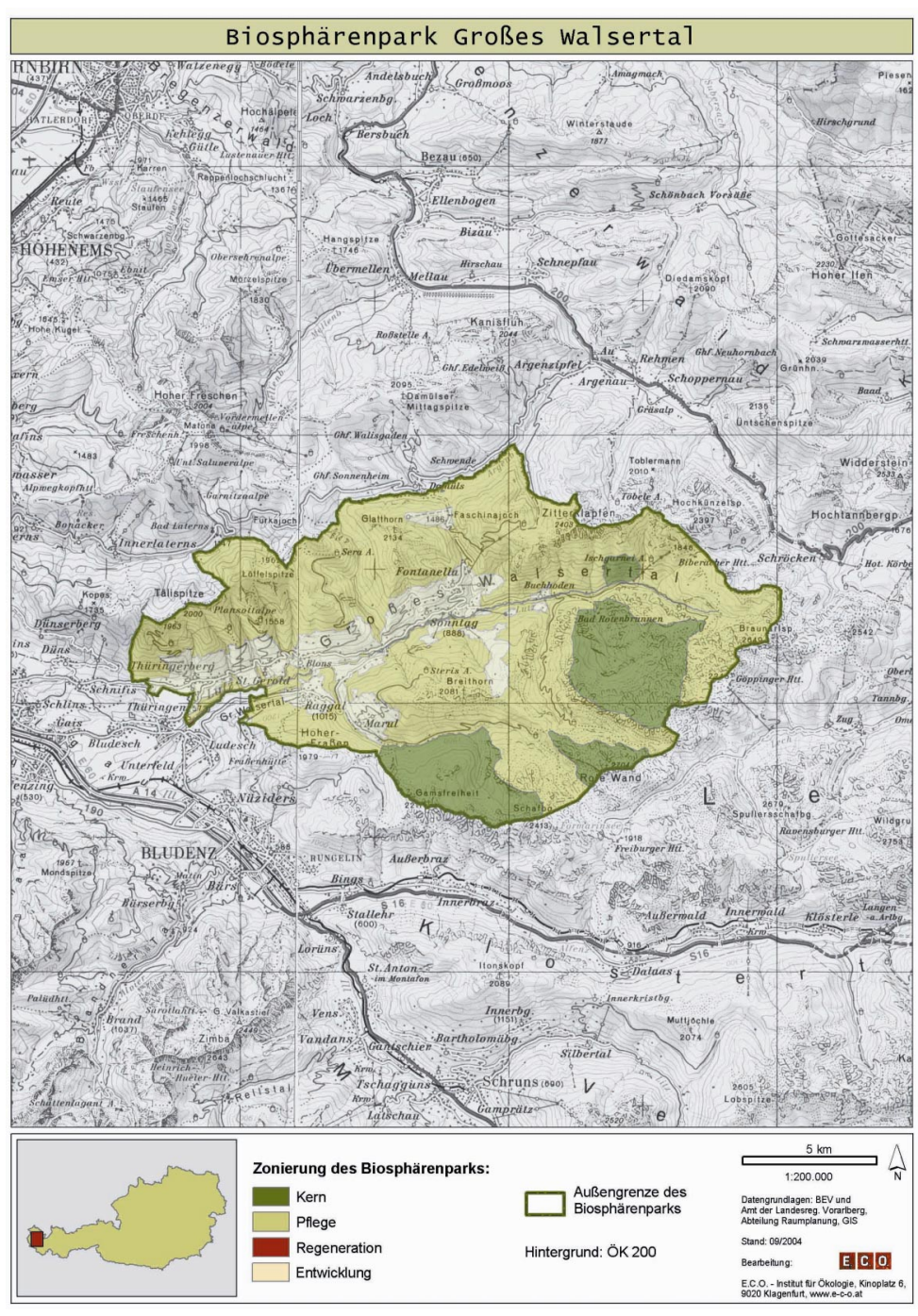

Abaildung20: ÜbersidtskarteBiosphärenpark Großes Walsetal.

\section{Geschichte der Forschung (Einführung)}

Das Große Walsertal ist der einzige Biosphärenpark Österreichs, der nach der Erstellung der Sevilla Strategie (1995) eingerichtet wurde. Seine Entstehungsgeschichte beinhaltet eine starke regionalwirtschaftliche Komponente, die Forschung spielte nur eine untergeordnete Rolle. Es wurden in der Vergangenheit keine bedeutsamen Forschungsvorhaben im Großen Walsertal realisient und es gibt keine Forschungseinnichtungen, weder privater noch universitärer Natur.

\section{Ausmaß der Forschung (Wieviel?)}

Forschung im Biosphärenpark Großes Walsental findet in vergleichsweise geningem Ausmaß statt. Der Stellenwent der Forschung und das Interesse am Forschungsraum Großes Walsental sind niedrig konkrete Forschungsvorhaben für die Zukunft gibt es nur in Ansätzen. Die Ressourcenausstattung für Forschungszwecke ist dementsprechend schwach.

\section{Ziele der Forschung (Wozu?)}

Weder für die Region noch für den Biosphärenpark existieren klar definierte Forschungsziele. Demnach ist weder ein inhaltliches, noch ein räumliches oder zeitliches Forschungsdesign vorhanden. Ein direkter Bezug der aktuellen Forschungsaktivitäten zu MAB-Forschungsschwerpunkten ist nicht festzustellen. 


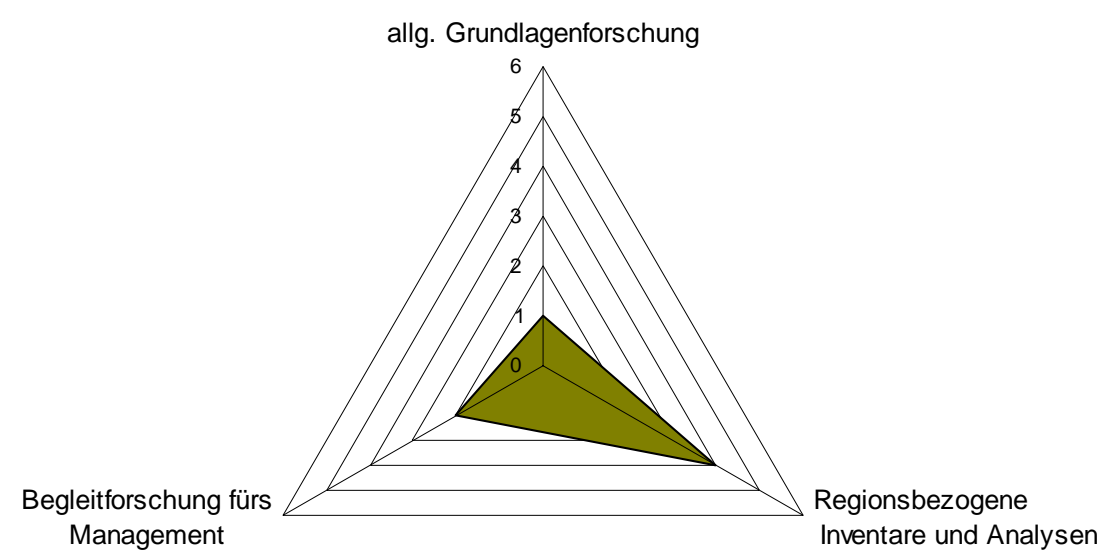

Abbildung 21: Forshungarten Großses Welsetal.

Die grundsätzliche Positionienung der Forschumg zeigt Abbildung 21. Der Schwerpunkt der vorhandenen Forschungsaktivitäten liegt im Bereich der regionsbezogenen Inventare und Analysen. Begleitforschung fürs Management findet in zunehmendem Maße statt, allgemeine Gnundlagenforschung nur in Ansätzen.

Inhalte und Gegenstand der Forschung (Was?)

Inhalte können nach verschiedenen, sich überschneidenden Gesichtspunkten bzw. Ebenen angegeben werden:

- Forschungsdisziplin

- Themenschwerpunkt/ Forschungsfelder

- Forschungsleitfragen

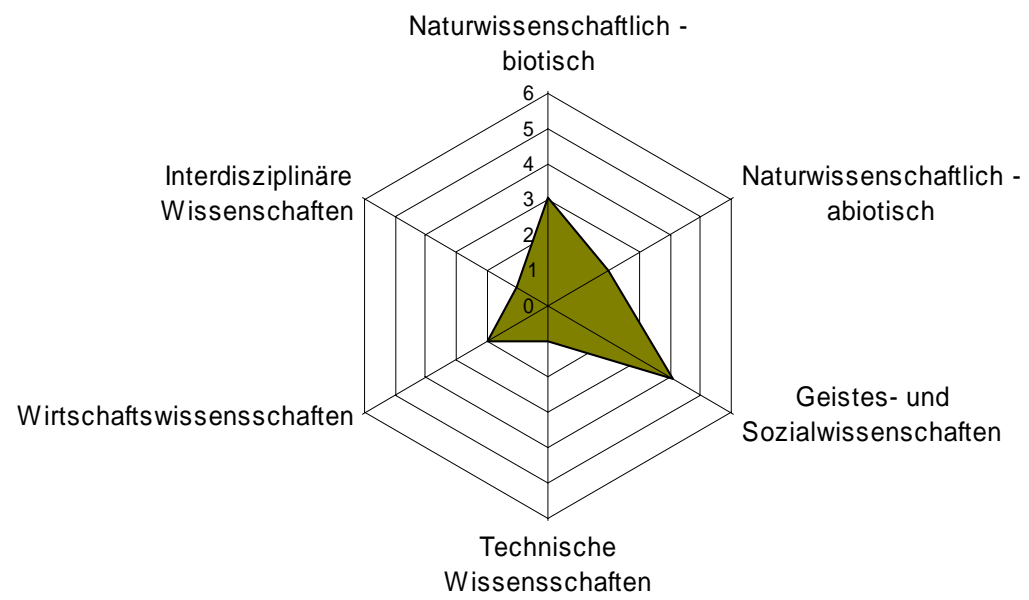

Abbildung22: Forshunggdisziplinen Großes Walsatal.

Forschungsdisziplinen (vergl. Abbildung 22): Die Forschungsaktivitäten im Biosphärenpark gehen vor allem auf volkskundliche und kulturelle Aspekte ein (Studien zum Brauchtum, der Bevölkenung - den Walsem, etc.), haben also starken Bezug zu den Geistes- und Sozialwissenschaften Weitere enkennbare Schwerpunkte liegen im naturwissenschaftlichen (z.B. Landschaftsinventar, geologische Abhandlungen, Vegetationserhebung im Zuge von RAUMALP) oder im wirtschaftswissenschaftlichen Bereich (z.B. Studien zu Vermarktungsstrategien, Produktentwicklung für BSP HaushaltsIst Analysen).

Als Themenschmenpunkt der Forschung in der Region kann man durchaus die Volkskunde bezeichnen.

Konkrete Forschumgsleitfragen lassen sich aus den vorhandenen Untedagen nur schwer ableiten.

Beispielhafte Forschungs-/Planungsaktivitäten und -programme

Die im Folgenden genannten Forschungsprogramme/ -projekte/ -aktivitäten können sowohl Forschungs- als auch Planungscharakter besitzen. Eine eindeutige Zuordnung ist oft nicht möglich. 
Vorarlberger Biotopkantienung: Im Zuge der landesweiten Inventanisienung der Biotope in den 80er Jahren wurden auch die Biotope des Großen Walsertales emoben. Demnächst soll eine Aktualisienung enfolgen.

ECO-Monte: Im Rahmen dieses EU-LIFE-Projektes mit den Schwerpunkten Tourismus und Energie vird eine Vielzahl von Einzelprojekten mit dem Ziel der Emichtung eines Umweltmanagementsystems durchgeführt (Anwendbarkeit von EMAS). Die Umsetzung des „Ummeltzeichen für Tourismusbetriebe“ und des Qualitätslabels „Partnenbetrieb Biosphärenpark" sind weitere Ziele. Als Teilprojekt wurde auch eine Haushalts-Ist-Analyse durchgeführt.

e5-Programm Programm zur Qualifizienung (european energy award) energieeffizienter Gemeinden. An diesem Programm nehmen die Gemeinden des Großen Walsertales teil mit dem Ziel, in zwei Jahren zwei „e"s zu erreichen (vergl. ENERGIEINSTITUT VORARLBERG).

Machbarkeitsstudie Biodiesel und Biogas: Untersuchung zum Potenzial der Erzeugung und des Einsatzes von Biodiesel und Biogas in der Region Großes Walsertal.

RAUMALP: "Raumstrukturelle Probleme im Alpenraum" ist ein interdisziplinäres Projekt der Östemeichischen Akademie der Wissenschaften im Rahmen des Programms zur Alpenforschung. Neben flächendeckenden Analysen des österreichischen Alpenraums mit den Schwerpunkten Siedlung, Tounismus, Agrarwirtschaft und Biodiversität im Spannungsfeld wirtschaftlicher Entwicklungen und alpiner Raumordnung werden in Fallstudiengemeinden ( $u$. a. Gemeinde Sonntag im Großen Walsertal) weitere Detailuntersuchungen durchgefühnt (vergl. RAUMALP).

\section{Organisation und Rahmen der Forschung (Wie?)}

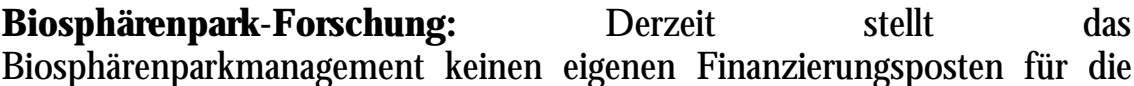
Forschung bereit. Es werden jedoch im Zuge von Umsetzungsprojekten Forschungsaktivitäten als Unterstützung fürs Management gefördert (z.B.
Haushalts-Ist Analyse, Machbarkeitsstudie Biodiesel und Biogas, EU-LIFEProjekt Eco-Monte). Zurzeit bemüht sich der Biosphärenpark um den Aufbau von Forschungskompetenz (Forschungs- und Monitoningkonzept).

Regionale Forschung: In der Region des Biosphärenparks sind die Forschungskompetenzen dezentral verteilt, d. h. es gibt keine zentrale Koordinationsstelle für die Forschung (=freie Forschung).

Forschungskooperationen: Es gibt keine Forschungskooperationen im engeren Sinne (beispielsweise in Form von Ko-Finanzienung, Projekten, Datenaustausch).

Intemationaler Kontext: Internationale, fachliche Kooperationen in größerem Umfang existieren nicht. Sehrwohl tragen intemationale Finanzienungsinstrumente zur Erhöhung des regionalen Forschungsetats bei.

Forschungsdokumentation und Infrastulkturen: Die Forschungsergebnisse verden dezentral dokumentient, eine exakte Übersicht aller Forschungsaktivitäten in der Region lässt sich daher kaum gevinnen. Neben der Voranlberger Landesbibliothek werden vor allem Forschungsergebnisse, die aus Studien im Auftrag des Biosphärenparkmanagements hervorgehen, in der vereinseigenen Bibliothek dokumentiert. Weitere Forschungsinfrastrukturen (z.B. Forschungsstützpunkte) sind nicht bekannt.

Öffentlichkeitsarbeit: Die PR-Methoden, mit denen die Forschungsergebnisse verbreitet verden, sind im Allgemeinen projektspezifisch. Derzeit werden im regionalen Informationsblatt „Blickwinkel“ Informationen zum Biosphärenpark für die Bevölkenung bereitgestellt. Ab 2005 sollen im Zuge einer erweiterten Fassung auch ausführlichere Berichte zu aktuellen Forschungs- und Projektaktivitäten verfasst werden.

\section{Biosphärenparkspezifikum}

Im Gegensatz zu den anderen österreichischen Biosphärenparks zählt das Große Walsertal nicht zu den „traditionellen“ Forschungsräumen. Forschungsdefizite und fehlende Forschungsinfrastrukturen sind daher 
spezifisch für die Region. Diese Defizite aufzuholen ist ein künftiges Aufgabenfeld, um eine auf den Biosphärenpark abgestimmte Forschungslandschaft zu etablieren (vergl auch Abbildung 38).

\subsubsection{Gossenköllesee}

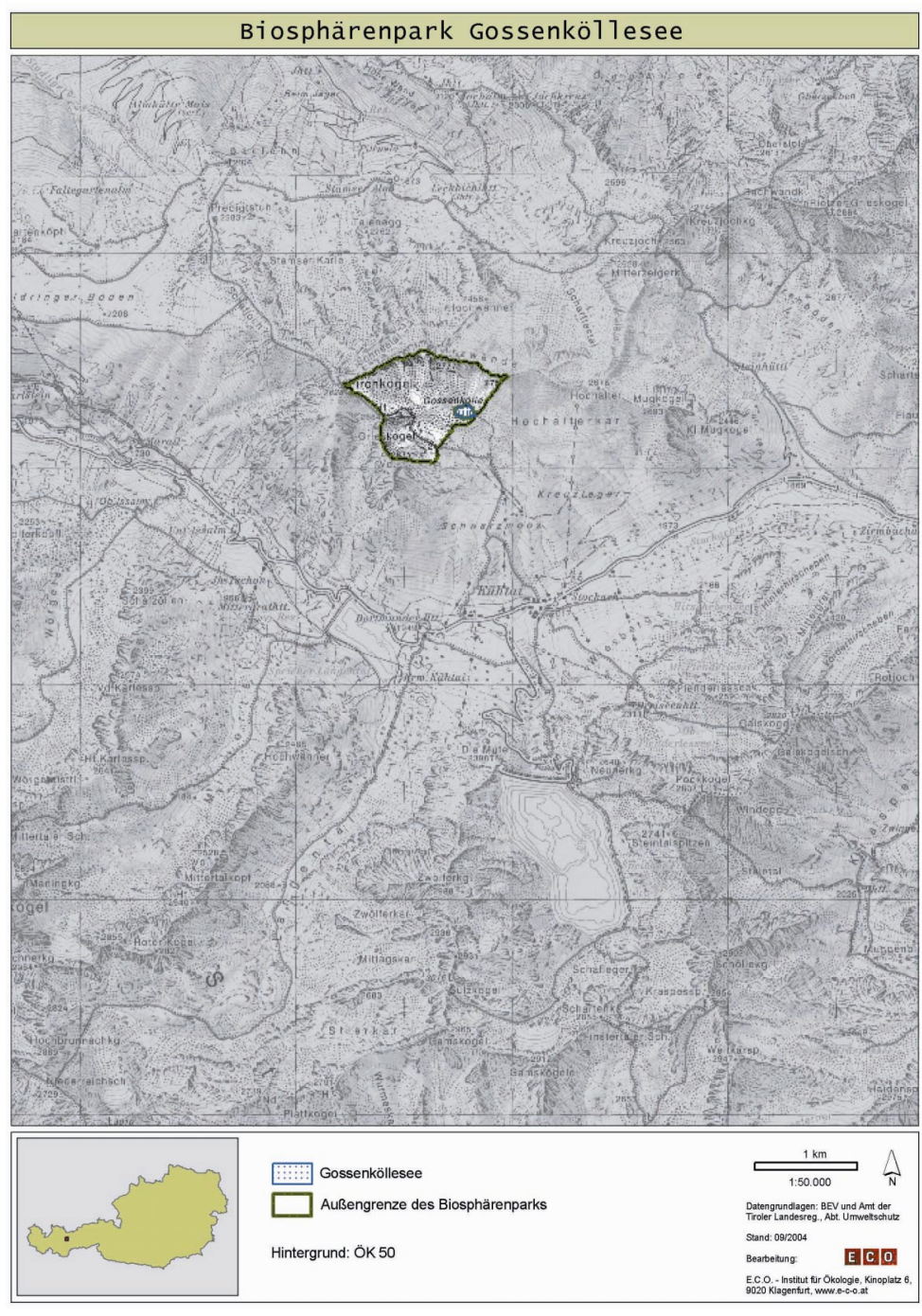

Abbildung23: ÜbersidıskarteBiosphärenpark Gossenköllesee 


\section{Geschichte der Forschung (Einführung)}

Seit den 1950er Jahren wurde im Kühtai am Finstertaler See geforscht. Vor ca. 30 Jahren wurde im Zuge der Emichtung eines Stausees die dort gelegene Forschungsstation überflutet und an den Gossenköllesee verlegt. Für die Forschung war das ein schwerer Rückschlag, da damit über mehrere Jahrzehnte erstellte Messreihen der alpinen Seenforschung wertlos wurden. Um die Forschungsstation am Gossenköllesee vor einem ähnlichen Schicksal zu bewahren, beschloss die damalige Tiroler Landesregienung nund um den See einen Biosphärenpark zu emichten und damit den Weitedbestand der Forschungsstation zu garantieren. 1995 wurde die Station von TIWAG (Tiroler Wasserkraft AG) und Bund gemeinsam generalsanient. Sie stellt heute aus logistischer Sicht einen sehr günstigen Forschungsstützpunkt dar, doch aus Sicht der Forscher ist ihr Fortbestand weiterhin nicht abgesichent. Immer vieder wird die Forschung am Gossenköllesee durch Projekte zur Pistenerschließung und zum Liftbau in Frage gestellt.

\section{Ausmaß der Forschung (Wieviel?)}

Der Forschung wird im Biosphärenpark Gossenköllesee ein hoher Stellenwert eingeräumt. Die Universität Innsbruck setzt sich im Rahmen ihres Schwerpunktes „Alpiner Raum und Umwelt" für die Forschung am Gossenköllesee ein. Vor allem das Institut für Zoologie und Limnologie engagient sich in den Bereichen EUROLIMPACS und ALTER Net, zwei Schwerpunkten des 6. EU-Rahmenprogramms.

\section{Ziele der Forschung (Wozu?)}

Es existieren klar definiente Forschungsziele, ein direkter Bezug der aktuellen Forschungsaktivitäten zu MAB-Forschungsschwerpunkten kann jedoch nicht hergestellt werden. Dafür verantwortlich gemacht wird vor allem die Tatsache, dass der Biosphärenpark nicht als solcher wahrgenommen wird.

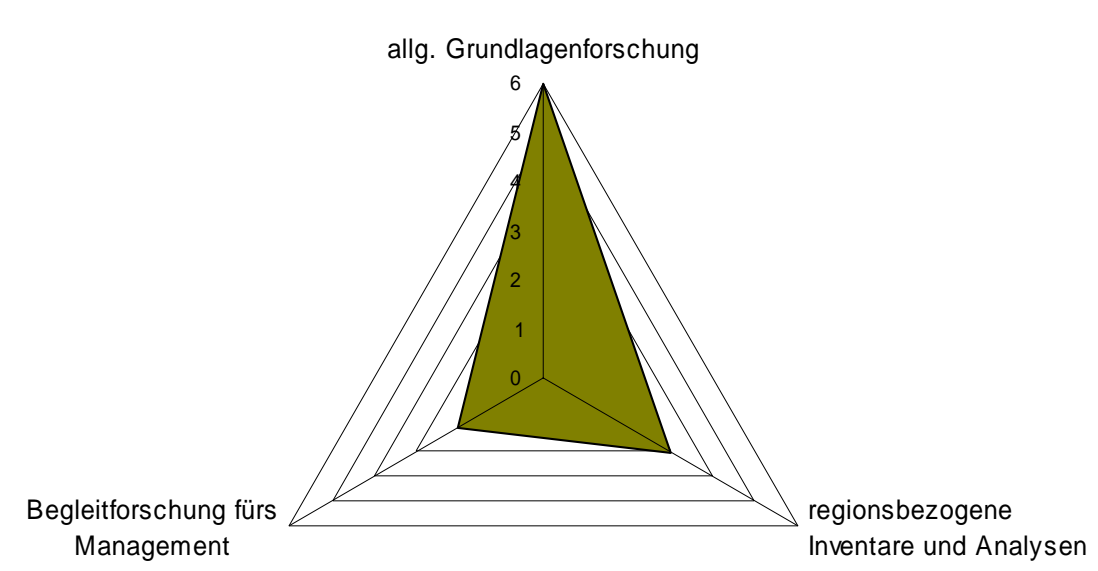

Abbildung24: Forshungsarten Gossenkdilesee

Es gibt zahlreiche Kooperationen mit Fakultäten ausländischer Universitäten in Ausbildung und Forschung. Es wird vor allem Grundlagenforschung betrieben, angewandte Biosphärenparkforschung ist durchaus vorstellbar, doch fehlt derzeit die Nachfrage dafür. 


\section{Inhalte und Gegenstand der Forschung (Was?)}

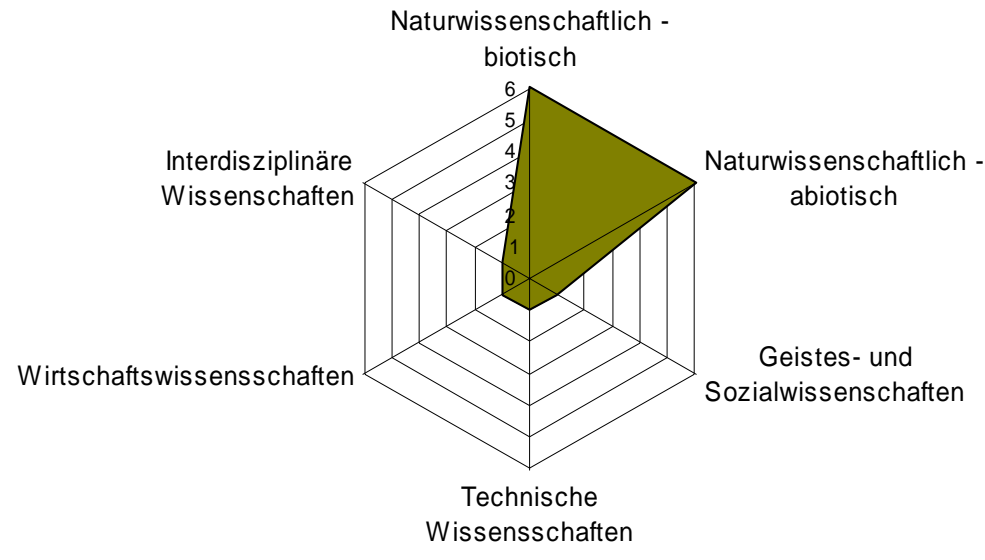

Abbildung25: Forschungsdisziplinen Gossenkölesee

Hinsichtlich Forschungsdisziplinen (vergl. Abbildung 25) lässt sich ein eindeutig naturwissenschaftlicher Schwerpunkt erkennen (Studien zu den Systemfunktionen alpiner Extremstandorte, sowohl in biotischer als auch in abiotischer Hinsicht). Die Bereiche der Geistes,- Sozial- und Wirtschaftswissenschaften bleiben weitgehend ausgeklammert.

Die Themenschmerpunkte der Forschung liegen im Bereich des Verständnisses für Stoffflüsse und Nahnungsnetze hochalpiner Gewässersysteme.

Die Forschumgsleitfragen setzen sich mit den Krätten, die den Global Change beeinflussen, auseinander. Dafür eignen sich alpine Gebiete in besonderem Maße, da sie lokal nicht gestört sind und die Ergebnisse der Forschung weltweit vergleichbar sind.

\section{Beispielhafte Forschungs-/Planungsaktivitäten und -programme}

FMF-Projekte: Der FWF - Fonds zur Fördenung der wissenschaftlichen Forschung - ist Österreichs zentrale Einnichtung zur Fördenung der Grundlagenforschung, die am Gossenköllesee einen hohen Stellenwert einnimmt. In den Projekten „Climate waming impact on alpine's lake bacterioplankton" (Perez, M \& Sommanuga R.) und "Temporal and spatial vaniation of bacterioplankton subgroups" (Psenner, $R$, Andreatta, St., Hofer, J. \& Sommanuga, R.) geht es um die zentrale Rolle des Bakterioplanktons in nährstoffamen alpinen Seen. Ziel ist die Erforschung von Faktoren (UV-Strahlung Nährstoffe, Räuber, etc), die das Artenspektrum, die Biomasse und Produktion aquatischer Bakterien bestimmen.

MOLAR (Mountain Lake Research): 4. Rahmenprogramm der EU Umwelt. In diesem Projekt werden Hochgebirgsseen, die weitgehend von anderen Einflüssen unberührt bleiben, auf die Auswirkungen des Global Change hin untersucht.

EURO-LIMPACS (Integrated Project to Evaluate the Impacts of Global Change on European Freshwater Eoosystems): Im Zuge dieses 6. Europäischen Rahmenprogramms sollen alle Themen- und Problembereiche, die mit Gewässem in Zusammenhang stehen, untersucht werden. Der Gossenköllesee ist ein ideales Forschungsobjekt für Fragen im Bereich alpiner Gewässer.

ALTER_Net (A Long-term Biodiversity, Eoosystem and Awareness Research Network): Aufbau eines östemeichischen LTER-Netzknotens für Alpine Ökosysteme im 6. Europäischen Rahmenprogramm Ziel der Initiative ist die Enichtung einer multifunktionalen Forschungsplattform.

EMERGE (European Mountain Lake Ecosystems): 5. Rahmenprogramm der EU über Global Change, Climate and Biodiversity. Der Gossenköllesee ist eines von zwei Projektgebieten, in dem Sedimentanalysen durchgeführt werden.

MRI: Ziel der Mountain Research Initiative ist die Entwicklung von Strategien zur Entdeckung von globalen Anzeichen der Umweltverändenung in Bergregionen. In Kooperation mit UNESCO MAB wird das Projekt "Global Change Research in Mountain Biosphere Reserves" ausgeführt

GLOCHAMORE (Global Change in Mountain Regions): 6. Europäisches Rahmenprogramm „Sustainable Development, Global Change and Eoosystems". GLOCHAMORE zielt auf Enkenntnisgewinnung über Ursachen des Global Change und Auswirkungen auf die Bergregionen ab. 
AL.PE: Acidification of mountain lakes: Paleolimnology and ecology. Zie ist die Enforschung der weitgehend unbeeinflussten Ökosysteme alpiner Seen und ihrer Bedeutung als Indikatoren für Luftverschmutzung und Klimawandel.

\section{Organisation und Rahmen der Forschung (Wie?)}

Biosphärenpark-Forschung: Es existient kein BSP-Management, daher gibt es auch keinen eigenen Finanzienungsposten. Forschung wird nicht unter dem Dach des Biosphärenparks betrieben, die aktuellen Forschungsaktivitäten stehen thematisch aber in Bezug zu MAB-Forschung (Projektbereiche 5 - Wetlands und 6 - Global change).

Regionale Forschung: Die Forschung konzentriert sich ausschließlich auf den Gossenköllesee, fedenführend sind dabei die Institute der Universität Innsbruck.

Forschungskooperalionen: Ein alpines Netzwerk (ALTER Net) befindet sich derzeit im Aufbau, daneben gibt es in Ausbildung und Forschung zahlreiche Kooperationen mit ausländischen Universitäten.

Intemationaler Kontext: Die Forschung bewegt sich hauptsächlich im intemationalen Rahmen, die Zusammenarbeit entsteht zumeist aus Initiativen der Einzelforscher.

Forschungsdokumentation und Infrastnukturen: Forschungsergebnisse werden derzeit dezentral dokumentiert, jeweils an den beteiligten Instituten Über ALTER_Net sollen zentrale Dokumentation, Verwaltung und Zugniff auf die Forschungsergebnisse emmöglicht werden.

Öffentlichkeitsanbeit: Die Öffentlichkeitsarbeit enfolgt derzeit hauptsächlich anlassbezogen (z.B. Konflikt mit Schiliftgesellschaft).

\section{Biosphärenparkspezifika hinsichtlich Forschung}

Der Gossenköllesee gehört zu den „traditionellen“ Forschungsräumen. Spezifisch für den Gossenköllesee sind die ausgeprägte Forschungsintensität (mit naturwissenschaftlichem Schwerpunkt) und die sehr guten Forschungsinfrastrukturen. Dies ist nicht zu Letzt auf die Eigeninitiative von Forschem der Universität Innsbruck zurückzuführen, die sich vehement für den Standort einsetzen. Mit der Universität Innsbruck als Hauptforschungsinstitution existient auch eine zentrale Datendokumentationsstelle für den Biosphärenpark (vergl. auch Abbildung 38). 


\subsubsection{Gurgler Kamm}

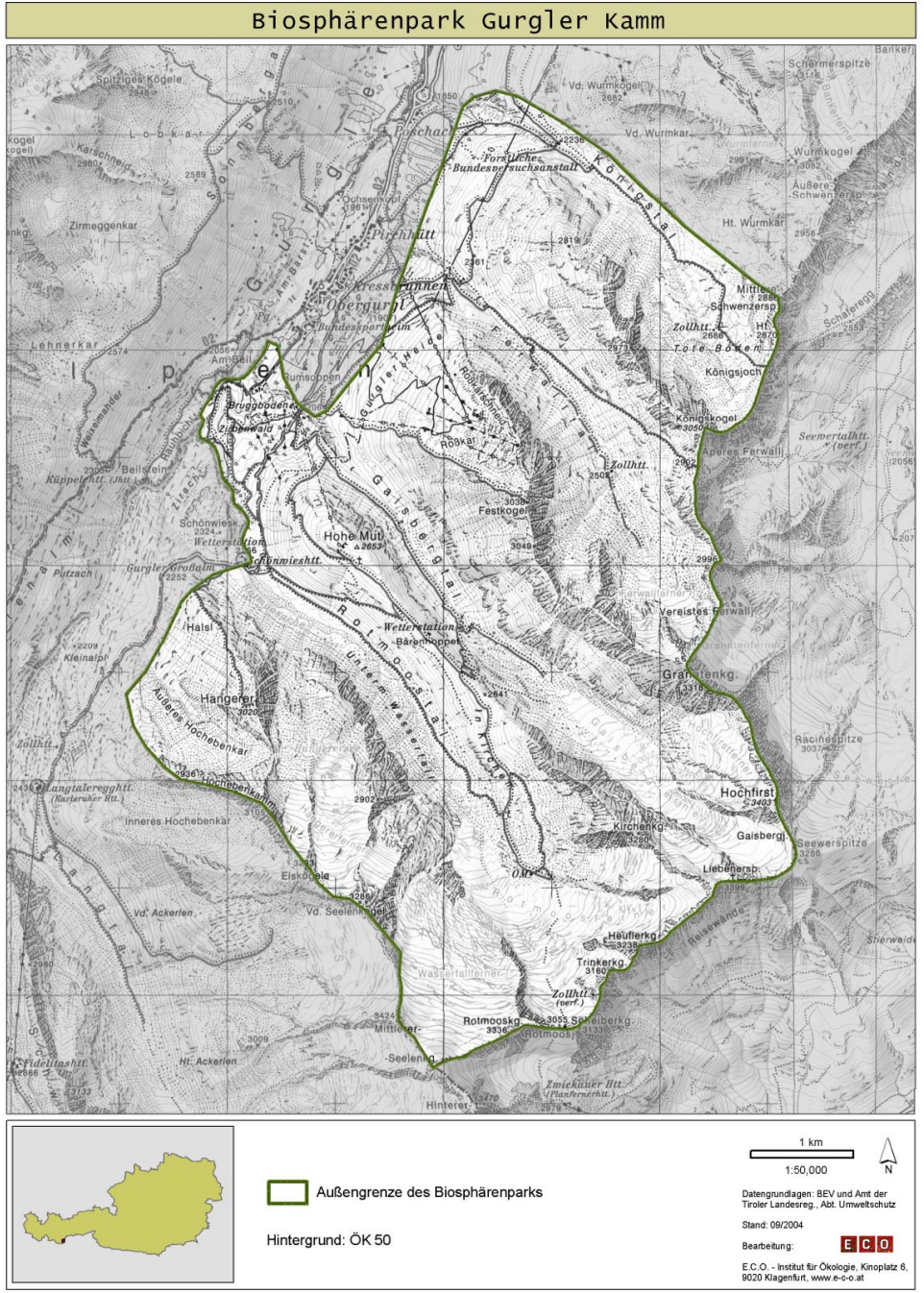

Abbildung26: ÜbersidtskarteBiosphärenpark Gurger Kanm

\section{Geschichte der Forschung (Einführung)}

1970 wurde in Obergurgl, einem touristisch intensiv erschlossenen Gebiet ein Studie gestartet, die noch heute als ein MAB-Musterprojekt für interdisziplinäre Forschung gilt. Der Biosphärenpark Gurgler Kamm wurde 1977 emichtet, seine Existenz wird heute kaum wahrgenommen. Die Forschungstätigkeit verfiel nach der Euphorie der 1970er Jahre in eine Art „Domröschenschlaf". Erst der „Ötzi-Fund“ am Similaum weckte in dieser Region ein neueriches Interesse an der Forschung. Heute fehlen im Biosphärenpark Management und Verantwortlichkeiten, es gibt aber weiterhin die gut ausgestaltete Alpine Forschungsstation im ehemaligen Bundessportheim, die vor allem von Forschem der Universität Innsbruck genutzt wird. Derzeit befindet sich die Forschungsstelle in einer Phase der Umstrukturienung, sodass Zuständigkeiten und Verantwortlichkeiten nicht kar sind.

\section{Ausmaß der Forschung (Wieviel?)}

Generell wird die Region um den Gurgler Kamm intensiv beforscht. Es gibt eine Vielzahl von Einzelprojekten, die allerdings nicht alle unmittelbar im Gebiet des Biosphärenparks stattfinden. In der Alpinen Forschungsstelle Obergurgl sind vor allem Forscher der Universität Innsbruck im Rahmen des universitären Schwerpunktes „Alpiner Raum und Umwelt“ tätig.

\section{Ziele der Forschung (Wozu?)}

Ein großer Teil der Forschungsprojekte steht nicht in unmittelbarem Zusammenhang mit der Biosphärenparkforschung. 


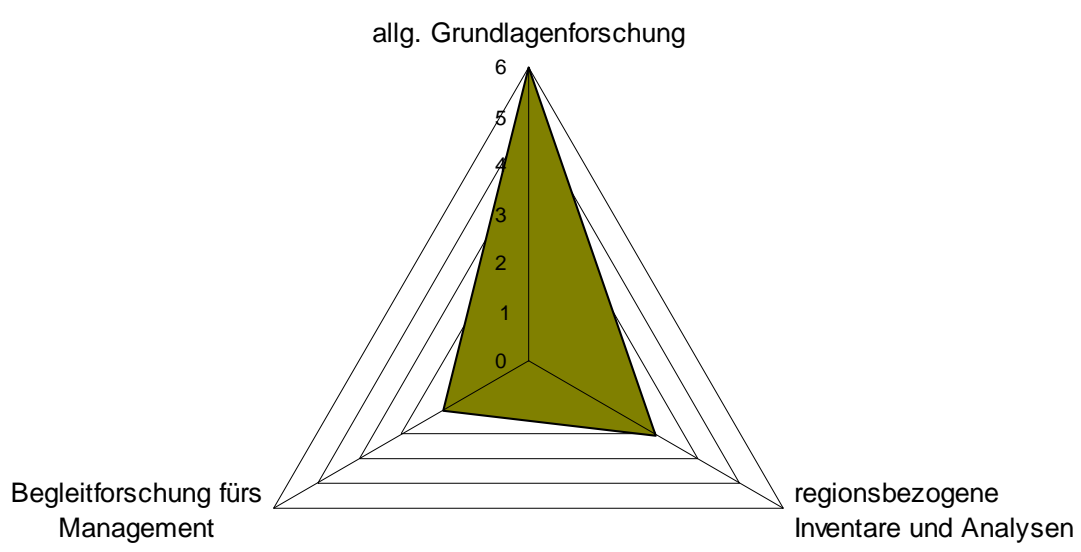

A bbildung 27: Forshungsarten Gurder Karm

Die grundsätzliche Positionienung der Forschung zeigt Abbildung 27. Der Schwerpunkt der Forschungsaktivitäten liegt in den Bereichen der allgemeinen Grundlagenforschung und der regionsbezogenen Inventare und Analysen. Angewandte Biosphärenparkforschung bzw. Begleitforschung fürs Management finden derzeit nicht statt.

\section{Inhalte und Gegenstand der Forschung (Was?)}

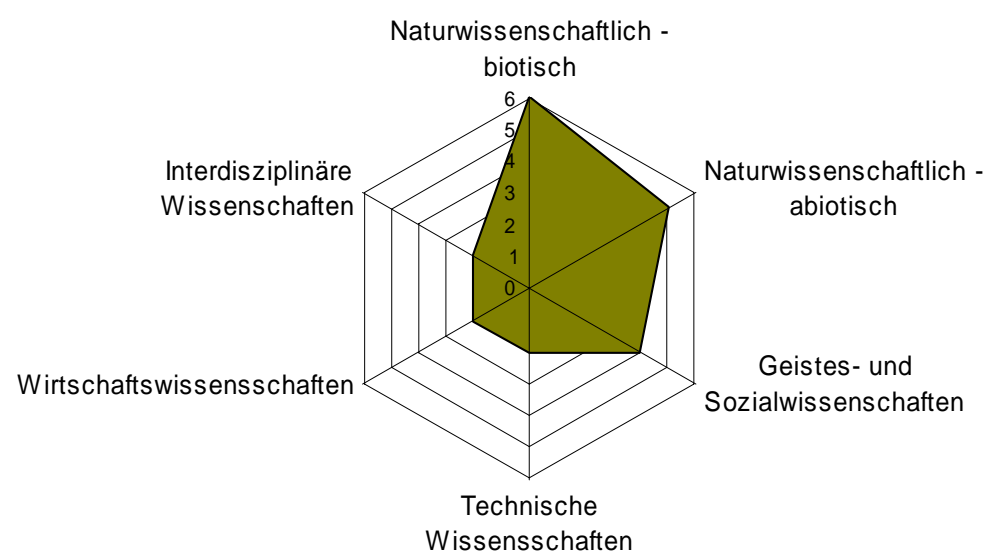

Abbildung28: Forshungsdiszipinen Gurge Kamm

Hinsichtlich der vertretenen Forschungsdisziplinen (vergl. Abbildung 28) liegt der Schwerpunkt bei den Naturwissenschaften (biotisch und abiotisch). Aber auch die Bereiche der Archäologie und der Siedlungsgeschichte haben eine lange Tradition, die durch die Entdeckung des „Mannes aus dem Eis“ neuen Aufschwung effahren hat. Technische Wissenschaften sind nur am Rande vertreten, die Wirtschaftswissenschaften fehlen.

Die Themenschmenpunkte der Forschung liegen im Bereich der Ökosystemforschung. Obergurgl bietet hier eine alpine Modellsituation.

Die Forschungsleitfragen sind die Fragen nach dem Druck, den verschiedene Landnutzungen auf alpine Landschaften ausüben können, wobei auch sozio-ökonomische Druckpunkte nicht außer Acht gelassen werden sollen, Fragen des Klimawandels und die Entwicklung von Monitoning-Methoden 


\section{Beispielhafte Forschungs-/Planungsaktivitäten und -programme}

Langzeit-Ökosystem Monitoning im Alpinen Raum (2000-2005): Dieses Projekt wird vom Botanikinstitut gemeinsam mit dem Institut für Zoologie und Limnologie der Universität Innsbruck durchgeführt. Das Monitoring umfasst Vegetation und Fauna der Böden, der Pflanzendecke, Amphibien und Vögel und soll Verändenungen im Ökosystem unabhängig vom auslösenden Faktor (z.B. Klimawandel, Ändenung der Landnutzung, Einwandenung von Arten) erkennbar machen. Gleichzeitig sollen Effekte des Landnutzungswandels untersucht werden, wie die Auswirkungen von Beweidungsdruck und der Nutzung von Flächen als Schipisten in der alpinen Stufe. Die Auswirkungen der Beweidung werden in einem experimentellen Ansatz mit Weideausschlussflächen untersucht. Die Entwicklung der Schipisten wird im Vergleich mit angrenzenden Arealen beobachtet. Schließlich sollen Monitoringmethoden für alpine Ökosysteme getestet und evaluiert werden. So sollen beispielsweise kostengünstige Screening-Verfahren entwickelt und für eine breitere Anwendung in anderen Gebieten standardisiert werden.

Mechanismen der Primärsukzession und Populationsökologie (1997laufend): In einer Kooperation der Institute für Zoologie und Limnologie, Botanik und Mikrobiologie werden Primärbesiedlung und Sukzession im Gletschervorfeld des Rotmoosfemers untersucht. In diesem interdisziplinären Projekt werden Gletschemückzugsflächen als „natüdiche Experimente" betrachtet, anhand derer verschiedenste Kolonisationsprozesse, die Entwicklung hochalpiner Lebensgemeinschaften und Nahnungsnetze und die treibenden Kräfte der Sukzession efforscht werden.

ALTER_Net (A Long-tem Biodiversity, Eoosystem and Awareness Research Network): Aufbau eines österreichischen LTER-Netzknotens für Alpine Ökosysteme im Rahmen des 6. Europäischen Rahmenprogramms. Ziel dieser Initiative ist die Emichtung einer multifunktionalen Forschungsplattform: Infrastrukturelle Basisstationen sollen Routineerhebungen durchführen, Basisdaten emitteln und verwalten, die Forscher sollen neue Fragestellungen und Ansätze einbringen.

MRI (Mountain Research Initiative): Ziel der Mountain Research
Initiative ist die Entwicklung von Strategien zur Entdeckung von globalen Anzeichen der Umweltverändenung in Bergregionen. In Kooperation mit UNESCO MAB wird das Projekt „Global Change Research in Mountain Biosphere Reserves" ausgeführt. Der Biosphärenpark Gurgler Kamm wurde als MRI master station ausgewählt.

Alpiner Raum und Ummelt: Die Leopold-Franzens-Universität Innsbruck hat in ihrem Leitbild den Schwerpunkt „Alpiner Lebensraum“ verankert. Sie übemimmt damit in Forschung und Lehre Verantwortung für die ökologischen, sozialen und wirtschaftlichen Probleme dieses einzigartigen, gefährdeten, aber auch gefährdenden Lebensraumes. Der Forschungsschwerpunkt umfasst Umweltthemen, Entwicklung und Konzipienung des Biosphärenparks und die Entwicklung von Longterm Eoological Sites.

\section{Organisation und Rahmen der Forschung (Wie?)}

Biosphärenpark-Forschumg: Die MAB-Forschung der 1970er Jahre (MAB6 Projekt Obergurgl) wurde 1979 wegen Geldmangels abgebrochen. Derzeit wird an der Weiterentwicklung des Biosphärenparks gearbeitet. Forschungsthemen sind im Spannungsfeld zwischen alpinen Rückzugsgebieten und Wintertourismus in ausreichendem Maße vorhanden. Ein Hindemis stellen fehlendes Management und fehlende Finanzienung dar.

Regionale Forschung: Die Forschungskompetenzen konzentrieren sich auf die universitäre Forschung der Universität Innsbruck, meist handelt es sich um freie Forschung (Eigen- und Antragsforschung), in gewissem Maße findet Auftragsforschung für den Naturschutz statt.

Forschungskooperationen: Es bestehen zahlreiche Kooperationen, z.B. mit dem Institut für Ökologie und Naturschutz der Universität Wien, der Universität Hamburg der Universität Hohenheim und der Universität Damstadt.

Intemalionaler Kontext: Intemationale Kooperationen bestehen z.B. im Rahmen von ALTER_Net, GLORIA (MRI master station) oder des Marie Curie Research Training Networks. 
Forschumgsdokumentation und Infrastnukturen: Es gibt das gut ausgestattete Universitätszentrum Obergurgl (früher Bundessportheim, jetzt Universität Innsbruck), ein Veranstaltungs- und Tagungszentrum, mit einer angeschlossenen Alpinen Forschungsstation, die von in- und ausländischen Wissenschaftem intensiv für Forschung und Kurse genutzt wird.

Die Forschungsergebnisse urrden bisher dezentral dokumentient: Universitätszentrum Obergurgl mit Bibliothek, Berichte an den beteiligten Instituten, GIS-Daten in der Landesregienung, Datenbanken am Landesmuseum Femandeum Über ALTER Net sollen zentrale Dokumentation, Verwaltung und Zugniff auf die Forschungsergebnisse emöglicht werden.

Öffentlichkeitsarbeit: Hans Haid und seine Ötztalforschung haben Bekanntheitsgrad und Interesse an der Region gesteigent, Gemot Patzelt repräsentierte bis jetzt die Alpine Forschungsstelle, es gibt jedoch keine für den Biosphärenpark spezifische Öffentlichkeitsarbeit.

\section{Biosphärenparkspezifika hinsichtlich Forschung}

Ähnlich wie der Gossenköllesee ist der Gurgler Kamm ein „traditioneller" Forschungsraum. Es stellt eine Modellregion für alpine, intensive Nutzung dar und verfügt über gute infrastrukturelle Forschungseinnichtungen. Die derzeit intensive Forschungstätigkeit in der Region ist vor allem auf die Eigeninitiative der Forscher der Universität Innsbruck zurückzuführen (vergl. auch Abbildung 38). Das Thema „Nutzungstradition und steigender Nutzungsdruck einer Bevölkenung mit großem wirtschaftlichen Potenzial in einer sensiblen Gebirgslandschaft" könnte Obergurgl zukünftig zu einem interessanten Forschungsraum für das MAB-Konzept machen.

\subsubsection{Neusiedler See}

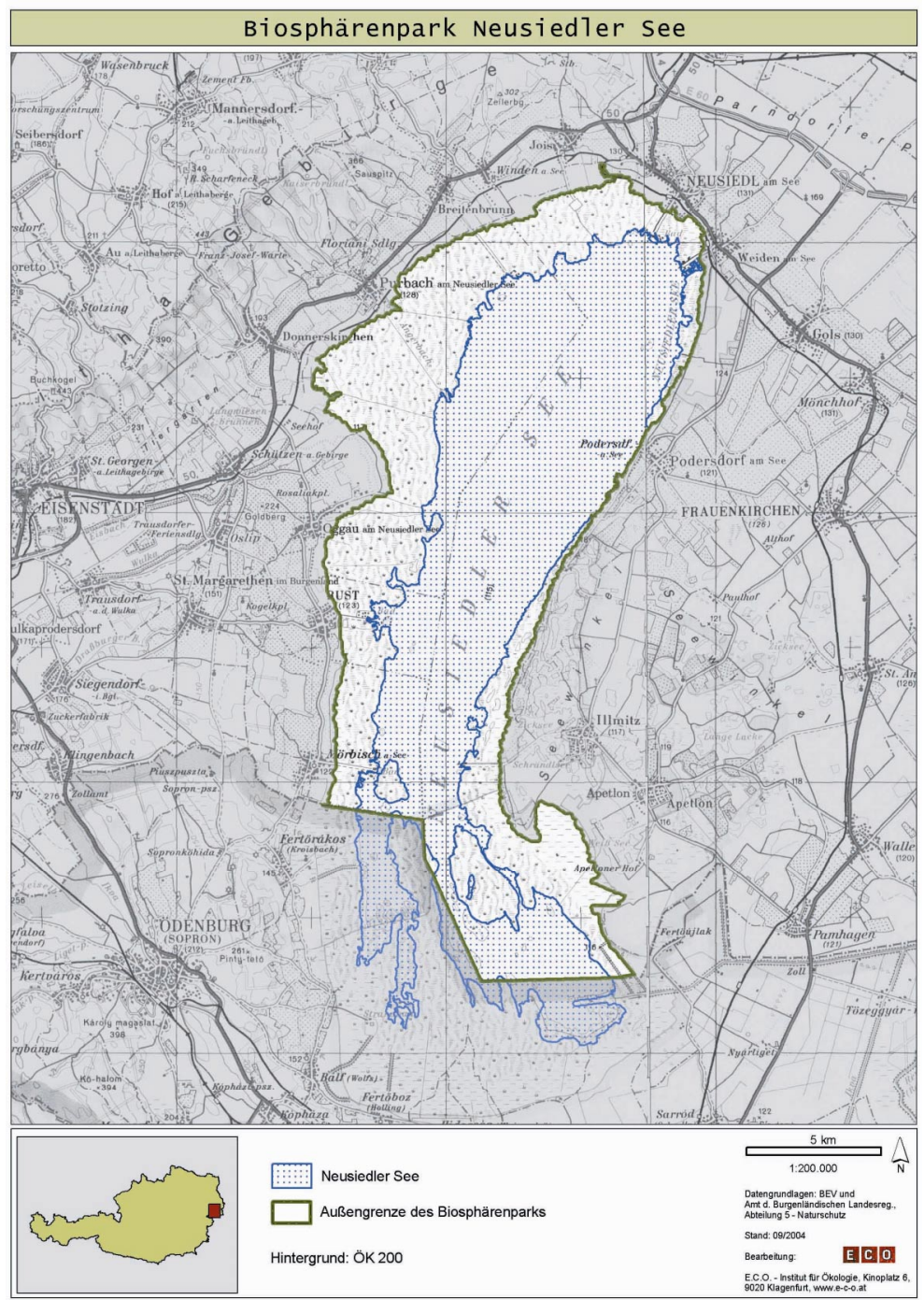

Abbildung29: ÜbersidtskarteBioghärenpark Nexieder See 


\section{Einführung zur Forschung in der Region}

Der Neusiedler See war schon in den Vorkriegsjahren ein intensiv beforschter Raum. Naturwissenschaftliche Untersuchungen zu Fauna und Flora, Hydrologie und Geologie, aber auch Studien zur Archäologie und Volkskultur fanden statt. Ab 1950 wurde der intemationalen Bedeutung des Forschungsraumes durch die Emichtung der Biologischen Station Neusiedler See (Vorläufer der Biologischen Station Illmitz, eröffnet 1971) Rechnung getragen. Seit diesem Zeitpunkt ist auch eine markante Steigenung der Forschungstätigkeiten zu verzeichnen.

\section{Ausmaß der Forschung (Wieviel?)}

Entsprechend der intemationalen Bedeutung sind der Neusiedler See und seine Umgebung Kristallisationspunkt zahlreicher Forschungsaktivitäten. Der Forschung wird ein überaus hoher Stellenwert zuerkannt. Die Ressourcenausstattung für Forschungszwecke ist mittelmäßig.

\section{Ziele der Forschung (Wozu?)}

Für den Biosphärenpark Neusiedler See existieren keinedei dekłarierte Forschungsziele. Im regionalen Kontext gibt es im Rahmen der Nationalparkforschung Ziele, die im Zusammenhang mit der Erstellung von Managementplänen stehen. Das Monitoning zur laufenden Kontrolle und Beweissichenung nimmt dabei eine herausragende Rolle ein.

Durch das MAB5-Projekt „Der Einfluss des diffusen und punktuellen Nährstoffeintrags auf die Eutrophienung von Seen. Teil 2 Neusiedler See und Attersee" ist ein direkter Bezug zur MAB-Forschung gegeben. Indirekt lassen große Teile der Forschungsaktivitäten einen Zusammenhang zu MAB-Forschungsschwerpunkten erkennen, in dem Nutzungseinflüsse des Menschen zentrale Forschungsleitfragen darstellen.

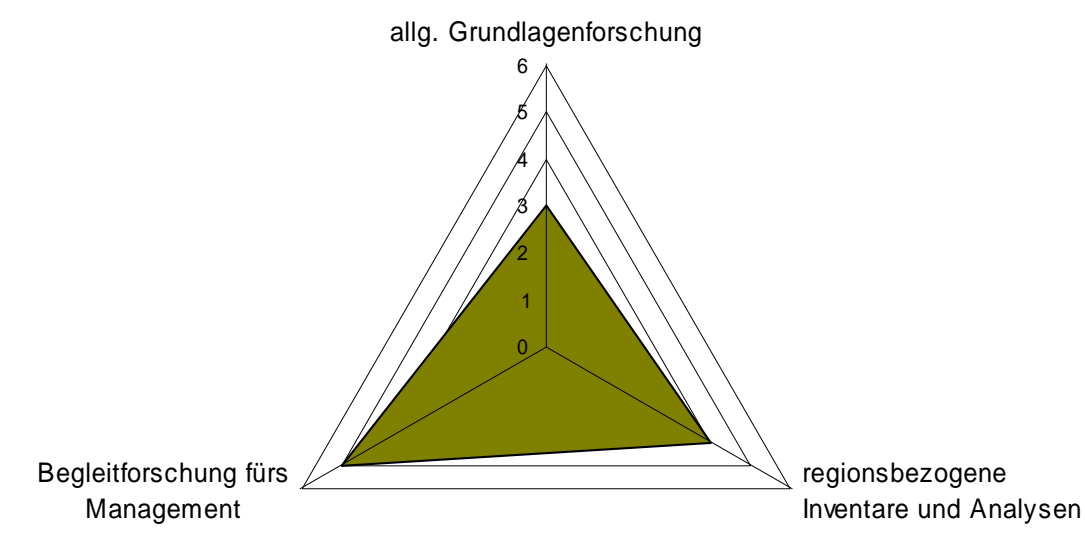

Abbildung30: Forshungsarten Neriedler See

Die gnundsätzliche Positionienung der Forschung in der Region zeigt Abbildung 30. Die Begleitforschung für das Nationalparkmanagement (vor allem Monitoring) spielt eine wesentliche Rolle. Daneben existient eine Vielzahl von zoologischen und botanischen Inventaren und Analysen, die sich jedoch selten über den gesamten Bereich des Neusiedler Sees erstrecken. Die allgemeine Grundlagenforschung ist im Verhältnis zu den anderen Forschungsarten am wenigsten stark vertreten. 


\section{Inhalte und Gegenstand der Forschung (Was?)}

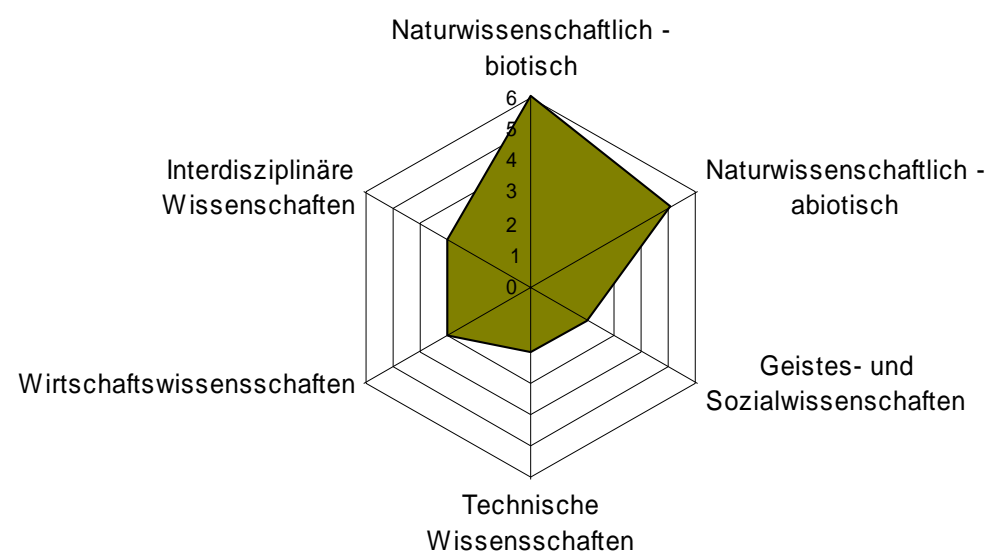

Abbildung31: Forshungodisziplinen Neusieder See

Hinsichtlich der Forschumgsdisziplinen (vergl. Abbildung 31) ist der Schwerpunkt im naturwissenschaftlichen Bereich angesiedelt. Limnologische und omithologische Studien sowie Untersuchungen zu Auswirkungen der Landnutzung (Beweidungsmonitoring traditionelle Landbewirtschaftung, Jagd und Fischerei) stellen dabei wichtige Eckpfeiler dar. Wasseranalytische und kimatologische Untersuchungen nunden das Bild ab. Die übrigen Disziplinen sind im Verhältnis dazu untemepräsentiert.

Themenschmerpunkte: Ganz allgemein sind die Forschungsthemen im Bereich der Botanik, Zoologie und Hydrologie angesiedelt. Speziell die Limnologie, die Omithologie und Fragen zur Landnutzung (Beweidung Schilfnutzung) spielen eine bedeutende Rolle.

\section{Beispielhafte Forschungs-/Planungsaktivitäten und -programme}

- Nationalparkforschung: Die Nationalpark-Gesellschaft hat die Aufgabe in den Natur- und Bewahnungszonen langfristige wissenschaftliche Forschungen, laufende Kontrollen (Monitoring) und Beweissichenung durchzuführen. Seit 1994 bilden die
Forschungsergebnisse die Gnundlage für die Erstellung von Managementplänen. Thematische Schwerpunkte der Nationalparkforschung (hpts. Nationalparkmonitoning) sind der See und seine unmittelbare Umgebung sowie die Salzlacken und Schilfgürtel. Die Nationalparkforschung wird von der Biologischen Station Illmitz koordinient, die Abstimmung der Programme effolgt im Rahmen und mit Zustimmung des wissenschaftlichen Beirates. Die Finanzienung obliegt dem BMLFUW, die Ausfïhnung der Forschung erfolgt durch exteme Forschungsinstitutionen (Biologische Station Illmitz, Universitäten, Naturschutzbund, Birdlife etc.). Als beispielhafte Projekte seien die fischökologische Untersuchung des Schilfgürtels, die Bestandsentwicklung, Habitat- und Nahnungswahl in Kolonien brütender Reiherarten oder das Monitoningprojekt Fischbestand im Neusiedler See erwähnt (vergl. HERZIG, A., 2004, BUNDESMINISTERIUM FÜR LAND- UND FORSTMIRTSCHAFT, UMMELT UND WASSERWIRTSCHAFT, 2002).

Beweidungsmonitoning im Nationalpark Neusiedler See Seewinkel (Universitätt Wien): Seit 1990 wird im Nationalpark ein Vegetationsökologisches Monitoning (Modul A) durchgeführt, das die Auswirkungen von Fraß und Tritt unterschiedlicher Weidevieharten auf verschiedene Vegetationstypen des Seewinkels im Großraum von Illmitz hinsichtlich Bewirtschaftungsfrequenz, ProblemartenEindämmung und Trockenrasen-Rückfühnung analysient. Eine Erweitenung des Projektes schließt seit 2001 auch ein umfassendes Entomologisches Monitoning auf Weide und Bracheflächen ein (vergl. DEPARTMENT OF ECOLOGY AND SOIL ZOOLOGY; TRAXLER, 1998).

- „Wasseahaushaltsstudie für den Neusiedler See mit Hilfe der Geophysik und Geochemie" (1980 bis 1990, Technische Universitäit Wien): Ziel der Untersuchungen war die Enfassung des Grundwasserhaushaltes, speziell im Hinblick auf die Gnundwassemeubildung und die Wechselwirkungen zwischen Grundwasser und Oberflächengewässem. Für dieses Vorhaben wurden Messstationen eingenichtet, Feldversuche durchgeführt und Gnundwasserdaten ausgewertet. Ergänzend dazu vurden in der 
"Wasserhaushaltsstudie Neusiedler See“ (1985 bis 1989) im österreichischen Teil des Neusiedler See-Einzugsgebietes Detailuntersuchungen durchgeführt (vergl. TECHNISCHE UNIVERSTTÄT WIEN. INSTITUT FÜR HYDRAULIK, GEWÄSSERKUNDE UND WASSERWIRTSCHAFT)

- Bird Monitoning Nationalpark Neusiedler See: BirdLife Östemeich wurde im Jahr 2001 vom Nationalpark beauftragt, jährliche Bestandskontrollen typischer und gefährdeter Vögel des Nationalparks durchzuführen. Vogelzählungen gibt es im Seewinkel schon seit vielen Jahren. Die Neuenung in diesem Projekt ist, dass für die wichtigsten Arten gleichzeitig über (vorläufig) einen Zeitraum von fünf Jahren kontinuiedich und in standardisienter Form gezählt wird, um die Bestandsentwickungen nachvollziehbar dokumentieren zu können. Damit sollen einerseits die Bestände einiger gefährdeter Vogelarten, die nirgendwo sonst in Östemeich vorkommen, überwacht werden, andererseits eine Erfolgskontrolle der Schutzaktivitäten des Nationalparks durchgeführt werden (vergl. BIRDLIFE ÖSTERREICH).

\section{Organisation und Rahmen der Forschung (Wie?)}

Biosphärenparkforschung: Zurzeit werden keine finanzielle Mittel für Biosphärenparkforschung bereitgestellt. Biosphärenparkforschung als solche ist daher auch nicht existent. Es gibt jedoch zahlreiche relevante Fragestellungen, die im Zuge der Nationalparkforschung bearbeitet werden.

Regionale Forschumg: Der Neusiedler See verfügt mit der Biologischen Station Illmitz (Außenstelle der Naturschutzbehörde des Landes Burgenland) über ein zentrales Forschungskompetenzzentrum. Der Leiter des Forschungszentrums (Dr. A. Herzig) ist gleichzeitig Biosphärenparkmanager und Koordinator für die Nationalparkforschung. Daher kann das Biosphärenparkmanagement Einfluss auf die Auswahl von Fragestellungen und Methoden nehmen. Generell kann jedoch festgestellt werden, dass die Biosphärenparkforschung von der Nationalparkforschung überlagent wird. Außerhalb des Forschungszentrums sind eine Vielzahl von extemen Forschungsorganisationen in der Region tätig (z.B. Universität
Wien, Technische Universität Wien, Birdlife, AGN, Naturschutzbund, Biologische Station Lunz BSL, Konrad Lorenz Institut der ÖAW, etc.).

Forschungskooperationen: Es gibt Forschungskooperationen zwischen den einzelnen Forschungseinnichtungen (z.B. Biologische Station Illmitz mit der Universität Wien oder dem Naturhistorischen Museum Wien), die in Zusammenhang mit dem Nationalpark, nicht aber mit dem Biosphärenpark stehen. Umfangreiche Forschungsnetzwerke existieren nicht.

Intemationaler Kontext: Die so genannte Biosphärenparkkommission Österreich/ Ungam trifft sich in regelmäßigen Abständen, um Erfahnungen auszutauschen.

Forschungsinfirastmukturen und -dokumentation: Der Biosphärenpark Neusiedler See verfügt über keine eigene Infrastruktur und Forschungsdokumentation.

Im Allgemeinen werden Forschungsergebnisse von den ausführenden Institutionen archiviert (dezentrale Dokumentation). Als regionales Forschungszentrum verfügt die Bibliothek der Biologischen Station Illmitz über die umfangreichste Sammlung von Forschungsergebnissen zur Region. Darüber hinaus besitzen auch die Bibliothek des Nationalparks Neusiedler See, die Burgenländische Landesbibliothek, das Burgenländische Landesmuseum sowie einzelne Fakultäten der Universität Wien umfangreiche Datenbestände.

Öffentlichkeitsarbeit: Biosphärenparkbezogene Öffentlichkeitsarbeit findet aktuell nicht statt. Sehr wohl wird im Zuge der Nationalparkforschung (Neusiedler See Tagungen - aquatische und terrestrische Themen, Spezialtagungen - z.B. zum Thema Schilf, Großtrappen, Sandleben, etc. oder Nationalparkinfos), versucht, die Forschung einer breiten Öffentlichkeit zugänglich zu machen.

\section{Biosphärenparkspezifika hinsichtlich Forschung}

Der Biosphärenpark Neusiedler See ist gekennzeichnet von der Überlagenung des Gebietes durch den Nationalpark, wodurch grundsätzlich gute Forschungsinfrastrukturen in der Region vorhanden sind. Im Rahmen der Nationalparkforschung existiert bereits eine Reihe von Fragestellungen 
zur Region, die auch Biosphärenparkrelevanz aufweisen. Als sehr bedeutend außerordentlicher Bedeutung kann die Möglichkeit zur transnationalen Forschungskooperation mit dem Biosphärenpark Fertö in Ungam gesehen werden (vergl. auch Abbildung 38).

\section{3 .25 Lobau}

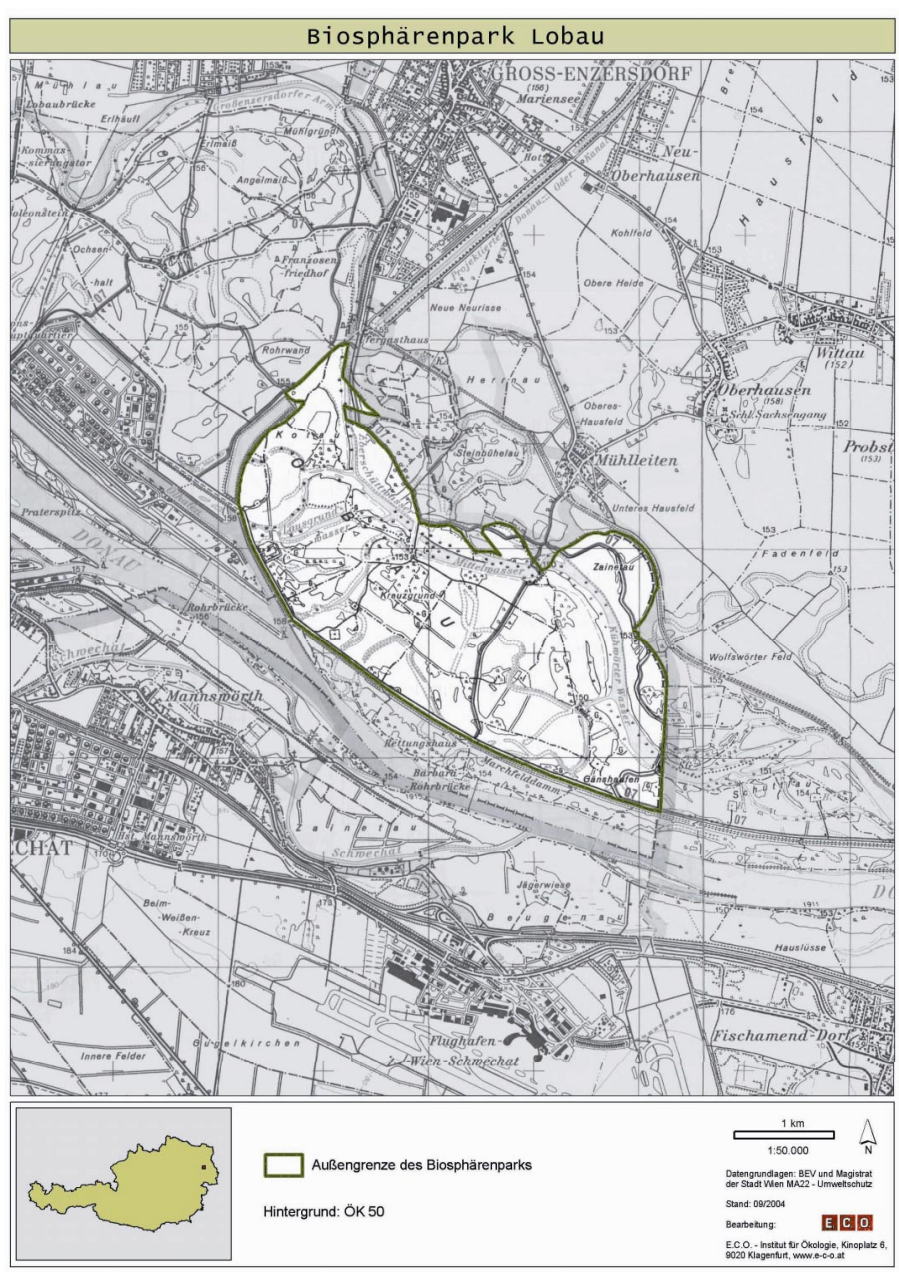

Abbildung32: ÜbesidhtskarteBiosphärenpark Ldbeu

Da keine offizidlen Biosphärenparkgenzen existieren nurde bei der Darstellung auf die Gdidsabgenzung des Ramsar-Gdides zurürkgegiffen, wdihes sich weitghend mit dem Biosphärenparkareal dedkt. 


\section{Geschichte der Forschung (Einführung)}

Eine sehr gute Übersichtsdarstellung zur Forschung in der Lobau gibt IMHOF (1999). Demnach war die Lobau vor 1970 (zurückreichend bis 1860 als es bereits eine nicht veröffentlichte, sehr präzise Darstellung der Vegetation gab) nur zufällig Gegenstand von Forschungsaktivitäten. $\mathrm{Ab}$ 1970 wurden im Auftrag des Magistrats der Stadt Wien Studien zur Erfassung des Naturraumpotenzials durchgeführt. Aus diesen Bemühungen resultierte die Erkdänung zum Biosphärenpark im Jahr 1977. 1978 wurde die Lobau vom Land Wien unter Naturschutz gestellt. Des Weiteren sollte die Möglichkeit der Gnundwasseranreichenung untersucht werden - daraus ging das Dotationsprojekt Lobau hervor. In den 80er Jahren kam es zur Intensivienung von Untersuchungen der Biotope und Biozönosen des Naturschutzgebietes und zur Durchfühnung erster limnologischer Studien durch die Universität Wien. In den 90er Jahren gab es vermehrt wissenschaftliche Aktivitäten in den Bereichen Wasservirtschaft (Hochwasserentlastung) und Auenökologie. Ab 1996 enfuhr das Gebiet durch die Emichtung des Nationalparks Donau-Auen (der den Biosphärenpark Lobau mit einbezieht) einen neuedichen Impuls für die Forschung in der Lobau.

\section{Ausmaß der Forschung (Wieviel?)}

Forschung findet in der Lobau in exheblichem Ausmaß statt. Der Forschung kann somit ein hoher Stellenwert zuerkannt werden. Die Aktivitäten finden jedoch nicht im Rahmen des Biosphärenparks statt, sondem sie sind eingebettet in die Vorhaben und Interessensschwerpunkte der Stadt Wien bzw. des Nationalparks Donau-Auen. Diese sind auch die maßsgeblich für die gute Ressourcenausstattung. Es werden laufend neue Forschungsvorhaben geplant bzw. aktuelle Projekte weitergeführt.

\section{Ziele der Forschung (Wozu?)}

Zielvorgaben vom Biosphärenparkmanagement existieren nicht. Für die Lobau wurden jedoch im Auftrag der Stadt Wien und des Nationalparks Donau-Auen die „Ökologischen Entwicklungsziele für den Nationalparkteil
Lobau" erstellt (vergl. IMHOF, 1999). Weiters ist die Lobau auch Gegenstand des 1998 erstellten Forschungskonzepts des Nationalparks. Aktuelle Zielsetzungen haben keinen direkten Bezug zu MABForschungsschwerpunkten. Thematisch ist jedoch durch das MAB-5/ 21 Projekt Ökotone Donau-March und die MAB-5/14 und 18 Ökosystemstudien Donaustau Altenwörth (Teil 1 und 2) ein Bezug zum MAB-Projektbereich 5 gegeben.

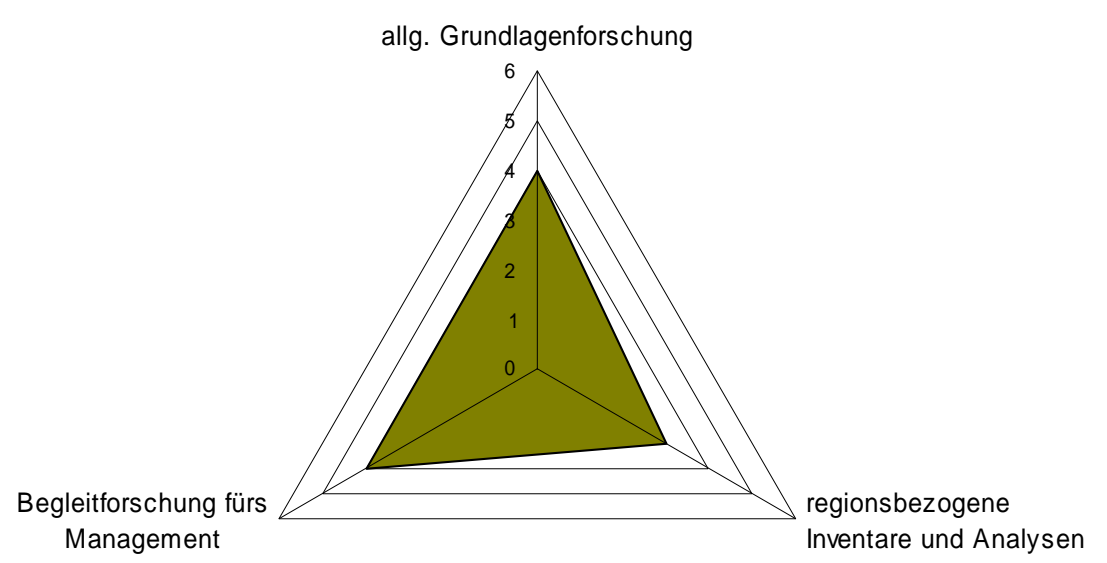

Abbildung33: Forshungsarten Ldbau

Die gnundsätzliche Positionienung der Forschung zeigt Abbildung 33. Demnach sind alle Forschungsarten relativ stark vertreten, mit leichter Betonung der Gnundlagenforschung (vor allem Auenökosysteme) und in jüngerer Zeit der nationalparkrelevanten Begleitforschung fürs Management. 


\section{Inhalte und Gegenstand der Forschung (Was?)}

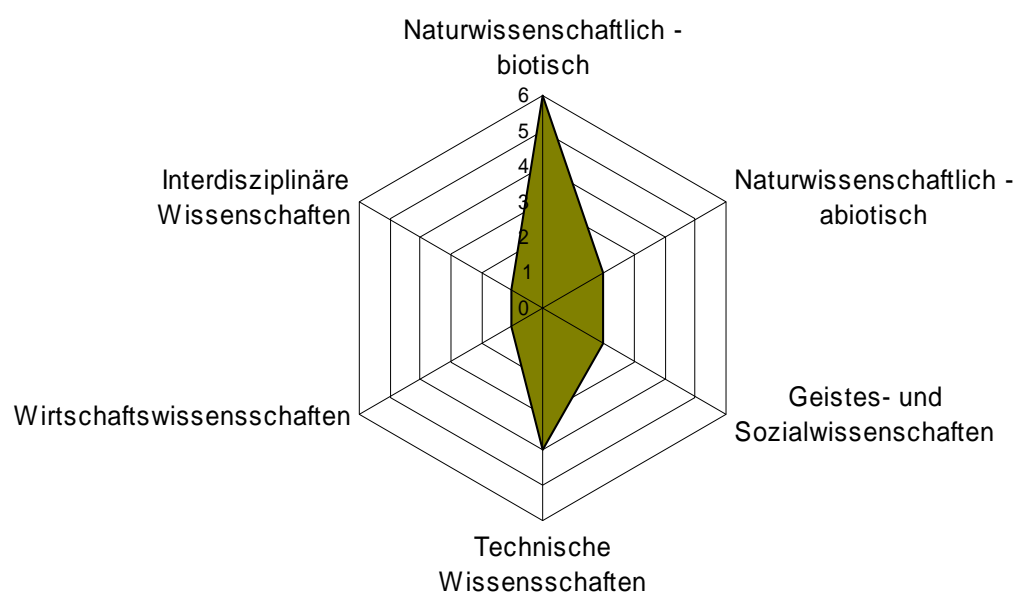

Abbildung 34: Fashungodisziplinen Ldhall

Hinsichtlich der Forschungsdisziplinen zeigt Abbildung 34 einen naturwissenschaftlichen Schwerpunkt (vor allem biotische Aspekte im aquatischen und semiaquatischen Milieu). Ein weiterer Schwerpunkt liegt im Bereich der technischen Wissenschaften (wasserwirtschaftliche und hydrochemische Studien). Geistes- und sozialwissenschaftliche Disziplinen kommen in Fragen des Erholungs- und Freizeittounismus zum Zug, die übrigen spielen nur eine untergeordnete Rolle.

Themenschmerpunkte: Auwaldökosysteme, abgedämmte Au und Gewässervemetzung Hochwasserschutz, Grundwasserökologie und Grundwasserschutz, Heißländen, Jagd und Fischerei.

Forschumgsleitfragen: Struktur und Funktion stark modifizierter Flusslandschaften als Gnundlage für Restaumienung und Management (Nährstoffkreislaufproduktion, Biodiversität und Steuenung, langfristige Entwicklung abgedämmter Auen).

\section{Beispielhafte Forschungs-/Planungsaktivitäten und -programme}

Projekt „Dotation Lobau“": Im Zuge der großen Donauregulienung 1875 kam es zur Abdämmung der Au vom Donaustrom und somit zur nachhaltigen Ändenung auwaldökologischer Strukturen und Funktionen. Das interdisziplinäre Langzeitprojekt Dotation Lobau (mit der Unteren Lobau als Teilraum) wurde 1986 von der MA 45 - Wasserbau in Auftrag gegeben. Fragen der Grund- und Oberflächenwasseranreichenung der Isolienung von Öl-Altlasten im Bereich des ÖMV-Zentraltanklagers und der Bereitstellung des Dotationswassers sollten untersucht werden. Neben den wasserbautechnischen Planungen zur Dotation der $\mathrm{Au}$ bildet ein mehrstufiges "begleitendes ökologisches Versuchsprogramm" (limnologische, hydrobotanische, faumistische und tierökologische Bestandserhebungen, Monitoringaktivitäten, Analysen etc.) die zweite Säule dieses noch immer andauemden Projektes (vergl. SCHIEL, 1992; IMHOF, SCHIEMER \& JANAUER, 1992; NATIONALPARK DONAU-AUEN, 2001).

\section{LIFE-Natur Projekt „Gewässenvemetzung und} Lebensraummanagement Donaur-Auen": Das Projekt gliedert sich in zwei Teile, wobei der erste Teil (1998 bis 2002) abgeschlossen, der zweite Teil (2002 bis 2006) in Ausfühnung ist. Das Projekt besitzt eine starke Umsetzungskomponente (wasserbauliche Baumaßnahmen), wobei auch der ökologischen Begleitforschung (Zustandserhebungen, Beweissichenung, Monitoring) eine zentrale Rolle zukommt. Die Untere Lobau stellt mit den hier durchgeführten Teilprojekten (z.B. „Gewässervemetzung Überschwemmungsgebiet Untere Lobau", "Gewässervemetzung Gänsehaufentraverse“, „Wiesenmanagement Überschwermmungsgebiet Untere Lobau", „Vorbereitung Dammöffnung Schönauer Schlitz", Schutzprogramm Heißländen“, „Wachtelkönig“) einen intensiv "gemanagten" und beforschten Raum dar (vergl. NATIONALPARK DONAUAUEN, 2001)

Flussbauliches Gesamtprojekt Donau-Auen: Das „Flussbauliche Gesamtprojekt östlich von Wien“" (aktuell UVE-Verfahren, anschließende UVP bis 2006, Umsetzung bis 2010) umfasst flussbauliche Maßnahmen im Donauabschnitt Kraftwerk Freudenau bis zur östemeichisch-slowakischen Staatsgrenze. Im Rahmen des Projektes soll eine Verbessenung der 
hydrologischen Vemetzung und der Dynamik in den Landschaftsstrukturen erreicht werden. Im Leitbild zum Gesamtprojekt werden eine Stabilisienung der mittleren Höhenlage der Stromsohle, die nachhaltige Verbessenung der ökologischen Funktionsfähigkeit des Donauraumes sowie die Verbessenung der Verhältnisse für die Schifffahrt angestrebt (vergl. FLUSSBAULICHES GESAMTPROJEKT).

Gedämmte Au - geffutete Au: Die vergleichende Untersuchung von 1987/ 88 über geflutete (am rechten Donaunfer - Mannswörther-Au, Revierteil Poigenau) und gedämmte Auwaldgebiete (am linken Donauufer Revier Untere Lobau) sollte die Auswirkungen der im Rahmen des Wettbewerbes Donauraum vorgeschlagenen Maßnahme „Öffnung des Marchfeldschutzdammes" und der damit ermöglichten periodischen Überschwemmung der Unteren Lobau auf die bestehenden Auwaldökosysteme untersuchen. Daraus ergab sich die Arbeitshypothese, dass sich der Auwald in der Unteren Lobau bei einem Rückbau des Hochwasserschutzdammes in Richtung eines gefluteten Auwaldbestandes (wie in der Mannswörther Au) entwickeln kann. Um diese Hypothese zu überprüfen, wurden forstöklogische, ertragskundliche, vegetationskundliche und hydrologische Fachgutachten in Auftrag gegeben. Das wesentlichste Ergebnis dieser Studie der Universität für Bodenkultur war der erstmals wissenschaftlich belegte Nachweis, dass die dynamischen Wassergegebenheiten der frei strömenden Donau die wichtigste Voraussetzung für einen vitalen Auwald sind - somit eine Stauhaltung durch das KW Hainburg mit einem Auwald-Nationalpark unvereinbar ist! (vergl. FORSTAMT DER STADT WIEN; HAUBENBERGER \& WEIDINGER 1988).

DAPTF: Die Österreichische Arbeitsgnuppe der Declining Amphibian Populations Task Force (DAPTF) der Species Survival Commission (SSC) der World Conservation Union (IUCN) gehört einem weltweiten Netz an Es unterstützt vissenschaftliche Bemühungen, die Gefährdung von Amphibien auf lokaler, regionaler und globaler Ebene hinsichtlich Art Ausmaß und Ursachen zu enfassen sowie Maßnahmen voranzutreiben, die goeignet sind, den Bestand von Amphibienpopulationen zu sichem. In diesem Rahmen werden seit 1989 unter anderem Amphibienkartienungen von der Universität Wien in der Lobau durchgeführt (vergl. DAPTF-
AUSTRIA).

\section{Organisation und Rahmen der Forschung (Wie?)}

Biosphärempark-Forschung: Das Biosphärenparkmanagement stellt keinen eigenen Finanzienungsposten für die Forschung bereit Biosphärenparkforschung als solche ist daher auch nicht existent. Aufgnund enger Kooperation zwischen dem Nationalpark und Biosphärenparkmanager DI Haubenberger (Forstverwaltung Lobau - MA 22) ist aber eine Einflussnahme hinsichtlich biosphärenparkrelevanter Fragestellungen gegeben

Regionale Forschung: In der Region des Biosphärenparks (Untere Lobau, teilweise Obere Lobau) sind die Forschungskompetenzen stark mit dem Nationalpark DonautAuen bzw. dem Magistrat der Stadt Wien verknüpft, die ihrerseits eng zusammenarbeiten. Als Hauptkoordinator fungiert Univ.Prof. Dr. Schiemer (Universität Wien), der dem Wissenschaftlichen Beirat des Nationalparks Donau-Auen vorsteht. Als ausführende Institutionen sollen beispielhaft die Universität Wien, die Universität für Bodenkultur, die Universität für Veteninämmedizin, Birdlife, das Institut für Limnologie/ Station Mondsee der ÖAW und das Ludvig-BoltzmannInstitut genannt werden.

Forschumgskooperationen: Geregelte Forschungskooperationen sind wesentlicher Bestandteil des Forschungskonzepts des Nationalparks DonautAuen.

Intemationaler Kontext: Die Lobau ist eine Domäne österreichischer Forschungsinstitutionen. Intemationale, fachliche Kooperationen gibt es beispielsweise mit der ETH Zünich (Institut für Limnologie), der Universität Wageningen/ Holland oder der Universität Kansas/ Mississippi. Als Teil des Donaugewässers ist die Lobau Gegenstand zahlreicher Studien der intemationalen Arbeitsgemeinschaft Donauforschung (IAG). Im Zuge von DAPTF (Declining Amphibian Populations Task Force) gibt es Untersuchungen zur Situation der Amphibien

Forschungsdokumentation und Infrastmukturen: Forschungsinfrastrukturen wie z.B. Forschungsstützpunkte gibt es im Biosphärenpark 
Lobau nicht. Es existieren jedoch zahlreiche Forschungsinstitutionen in unmittelbarer Nähe (z.B. Universität Wien, Unversität für Bodenkultur, Östemeichische Akademie der Wissenschaften, etc.). Forschungsergebnisse werden dezentral bei den einzelnen Forschungsinstitutionen dokumentiert. Neben dem Nationalpark Donau-Auen (wo u. a. Forschungsdaten ins Nationapark-GIS integriert werden) sind zahlreiche Forschungsergebnisse bei den einzelnen Magistratsabteilungen der Stadt Wien (z.B. MA 22 Umweltschutz, MA 45 - Wassenbau, MA 49 - Forstamt und Landwirtschaftsbetrieb der Stadt Wien) und der Universität Wien zu finden.

Öffentlichkeitsarbeit: Die Öffentlichkeitsarbeit ist eingebettet in die Agenden des Nationalparks Donau-Auen und der Magistratsabteilungen der Stadt Wien.

\section{Biosphärenparkspezifika hinsichtlich Forschung}

Wie der Biosphärenpark Neusiedler See wird auch die Lobau von einem Nationalpark (Nationalpark Donau-Auen) überlagert. Dementsprechend untediegen forschungsrelevante Fragen dem Nationalparkmanagement Hinsichtlich der Forschungsschwerpunkte Renaturienung und Prozessdynamik abgedämmter Auen ist die Lobau ein Untersuchungsmodell von intemationaler Bedeutung (vergl. auch Abbildung 38).

\subsubsection{Wienerwald}

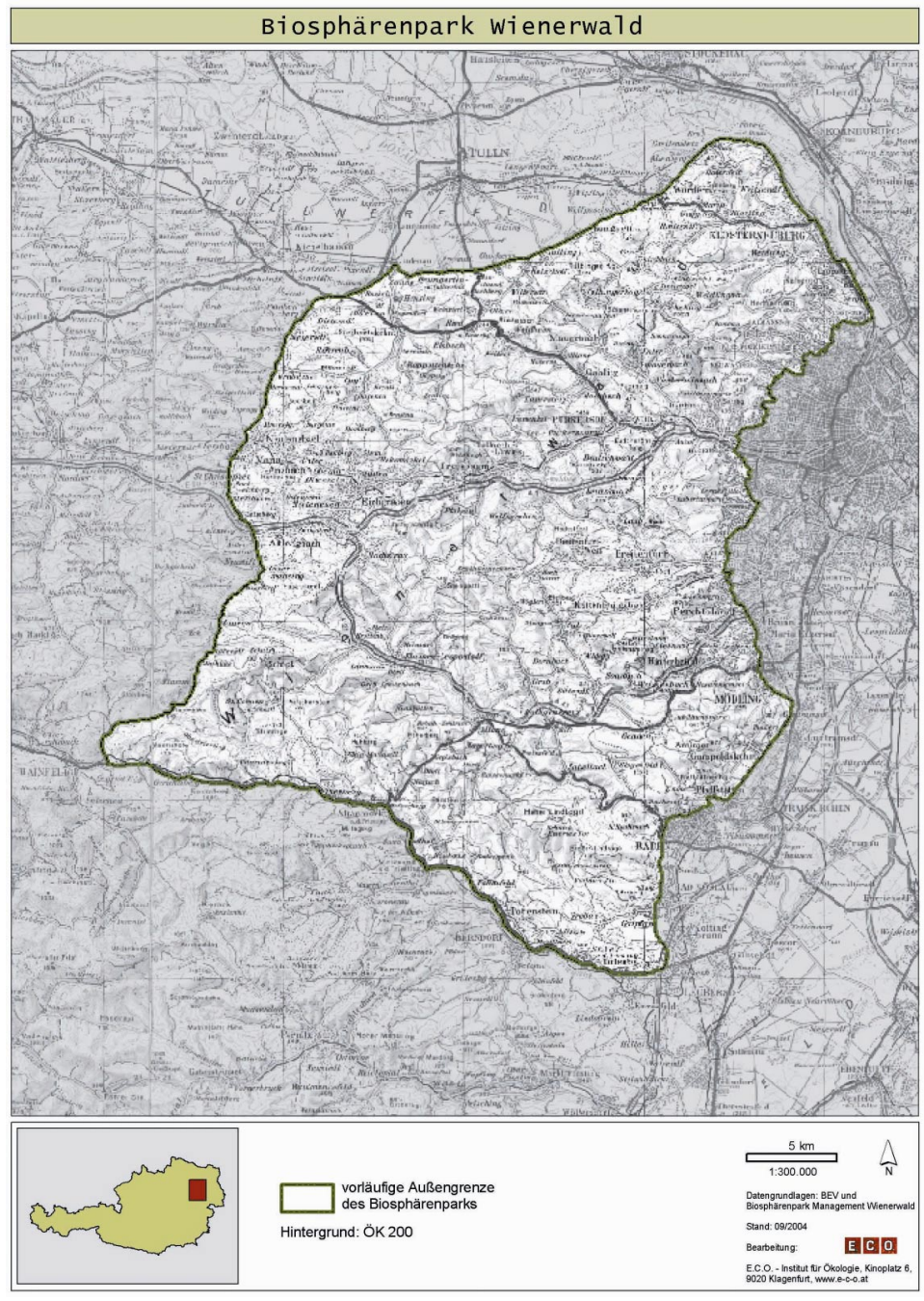

Abbildung35: ÜbesidtskarteBiosghärenpark Wienenald 


\section{Geschichte der Forschung (Einführung)}

Abhandlungen mit dem Anspruch zeitgemäßer wissenschaftlicher Forschung gab es seit Mitte des 19. Jahrhumderts. In dieser Periode und um das 1900 entstanden vor allem Werke zur Landes- und Volkskunde („Gschichtln“ zu Land und Leute, Liedergut, Sagen und Legenden, Kulturdenkmäler, Siedlungsgeschichte, etc.). Sehr früh gab es schon Schniften zur Nutzung des Wienerwaldes als Erholungsgebiet. Auch Beiträge zur Forstwirtschaft (K.k.-Staatsforste) und ihrer Entwickung auch heute noch wichtige Forschungsbereiche - gehen bis in diese Zeit zurück und zeugen von der Bedeutung des Holzes für die Region.

In den 1950er Jahren begann die naturwissenschaftliche Forschung verstärkt Fuß zu fassen (Beiträge zur Limnologie der Wienerwaldbäche, kimamonphologische Untersuchungen, geologische Untersuchungen zum Wienerwald-Flysch, etc.)

Ab den 1970er Jahren waren die Frage nach den Auswirkungen des nahen Ballungsraumes auf den Zustand des Wienerwaldes oder auch die Wiesenforschung vordringliche Anliegen der Forschung.

\section{Ausmaß der Forschung (Wieviel?)}

Der Wienerwald am Rand des Agglomerationsraumes Wien bietet aufgnund seiner Lage und seiner Ausstattung gute Voraussetzung für Forschungsaktivitäten. Zahlreiche universitäre Forschungseinnichtungen liegen im Biosphärenparkgebiet (z.B. Universität für Bodenkultur, Universität Wien, Institut für Ökologie und Wildtienforschung der Veterinämmedizinischen Universität Wien, Bundesanstalt für Wald, Zentralanstalt für Meteorologie, Konrad Lorenz-Institut). Das Ausmaß der Forschungsaktivitäten kann hoch eingestuft werden. Die Forschung erstreckt sich jedoch selten auf den gesamten Wienerwald. Charakteristisch ist eine ungleichmäßige Verteilung der beforschten Räume. Als „Hot spots“ können beispielhaft die Naturschutzgebiete Lainzer Tiergarten und Eichkogel, der Wienfluss, der Bereich um Wien-Kalksburg oder einzelne Naturwaldreservate angeführt werden.

\section{Ziele der Forschung (Wozu?)}

Eine Gesamtzielsetzung für den Wienerwald existient derzeit nicht. Der Wienerwald-Deklaration ist ein Hinweis auf Überprüfung der Idee eines Dokumentations- und Forschungszentrums als „Kristallisationspunkt" zu entnehmen. Im Zuge der Einnichtung des Biosphärenparks soll ein Forschungs- und Monitoringkonzept erarbeitet werden. Ein Bezug zu MAB-Forschungsaktivitäten ist vor allem mit der Studie „Hemerobie österreichischer Wald-Ökosysteme“" (vergl. GRABHERR et al. 1998; Projektbereich 2) herstellbar. Indirekt haben die Untersuchungen zur Luftverschmutzung und Bioindikation im Wienerwald Bezug zum Projektbereich 14, Studien zu Suburbanisationsprozessen beziehen sich auf Projektbereich 11

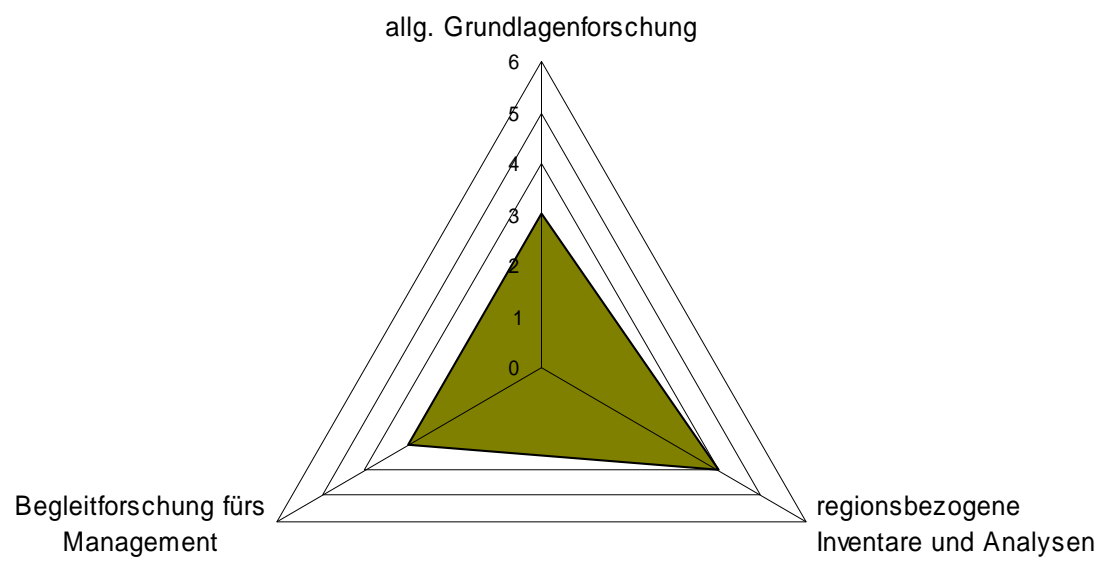

Abbildung36: Forshumosarten Wienewald

Abbildung 36 zeigt eine relativ gleichmäßige Verteilung der Forschungsarten mit leichtem Schwerpunkt auf regionalen Inventaren und Analysen (faunistische und flonistische Kartienungen, Studien zu Freizeitvenhalten und Suburbanisationsprozessen). Allgemeine Gnundlagenforschung findet vor allem im Waldbereich statt Managementbetonte Begleitforschung ist schwerpunktmäßig im Bereich "Wienerwaldwiesen" zu finden. 


\section{Inhalte und Gegenstand der Forschung (Was?)}

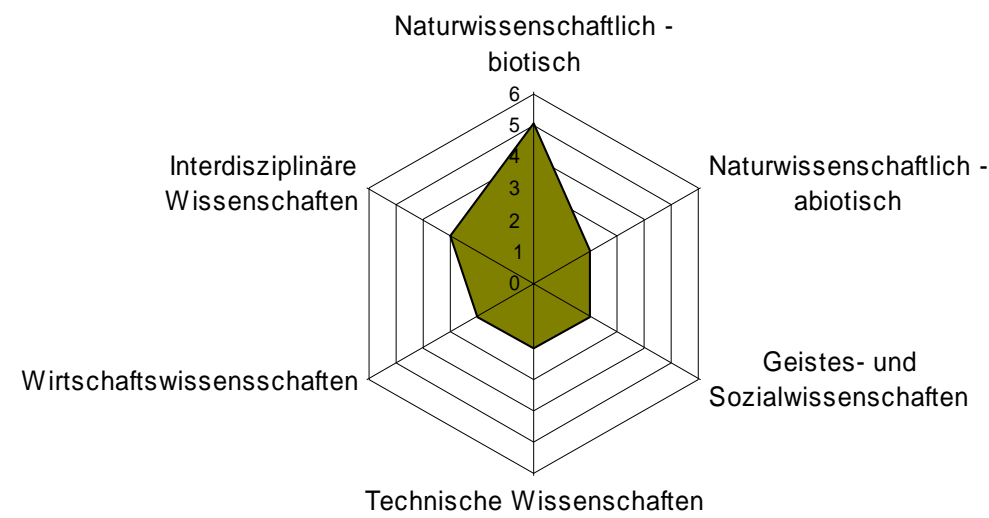

Abbildung37: Forshungodiszipdinen Wienevald

Hinsichtlich Forschungsdisziplinen zeigt Abbildung 37 den Schwenpunkt im Bereich der biotischen Naturwissenschaften (Waldforschung Wiesenforschung, omithologische Analysen, ingenieumbiologische Studien, Vegetationserhebungen). Ein bemerkenswent hoher Anteil ist den interdisziplinären Studien zuzuordnen, die technische, wirtschafts-, geistesund sozialwissenschaftliche Aspekte einbeziehen (Enforschung von Suburbanisationsprozessen und ihren Folgen, Freizeitforschung, Forschung der Emolungswirkung, etc).

Themenschmenpunkte: Gegenstand der "Wienerwaldforschung" sind in erster Linie der Wald (Buchenwaldökosysteme, Naturwaldreservate, Bioindikationen) und das Offenland (Wiesen, Trockenrasen) sowie die Suburbanisation (Stadt-Umland Beziehungen) und die Erholungsnutzung. Darüber hinaus spielen Vogelkunde, Ingenieurbiologie, Archäologie („Wienerwald-Kamel“), Mykologie (Pilze als Bioindikatoren für ökologische Umbrüche), Umweltanalytik und Höhlenforschung (286 Höhlen) eine wesentliche Rolle

\section{Beispielhafte Forschungs-/Planungsaktivitäten und -programme}

- Regionalanalyse Wienemald: Ziel der Studie war die Untersuchung der raumstrukturellen Gegebenheiten unter Berücksichtigung der funktionalen und räumlichen Wechselwirkungen sowie das Aufzeigen von Entwicklungsperspektiven vor allem hinsichtlich der Einnichtung eines Biosphärenpark Wienerwald (vergl. ÖIR, 2004). Hiezu enfolgte eine umfassende Auswertung von vorhandenen sozioökonomischen Daten.

- Machbarkeitsstudie Wienemwald: Die Machbarkeitsstudie uurde 2002 durchgeführt und untersuchte die Eignung des Wienerwaldes zum Nationalpark oder zum Biosphärenpark. Auf Gnundlage der Erhebungen zu den vielfältigen Nutzungsansprüchen an den Wienerwald war die Erstellung eines Zonienungskonzeptes ein zentraler Punkt. Die Machbarkeitsstudie stellte die fachliche Gnundlage für die (regional)politische Entscheidungsfindung („pro“ Biosphärenpark) und in weiterer Folge für eine detailliente Planungsund Umsetzungsphase dar (vergl. ARGE WIENERWALD, 2002).

- Naturwaldresenvate im Wienenwald: Die Vorstudie im Auftrag der MA49 ist ein Beitrag zur Schaffung weiterer Naturwaldreservate im Wienerwald. Ziel war die Zusammenstellung von Gnundlagenmaterial zur Auswahl zukïnftiger und zur Bearbeitung bestehender Naturwaldreservate im Wienerwald, die Abschätzung rechtlicher und forstbetrieblicher Auswirkungen von Naturwaldreservaten und die Erarbeitung einer Bibliografie naturwaldrelevanter Publikationen über den Wienerwald (vergl. FLESCH\& FRAISSL, 1994).

- COST-Programme: Mit COST-Programmen der EU (European Cooperation in the Field of Scientific and Technical Research) vird das Ziel verfolgt, kooperative Forschung in Europa zu fördem. Thematisch und auch räumlich besitzen einige Projekte Anknüpfungspunkte für den Wienerwald:

- COST E12 Aktion: Das von Dänemark initiieste COSTProgramm „Unban Forests and Trees" zielt auf Schutz, Pflege, Erhaltung und Planung städtischer Grünbereiche ab. Von 
Interesse für die Projektarbeit war, wie Grünrauminformation in anderen Städten gewonnen wird. Österreich beteiligte sich mit drei Projekten. $\mathrm{Zu}$ den Forschungsprogrammen zur Grünraumerhebung in Wien gehören das "BiotopMonitoning Wien“ (Informationssystem über Grünflächen, 1996 bis 2002, vergl. MA 22 - UMMELT), die „Waldzustandserhebung Wien" und die "Wienerwaldforschung im Systemzusammenhang" (Erhebung des Kronenzustands des Wiener Teiles des Wienerwaldes in den Jahren 1986 und 1991). Die Universität für Bodenkultur sowie das Östemeichische Bundesinstitut für Gesundheitswesen (ÖBIG) zeichnen für die Koordination des Programms in Österreich verantwortlich (vergl. BUNDESMINISTERIUM FÜR VERKEHR, INNOVATION UND TECHNOLOGIE - SEKTION V, 2002).

- COST Action C 10. Im Projekt „Outskirts of European Cities“ und der zugeordneten Fallstudie "Struktur und Dynamik des Wohnwesens in den Randzonen der Stadt Wien" werden die vielfältigen Stadt-Umland-Beziehungen und die räumlichen Vedagenungsprozesse städtischer Funktionen in das Stadtumland analysient (vergl. COST C10).

- Weitere COST Aktionen, an denen Östemeich des Weiteren beteiligt ist bzw. die vorbereitet werden: „Verkehr und Lebensraum: Darstellung und Bewertung von Zerschneidungseffekten durch Verkehrsinfrastrukturen", COST E27 Protected Forest Areas in Europe - Analysis and Harmonisation (PROFOR), oder „Habitat fragmentation due to transportation infrastructure".

- Hemerobiesturdie Östemeich: Das österreichweit angelegte MABForschungsprojekt attestient dem Wienerwald eine hohe Naturnähe: „Verglichen mit anderen Laubwaldgebieten Östemeichs ist der Wienerwald noch der mit Abstand natürichste. Mehr als $80 \%$ des Waldes sind als naturnah oder nur mäßig verändent anzusprechen. Damit ist der Wienerwald in seiner Gesamtheit natürdicher als die Auwälder des DonaurNationalparks und mit Abstand natïnlicher als die Wälder des Waldvientels und der Steiemark" (vergl. GRABHERR 2001; GRABHERR et al. 1998).

- Studie zum Schutz des Schwarzstorches: 2002 wurde eine mehrjähnige Untersuchung zu Bestand und Erhaltung des Schwarzstorches, des "geheimen Wienerwald-Königs", abgeschlossen. Diese Initiative der Östemeichischen Bundesforste (ÖBf AG) in Zusammenarbeit mit BirdLife Österreich und dem Österreichischen Naturschutzbund hatte zum Ziel, die Ursachen für die Gefährdung des Schwarzstorches zu analysieren und neue Schutzstrategien zu entwickeln (vergl. ÖSTERREICHISCHE BUNDESFORSTE AG).

\section{Organisation und Rahmen der Forschung (Wie?)}

Biosphärenpark-Forschung: Der Biosphärenpark Wienerwald befindet sich in der Einnichtungsphase. Biosphärenparkforschung im engeren Sinn findet daher noch nicht statt. Gemäß der Wienerwald Deklaration 2002 soll jedoch die Idee eines Dokumentations- und Forschungszentrums als „Knistallisationspunkt“ (vergl. PGO 2002) überprüft verden. Im Zuge der Planungsarbeiten des Biosphärenparkmanagements ist die Erarbeitung eines Forschungs- und Monitoningkonzeptes vorgesehen.

Regionale Forschung: Im Bereich des Wienerwaldes sind die Forschungskompetenzen dezentral aufgeteilt, d. h. dass zurzeit keine zentrale Koordinationsstelle für Forschung existient (=freie Forschung). Es gibt eine Vielzahl an Einzelprojekten und Forschungsakteuren. Größere, breit angelegte, den gesamten Wienerwald betreffende Forschungsinitiativen sind kaum vorhanden.

Forschumgskooperationen: Forschungskooperationen im Zuge von Projekten sind natüdich vorhanden. Geregelte, auf die Region bezogene Forschungskooperationen gibt es aufgnund der Einnichtungsphase jedoch noch nicht (beispielsweise in Form von Ko-Finanzienung, Projekten, Datentausch).

Intemationaler Kontext: Der Wienerwald ist eine Domäne österreichischer Forschungsinstitutionen. Es gibt jedoch auch umfangreiche Einbindungen in intemationale Programme (gerade an der Schnittstelle von 
Stadt-Land), wie zum Beispiel das COST-Programm beweist. Eine detailliente Betrachtung ist aufgnund der Vielzahl an beteiligten Forschungsinstitutionen und der Größe des Areals im Rahmen der vorliegenden Arbeit nicht möglich.

Forschungsinfrastrukturen und -dokumentation: Im Planungsgebiet des Wienerwaldes sind wichtige Forschungsinstitutionen angesiedelt, die auch wesentliche Forschungsaktivitäten im Gebiet ausführen (Universität für Bodenkultur, Bundesanstalt für Wald, Zentralanstalt für Meteorologie). Weitere befinden sich in unmittelbarer Nähe (Universität Wien, Österreichische Akademie der Wissenschaften, Birdlife, Naturhistonisches Museum Wien, Umweltschutzabteilung - MA 22, etc.).

Die Forschungsergebnisse verden dementsprechend dezentral dokumentiert, eine vollständige Übersicht über aller Forschungsaktivitäten in der Region ist daher kaum möglich.

\section{Biosphärenparkspezifika hinsichtlich Forschung}

Der in Planung befindliche Biosphärenpark Wienerwald ist hinsichtlich der Ausmaße (Größe, Einwohner) in Östemeich einzigartig. Inventare und
Analysen, die die gesamte Region abdecken, sind selten, wenngleich sich durch die zahlreichen nahen Forschungseinnichtungen dezentrale „Hot spots" der Forschung ausgebildet haben. Durch die intensive Venflechtung von Naturraum und Gesellschaft besteht ein hohes Potenzial für sozioökonomische Forschungsansätze (Freizeit- und Erholungsnutzung Zerschneidungseffekte, Suburbanisienungsprozesse, Emissionen, etc.) (vergl. auch Abbildung 38)

\subsubsection{Forschungsdeterminanten und Handlungsbedarf - Zusammenschau}

Abbildung 38 gibt einen Gesamtüberblick über forschungsrelevante Aspekte (Defizite und Probleme, Potenziale und Schwerpunkte) auf verschiedenen Ebenen. Sie können als Determinanten der Forschung gesehen werden, aus denen sich z.T. Handlungsbedarf ableiten lässt. 


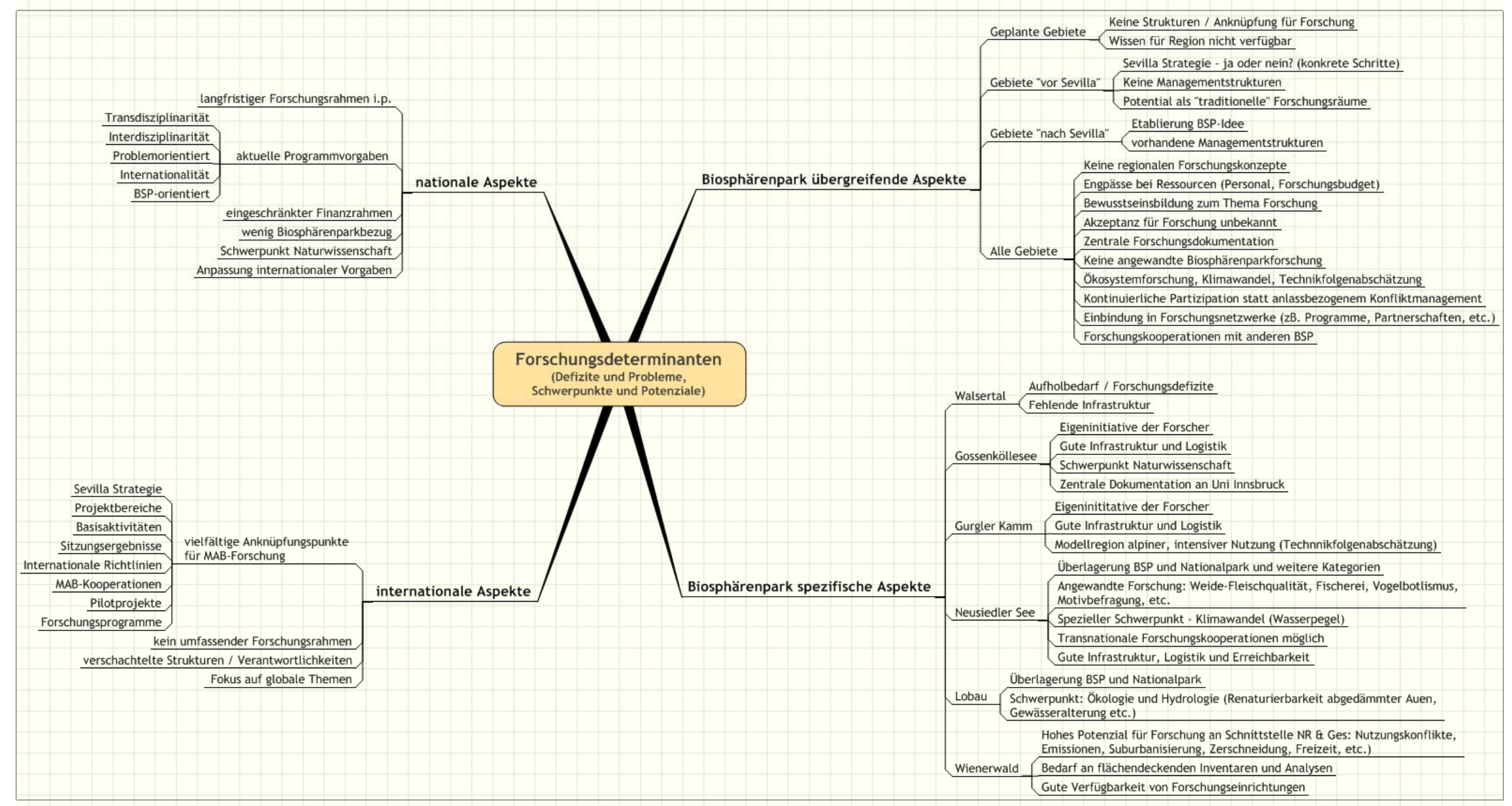

Abbildung 38: Übersidt über Forshungsdłeminanten auf vershiedenen Ebenen

Auf intemationale und nationale Aspekte wird in den entsprechenden Kapiteln (vergl. Kapitel 3.6.3 bzw. Kapitel 5.3.1) eingegangen.

Biosphärenpark spezifische Gegebenheiten sind in den jeweiligen
Biosphärenparkbeschreibungen zur Forschung edäutert (vergl. 5.3.2).

Biosphärempark übergreifende Sachverhalte werden im Folgenden dargestellt. 


\subsubsection{Biosphärenpark übergreifende Aspekte}

- Geplante Gebiete: In Planung befindliche Biosphärenparks, vie beispielsweise der Wienerwald (eingeschränkt Moravien), besitzen keine Strukturen, die die Region in ihrer Gesamtheit „verwalten“. Die regionale Forschung hat daher wenige Anknüpfungspunkte und enfolgt in der Regel unkoordinient und räumlich heterogen venteilt. Ziele, Methoden, die Ergebnisdokumentationen und der Einsatz von Ressourcen sind nur teilweise aufeinander abgestimmt. Diese Umstände haben zur Folge, dass Wissen für die Region aktuell nur schwer zugänglich ist. Es wird daher eine zentrale Aufgabe der einzurichtenden Biosphärenparkstrukturen sein, Forschung in all ihren Facetten in das Management zu integrieren. Mit der Erstellung eines Forschungs- und Monitoringkonzeptes könnte der Rahmen für Forschung abgesteckt werden.

- Gebiete „vor Sevilla“: Die Biosphärenparks, die vor der Erstellung der Sevilla-Strategie entstanden sind, haben gemeinsam, dass sie auf Initiative von Forschem eingerichtet wurden und daher einen stark wissenschaftsonientierten Hintergnund besitzen (vergl. 5.1). $\mathrm{Zu}$ ihnen zählen Gossenköllesee, Gurgler Kamm, Untere Lobau und Neusiedler See. Für eine zukünftige Regelung der Forschung ist zunächst zu klären, ob die Richtlinien der Sevilla-Strategie und somit die Biosphärenpark-Idee in den Gebieten umgesetzt verden sollten. Eine entsprechende Bereitstellung von Ressourcen für die Managementstrukturen ist dabei vonnöten. Aus Sicht der Forschung besitzen diese Gebiete ein hohes Potenzial ("traditionelle" Forschungsräume), weshalb Anstrengungen zur Weiterentwicklung dieser Gebiete vorangetrieben verden sollten. Im Zuge von Machbarkeitsstudien oder zielgerichteten Diskussionsprozessen könnte die weitere Vorgehensweise für jeden einzelnen Biosphärenpark abgekłärt werden.

- Gebiete „,nach Sevilla“: In diese Kategorie ist in Österreich nur das Große Walsertal einzuordnen. Es zeichnet sich durch die Umsetzung der Biosphärenpark-Idee gemäß Sevilla-Richtlinien und etabliente Managementstrukturen aus. Es sind daher gute Voraussetzungen gegeben, Forschung als integrativen Bestandteil in das Biosphärenparkgeschehen einzubauen. Ein zukünftiges Ziel des Managements muss daher die Schaffung von Rahmenbedingungen für Biosphärenparkforschung sein. Im Zuge eines Forschungs- und Monitoningkonzeptes können dabei die regionalen Forschungsfelder erhoben und mit übergeordneten Zielsetzungen abgeglichen werden.

- Alle Gebiete: Charaktenistisch für die österneichische Forschungslandschaft in Biosphärenparks ist die Vielzahl an bestimmenden Faktoren, die allgemeine Gültigkeit haben. Gnundsätzlich ist festzustellen, dass kaum Forschung unter dem Titel der Biosphärenparkforschung durchgeführt wird. Demnach gibt es auch keine Forschungskonzepte, zentralen Forschungsdokumentationen, Forschungskooperationen oder Einbindung in intemationale Netzwerke. Vieffach ist der Schnitt dorthin nicht weit (Gossenköllesee, Gurgler Kamm, Lobau, Neusiedler See), da vorhandene Forschungsstrukturen (Nationalpark, Universitäten etc.) genutzt werden könnten. Engpässe bei den Ressourcen (Personal für Management, Budget für Forschung, etc.) sind mitverantwortlich, dass die Biosphärenparkforschung nicht Fuß fassen konnte. Zudem ist der Nutzen der Forschung nicht im Bewusstsein der regionalen Bevölkenung verankent und die öffentliche Akzeptanz daher ungewiss. Aus diesen Voraussetzungen ergibt sich auch der Handlungsbedarf. Als Teil des ganzen Konzeptes muss die Forschung in einem Gesamtzusammenhang stehen. So ergibt sich für alle Gebiete zunächst die Notwendigkeit, adäquate Managementstrukturen mit ausreichenden Personal- und Finanzressourcen zu etablieren. Nur dadurch kann sichergestellt werden, dass in sämtlichen Biosphärenparks die relevanten Agenden, danunter auch die Forschung, hinreichend wahrgenommen und bearbeitet werden können (z.B. in Hinblick auf Konzeption, Öffentlichkeitsarbeit, Kooperation, Koordination, Dokumentation, etc.). 


\subsection{Stand der Implementierung der Sevilla- Strategie}

\subsubsection{Status quo auf nationaler Ebene und Handlungsbedarf}

Auf nationaler Ebene unterscheidet die Sevilla-Strategie zahlreiche Empfehlungen und Kriterien, die den vier Zielen zugeordnet sind. Die Biosphärenparklandschaft befindet sich in Österreich gerade im Aufbruch, der Sevilla-Strategie wurde daher bis dato wenig Beachtung geschenkt. Im Folgenden wird anhand einiger Kemkniterien der Status quo charakterisient.

Nationales Biosphärenpanknetzmerk: Es existieren zwei Organisationen, die sich um Agenden des Biosphärenparknetzwerks kümmem. Das MABNationalkomitee an der Österreichischen Akademie der Wissenschaften hat die Koordination und Vergabe nationaler MAB-Forschung die Österreichische UNESCO-Kommission die Bereiche Öffentlichkeitsarbeit und Bildung in den Biosphärenparks zur Aufgabe. Die tatsächliche Aufgabenverteilung zwischen diesen beiden Organisationen ist nicht völlig geklärt, auch fand in der Vergangenheit nur phasenweise eine Abstimmung untereinander statt.

Implementienung Sevilla-Strategie: Die Sevilla Strategie fand bisher nur in Ansätzen Eingang in die Überlegungen auf nationaler Ebene. Eine Umsetzung der Strategie auf nationaler Ebene ist nicht hinreichend diskutiert worden. Den Startpunkt für eine solche breite Diskussion sollten die in Auftrag gagebenen Basisstudien zu den Östemeichischen Biosphärenparks signalisieren.

\section{Bisherige Hindemisse der Implementienung der Sevilla-Strategie: Die} mangelnde Implementienung der Sevilla-Strategie entsprechend den Indikatoren auf nationaler Ebene hat zahlreiche Hintergnünde:

- In einer Biosphärenpark-abgewandten Forschungsstrategie des MABNationalkomitees der Neunziger Jahre, die sich stäkker mit anderen Themenfeldem beschäftigte
- Unklare Verteilung der Verantwortlichkeiten zwischen MABNationalkomitee und der Östemeichischen UNESCO-Kommission in der Vergangenheit

- Föderalistische Verwaltungsstruktur (Biosphärenparks sind Ländersache)

- Unzureichende Koordination aufgrund der unterschiedlichen, nicht gekärten Verantwortlichkeiten

- Fehlendes, nationales Rahmenprogramm, keine nationalen Planungsgnundlagen (Funktion des österreichischen Biosphärenparknetzwerks, Forschungsrahmenprogramm, Öffentlichkeitsarbeit, Überprüfungskniterien, Ausweisungsbedarf etc.)

- Unzureichender Bekanntheitsgrad in der Bevölkenung (Biosphäremparks sind in der Öffentlichkeit „,kein Thema“)

- Geschichtliche Entwicklung der Biosphärenparks (wissenschaftsmotivierte Ausweisungen)

- Fehlenden Ressourcenausstattung der Biosphäremparks (keine finanziellen Mittel, unzureichende personelle Ausstattung)

- Überlagenung durch bekanntere, national favonisienter Schutzgebietkategorien

- Geringes Interesse der Politik gegenüber dem BiosphärenparkPrädikat

- Schwierigkeit der Vemittlung und Bewerbung des Prädikats Biosphärenpark.

Ausblick: Für eine östemeichweit koordinierte Vorgangsweise bei der Umsetzung der Sevilla-Strategie ist das Setzen eines nationalen Rahmens notwendig. In diesem Rahmen sollten im Allgemeinen Aspekte entsprechend den Empfehlungen der Sevilla-Strategie, aber auch österneichspezifische Vorgaben behandelt verden. Beispielhaft sind folgende Kriterien angeführt:

- Wahmehmung der Schnittstelle zwischen intemationalen Vorgaben und regionalen Bedünfnissen

- Konzept zur Neuausweisung von Biosphärenparks 
- Konzept zur Weiterentwicklung der bestehenden Biosphärenparklandschaft

- Entwicklung von modellhaften Aktivitäten, Planungs- oder Verwaltungsinstrumenten, Programmen, etc. zur Unterstützung der Biosphärenparkaufgaben (z.B. koordinierte Bibliotheksverwaltung abgestimmte Managementpläne, etc.)

- Konzept für Öffentlichkeitsarbeit und Bewusstseinsbildung

- Konzept für nationalen Forschungsrahmen

- Akquirienung von zusätzlichen Budgetmitteln

- Einbeziehumg der Biosphärenparks in nationale Strategien und Programme

- Entwicklung einer Kommunikationsstrategie unter den Biosphärenparks

- Erstellung eines Systems zur Evaluienung der Sevilla-Strategie, abgestimmt auf die nationale Ebene

\subsubsection{Status quo und Handlungsbedarf auf Biosphärenpark-Ebene}

\subsubsection{Großes Walsertal}

\section{Überprüfung der grundsätzlichen Eignung}

Vor dem Hintergnund der im Kapitel 4.3 beschniebenen Ausschlusskniterien stellt Abbildung 39 die gutachtliche Einschätzung für das Große Walsertal dar. Zusammenfassend lässt sich attestieren, dass alle Kriterien den Schwellenwert übersteigen und damit als zutreffend eingestuft werden können. Das Große Walsental wird daher den grundsätzlichen Anfordenungen an das Biosphärenpark-Label gerecht.

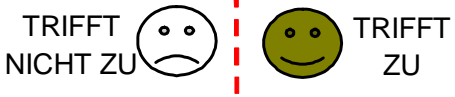

Natur- und kulturräuml. Repräsentativität

Adäquate Flächengröße

Angepasste Zonierung

Leistungsfähige Verwaltungsstruktur

Abgestimmtes Rahmenkonzept

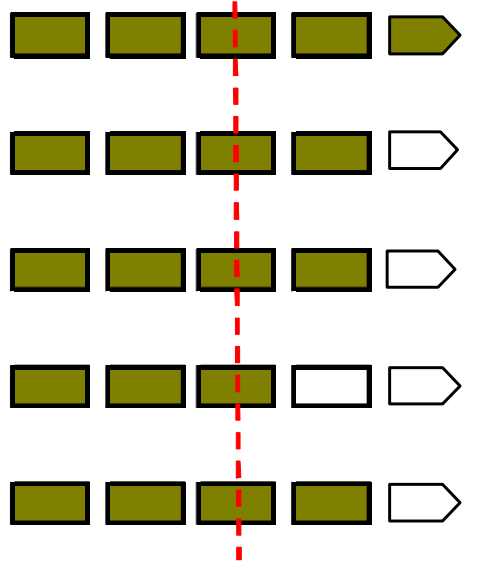

Abbildung39: GrundkätzlicheBiosphärenpark-EignungGroßes Walsatal.

Im Detail ist anzumerken:

- Natur- und kulturäumliche Repräsentativität: Das Große Walsertal ist eine geschlossene, einheitliche Talschaft. Das Tal repräsentient aufgnund der Höhenerstreckung vier für Östemeich ganz wesentliche, höhenzonale Kulturlandschaftstypen, die zusammen einen typischen alpinen Talkomplex bilden: Grünlandgeprägte Kulturlandschaften des Berglands, bandfömig ausgedehnte Waldlandschaften, subalpine und alpine Landschaften mit großen Weideflächen und Naturgnünland, und alpine Fels- und Eisregionen.

- Adäquate Flächengröße: Mit 19.200 Hektar ist das Große Walsental derzeit der zweitgrößste Biosphärenpark in Östemeich. Aufgnund der regionalen Einheit (geschlossene Talschaft, bodenständige Identität die "Walser", geschlossener Erholungsraum, pragmatische Verwaltungsgrenzen, etc.) scheint das Große Walsertal gut goeignet, die drei Leitfunktionen eines Biosphärenparks zu enfüllen.

- Angepasste Zonienung: Eine (nicht selbstverständliche) dreiteilige Zonienung des Großen Walsertals ist gegeben. Die Anteile an der 
Gesamtfläche betragen: Kemzone $17 \%$, Pflegezone $69 \%$ Entwicklungszone $13 \%$, (Regenerationszone 0,04\%). Aufgnund des hohen Anteils an naturbetonten Flächen (nund $90 \%$ ) und der gleichzeitig lockeren Besiedelungsstruktur besitzen die Kem- und Pflegezonen den weitaus größten Anteil (vergl. BIOSPHÄRENPARKMANAGEMENT GROSSES WALSERTAL, 2004). Die Verschiebung zugunsten dieser zwei Zonen und zum Nachteil der Entwicklungszone ist daher nachvollziehbar, ihre Sinnhaftigkeit kann im Hinblick auf die größenmäßig anders lautenden Vorgaben gemäß Kapitel 4.3 plausibel enklärt werden.

- Leistungsfähige Verwaltungsstruktur. Insgesamt kann das Biosphärenparkmanagement kann auf zwei Mitarbeiterposten zurückgreifen. Diese teilen sich auf: Managenin, zu $90 \%$ angestellt, Sekretärin, zu $30 \%$ angestellt, Ressouroen für PraktikantInnen, zu 80 $\%$. Es stehen insgesamt nund 130.000-200.000 Euro jährlich zur Verfügung. Wenngleich das Große Walsertal als einziger Biosphärenpark in Östemeich über derartige Ressourcen verfügt, ist das im Verhältnis zu vergleichbaren Schutzgebieten zu wenig. Die Fülle der Aufgaben kann mit diesem Mitarbeiterstand nur schwer bewältigt werden.

- Abgestimmtes Rahmenkonzept: Der Biosphärenpark verfügt über einige (sektorale) Konzepte mit richtungweisendem Charakter. Hierbei sind das Landschaftsleitbild und Zonienungskonzept, das Tourismuskonzept, die Gesamtprojektliste oder der Maßnahmenkatalog zur Optimienung des öffentlichen Verkehrs hervorzuheben. Eine Zusammenfühnung aller Teilkonzepte und Planungsunterlagen in einem umfassenden Rahmenkonzept ist bisher jedoch unterblieben

Implementierungsgrad der Sevilla-Strategie

Mit Bezug auf die in Kapitel 4.3 angeführte Methode visualisiert Abbildung 40 die SevillaTauglichkeit des Biosphärenparks Großes Walsertal.

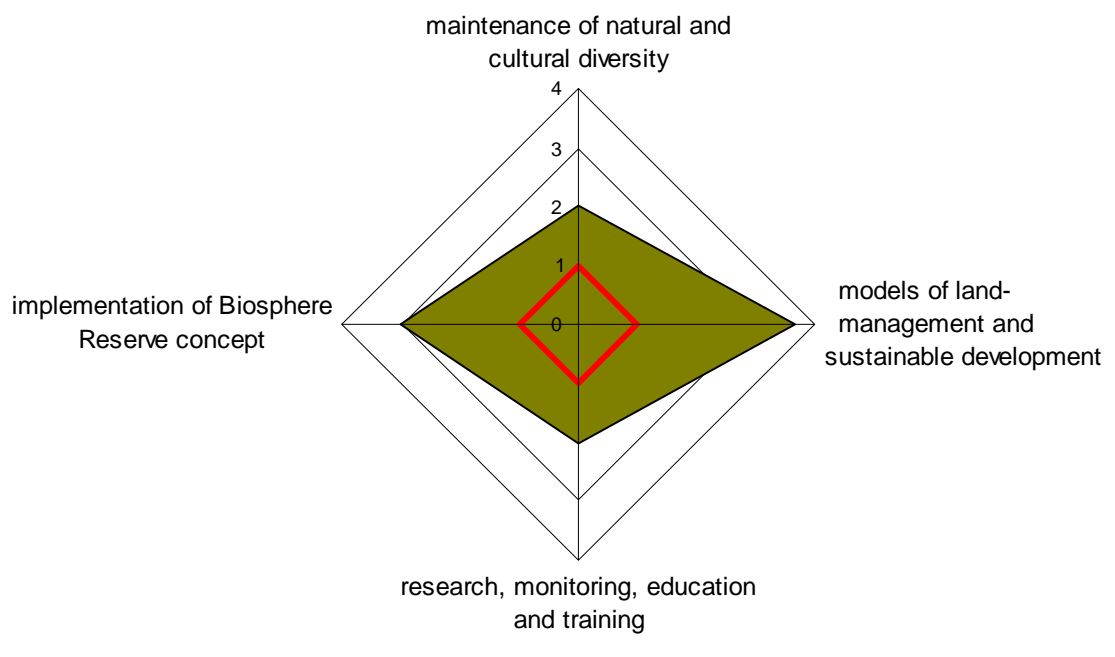

Abbildung40: Enridung de SevillaZideGroßes Walseta

Auf Grundlage der Auswertung des Expentenintervieus (vergl. Anhang-3), der Literaturauswertung und gutachtlichen Einschätzung und in Anbetracht der erst vor kurzem ausgesprochenen Anerkennung (2000) kann dem Biosphärenpark insgesamt eine recht positives Zeugnis ausgestellt werden Im Detail ist zu den vier Hauptzielen folgendes anzumerken.

- Use Biosphere Reserves to conserve natural and cultural diversity: Der Biosphärenpark Großes Walsental wurde 2000 designient. Der Aufbau des Biosphärenparkmanagements und die Erstellung von Rahmenkonzepten sind prionitäre Aufgaben in der Einnichtungsphase. Konkrete Maßnahmen zur Erhaltung der Biodiversität wurden daher vorerst hintangestellt, es existieren aber bereits entsprechende Leitlinien (vergl. BIOSPHÄRENPARKMANAGEMENT GROSSES WALSERTAL, 2004).

- Utilise Biosphere Reserves as models of land management and of approaches to sustainable development: In der Vielzahl von Rahmenkonzepten und Unterlagen (vergl. Tourismusleitbild, Landschaftsleitbild, Umweltmanagementsystem, Haushalts-Ist- 
Analyse, Nomination form, Experteninterview, Zusammensetzung der Regionalplanungsgemeinschaften, Landesenergieprogramm e5, PR-Aktivitäten) wird einer nachhaltigen Entwicklung angemessene Bedeutung zuerkannt. Es ist daher anzunehmen, dass in veiterer Folge diese Leitlinien - sofem nicht schon implementient - auch weiterhin zur Umsetzung kommen.

- Use Biosphere Reserve for research, monitoning, education and training: Hier lässt die Abbildung 40 im Gesamten zwar die Zielemeichung erkennen, jedoch sind die zwei Gruppen „research and monitoning" sowie "education and training" differenziert zu betrachten. Außer einigen sozioökonomischen Diplomarbeiten und dem Nachhaltigkeitsmonitoning mit Hilfe des Indikatorensets im Umweltmanagementsystem findet keine Biosphärenparkforschung statt. Ein spezifisches Forschungskonzept und damit finanzielle Ressourcen für die Forschung existieren nicht. Allerdings gibt es bereits jetzt ein Netzwerk an Weiter- und Ausbildungsangeboten für Kinder und erwachsene Besucher, Schulen und auch für Fachleute. Die Aufgabe der Öffentlichkeitsarbeit nimmt der Biosphärenpark sehr aktive wahr (Informationsveranstaltungen, Homepage, Poster, Folder etc.). Spezielle Informations- oder Ausbildungszentren gibt es jedoch nicht. So gesehen kann man dieses Kriterium in Summe als "erreicht" betrachten, wenngleich noch ein hoher Bedarf an Maßnahmen besteht.

- Implement the Biosphere Reserve concept: Die Implementienung der Biosphärenparkkonzeptes vird als „ausreichend enfüllt" eingestuft. Indikatoren, die darauf hinweisen: entsprechende Zonienung (mit Zuweisung der relevanten Funktion), Einbeziehung von Mensch, Natur und Wirtschaft in die Biosphärenparkplanung, entsprechende Flächengrößen, Planungs- und Strategiemechanismen etc. Allein durch die Anerkennung als Biosphärenpark durch die UNESCO aufgnund der Erfüllung der Basiskniterien kann das Emeichen dieses Zieles als gegeben angesehen werden.

\section{Handlungsbedarf}

Die obige Ausfühnung winft in Summe ein gutes Licht auf den Biosphärenpark Großes Walsertal. Nichtsdestotrotz kann in einigen Punkten auf kurz- oder mittelfinstigen Handlungsbedarf hingeviesen werden:

- Managementstruktur. Ausbau der vorhandenen Managementstruktur (Aufstockung der Personal-, Sach- und Finanzressourcen)

- „Capacity building“: Sichtung von Finanzienungsmöglichkeiten und Auf- und Ausbau von Kooperationen und Netzwerken auf regionaler, nationaler und intemationaler Ebene

- Biodiversität: Umsetzung von Maßnnahmen im Bezug auf Biodiversität und Erhaltung genetischer Ressourcen

- Forschung: Erstellung eines regionalen Forschungskonzeptes in Abstimmung mit übergeordneten Rahmenbedingungen und Bereitstellung/ Akquirienung von zweckgebundenen Ressourcen, Implementienung des Konzeptes Biosphere Reserve Integrated Monitoring (BRIM)

- Rahmenkonzept: Zusammenfühnung vorhandener Strategie und Planungskonzepte in ein regionales Gesamtkonzept, Erstellung von enfordedichen Managementplänen

- Öffentlichkeitsarbeit: Auf- oder Ausbau eines ständigen Informations-, Austausch- und Weitedbildungszentrums

- Sevilla-Richtlinien: Implementienung eines auf nationaler Ebene noch zu erstellendem Evaluienungssystems für die Sevilla-Richtlinie.

\subsubsection{Gossenköllesee}

Vor dem Hintergrund der im Kapitel 4.3 beschniebenen Ausschlusskniterien stellt Abbildung 41 die gutachtliche Einschätzung für den Gossenköllesee dar. Nur eines von fünf Kriterien übersteigt den Schwellenwert. Der Gossenköllesee wird daher den grundsätzlichen Anfordenungen an die Biosphärenpark-Prädikatisienung nicht gerecht. Die Beurteilung ist jedoch vor dem Hintergnund der von der aktuellen Sevilla-Strategie abweichenden 
Zielsetzungen bei der Entstehung des Biosphärenparks im Jahr 1977 entsprechend zu relativieren.

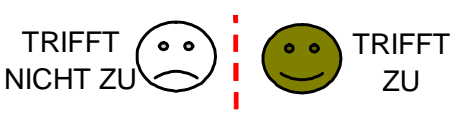

Natur- und kulturräuml. Repräsentativität

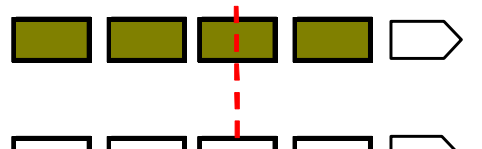

Adäquate Flächengröße

Angepasste Zonierung

Leistungsfähige Verwaltungsstruktur

Abgestimmtes Rahmenkonzept

Abbildung41: GrundsätzlidheBiosphärenpark-EignungGossenkällese

Im Detail ist anzumerken:

- Natur- und kulturräumliche Repräsentativität: Das zentrale Element des Biosphärenparks ist der 1,6 Hektar große Hochgebirgssee Gossenköllesee, der von alpinem, sporadisch beweidetem Grasland umgeben ist. Der Biosphärenpark stellt, wenn auch nur mit einem sehr keinen Ausschnitt anhand eines typischen Landschaftselementes dieser Höhenlage, den Kulurlandschaftstyp B (subalpine und alpine Landschaften mit großräumigem Weideland und Naturgrünland) dar. Die soziokulturelle Dimension ist - naturgemäß für diese Höhenlage nur sehr eingeschränkt repräsentiert (Beweidung).

- Adäquate Flächengröße: Mit 85 Hektar stellt der Biosphärenpark als kleinster Biosphärenpark der Welt ein „Kuniosum“ dar. Die Enfüllung aller drei Leitfunktionen ist dadurch ausgeschlossen.

- Angepasste Zonienung: Es existiert keine Zonienung. Aufgnund des kleinen Areals ist ihre Sinnhaftigkeit auch nicht gegeben

- Leistungsfähige Verwaltungsstruktur. Es gibt kein Biosphärenparkmanagement. Die offizielle Verwaltung wird im Zuge der ressortbezogenen Tätigkeiten von der Umweltschutzabteilung des Amtes der Tiroler Landesregienung wahrgenommen. Die Forschungsaktivitäten werden von der Universität Innsbruck koordinient.

- Abgestimmtes Rahmenkonzept: Der Biosphärenpark Gossenköllesee besitzt kein Rahmenkonzept. Konzepte oder Zielsetzungen bestehen für die Forschungsaktivitäten der Universität Innsbruck.

\section{Implementierungsgrad der Sevilla-Strategie}

Mit Bezug auf die in Kapitel 4.3 angeführte Methode visualisient Abbildung 42 die SevillarTauglichkeit des Biosphärenparks Gossenköllesee.

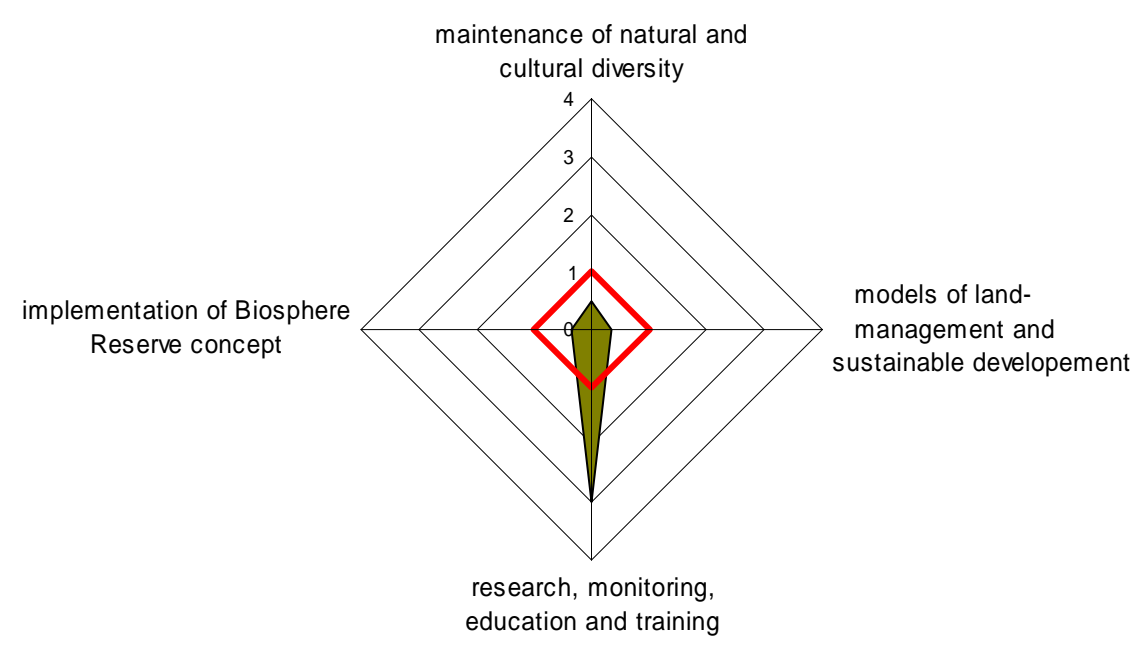

Abbildung42: Emeidungdr SeillaZideGosenkölese

- Use Biosphere Reserves to conserve natural and cultural diversity: Der Biosphärenpark ist mit 85 Hektar zu klein und kann dieses 
Kniterium daher nur teilweise enfüllen, z.B. als Refugium für seltene Arten.

- Utilise Biosphere Reserves as models of land management and of approaches to sustainable development: Da die soziokulturelle Dimension fehlt bzw. nur randlich gestreift wird, wird auch dieses Kniterium nicht erfüllt.

- Use Biosphere Reserve for research, monitoning, education and training: Es findet zwar keine MAB-Forschung statt, jedoch besitzen die Forschungsleitfragen und -themen Bezug zu MABSchwerpunkten (Projektbereiche 5 - Wetlands und 6 - Global Change). Der Biosphärenpark ist in zahlreiche Programme eingebunden, die entweder thematischen Bezug besitzen oder in direktem Zusammenhang mit dem MAB-Programm stehen (z.B. GLOCHAMORE, GLORIA, EURO-LIMPACS, MOLAR, EMERGE, etc.). Der naturwissenschaftlichen Ausrichtung steht das Fehlen sozioökonomischer, interdisziplinärer Forschung gegenüber.

- Implement the Biosphere Reserve concept: Den Empfehlungen der SevillaStrategie zur Implementienung des Biosphärenparkkonzeptes wird nur ansatzweise nachgekommen.

$\underline{\text { Handlungsbedarf }}$

Die obige Ausfühnung lässt Defizite bei fast allen Zielen erkennen. Handlungsbedarf ist in vieledei Hinsicht gegeben. Bevor detailliente Aspekte entsprechend der SevillaRichtlinie diskutient werden können, sollten zunächst gnundsätzliche Fragen, die die Weichenstellung für die Zukunft betreffen, im Vordergnund stehen.

- Biosphärenpark-Kategonie: Die Sinnhaftigkeit des Prädikats „Biosphärenpark" für den Gossenköllesee ist zu prüfen. Soll es beibehalten werden, ist die Ausweitung der Biosphärenparkfläche zu überlegen (Machbarkeitsstudie). Das ist auch die Vorraussetzung für eine adäquate Zonienung.

- Managementstruktur. Ein Biosphärenparkmanagement mit der entsprechenden Ressourcenausstattung ist einzusetzen, um die
Umsetzung der Sevilla-Strategie voranzutreiben

\subsubsection{Gurgler Kamm}

Vor dem Hintergnund der im Kapitel 4.3 beschniebenen Ausschlusskniterien stellt Abbildung 43 die gutachtliche Einschätzung für den Gurgler Kamm dar. Nur eines von fünf Kriterien übersteigt den Schwellenwert. Der Gurgler Kamm wird daher den gnundsätzlichen Anfordenungen an das Biosphärenpark-Label nicht gerecht. Die Beurteilung ist jedoch vor dem Hintergnund der von der aktuellen Sevilla-Strategie abweichenden Zielsetzungen bei der Entstehung des Biosphärenparks im Jahr 1977 entsprechend zu relativieren.

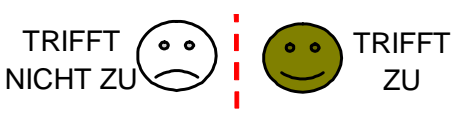

Natur- und kulturräuml. Repräsentativität

Adäquate Flächengröße

Angepasste Zonierung

Leistungsfähige Verwaltungsstruktur

Abgestimmtes Rahmenkonzept
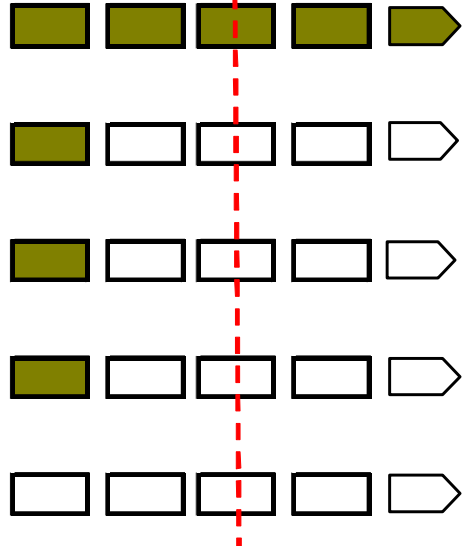

Abbildung43: GrundzätzlicheBiosphärenpark-EignungGurger Kamm

Im Detail ist anzumerken:

- Natur- und kulturäumliche Repräsentativität: Der Biosphärenpark erstreckt sich von der subalpinen, waldbestockten Zone über das subalpine und alpine Naturgnünland bis hin zur alpinen Fels- und Eisregion. Er repräsentiert daher ein für Westöstemeich typisches Landschaftsbild. Naturgemäß leben keine Menschen in diesen 
Höhenlagen. Kulturräumliche Aspekte sind jedoch - entsprechend dem natüdichen Potenzial - durch tounistische Nutzung und Schafbeweidung gegeben.

- Adäquate Flächengröße: Mit 1500 Hektar ist der Biosphärenpark relativ kein, und nimmt sich im Verhältnis zu den großräumigen Landschaftskomplexen, die er repräsentieren sollte, gening aus. Die Enfüllung der drei Leitfunktionen ist nur eingeschränkt möglich.

- Angepasste Zonienung: Es existient keine abgestufte Zonienung. Die gesamte Fläche ist als Kemzone ausgewiesen.

- Leistungsfähige Verwaltungsstruktur. Es gibt kein Biosphärenparkmanagement. Die offizielle Verwaltung wird im Zuge der ressortbezogenen Tätigkeiten von der Umweltschutzabteilung des Amtes der Tiroler Landesregienung wahrgenommen. Die Forschungsaktivitäten werden von der Universität Innsbruck (Alpine Forschungsstelle Obergurgl (AFO) als Teil des Universitätszentrums Obergurgl) koordinient.

- Abgestimmtes Rahmenkonzept: Der Biosphärenpark Gurgler Kamm besitzt kein Rahmenkonzept. Konzepte oder Zielsetzungen bestehen für die Forschungsaktivitäten der Universität Innsbruck.

\section{Implementierungsgrad der Sevilla-Strategie}

Mit Bezug auf die in Kapitel 4.3 angeführte Methode visualisiert Abbildung 44 die SevillarTauglichkeit des Biosphärenparks Gurgler Kamm.

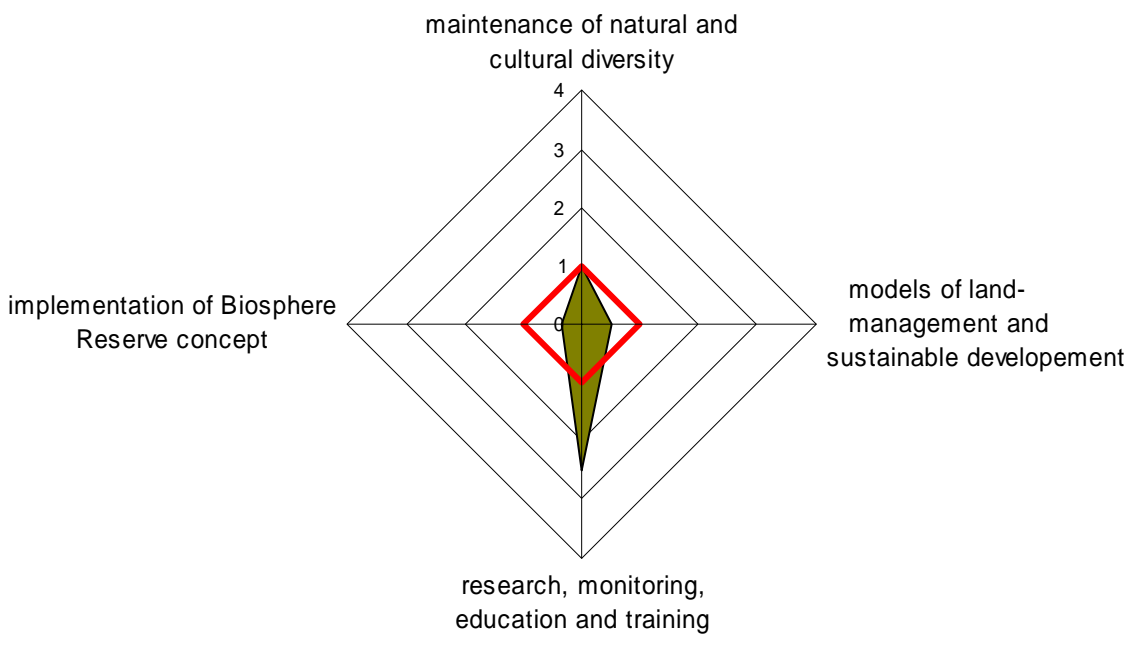

Abbildung44: Enridungdar SevillaZZideGurder Kamm

- Use Biosphere Reserves to conserve natural and cultural diversity: Der Biosphärenpark ist mit 1500 Hektar relativ klein und kann daher dieses Kniterium nur teilweise erfüllen. Im Rahmen der Schutzkategorien Ruhegebiet und Natura 2000 effolgt die Umsetzung dieser Ziele durch den amtlichen Naturschutz.

- Utilise Biosphere Reserves as models of land management and of approaches to sustainable development: Ein Abkommen über Weiderechte beschränkt die Schafauftriebszahlen und verhindent die Überweidung. Die expansive Bautätigkeit zur Emichtung wintertounistischer Anlagen in den letzten Jahren (Skilifte, Seilbahnen, Zufahrtstraßen, Speicherteiche, Beschneiungsanlagen) führte zu einem massiven Verbrauch von Naturressourcen.

- Use Biosphere Reserve for research, monitoring, education and training: Besonders erwähnenswert ist das interdisziplinäre „MAB6Projekt Obergurgl", in das auch die örtliche Bevölkenung miteinbezogen worden ist. Forschung mit dezidientem Bezug zum Biosphärenpark findet aktuell nicht statt. Es treten jedoch Schnittpunkte zu relevanten MAB-Forschungsschwerpunkten auf 
(MAB6 - Hochgebirgsforschung). Der Forschungsstützpunkt Alpine Forschungsstelle Obergurgl (AFO) der Universität Innsbruck befasst sich mit den Arbeitsrichtungen Naturraum, Kulturraum und Vorzeitforschung. Der Biosphärenpark ist in zahlreiche Programme eingebunden, die entweder thematischen Bezug besitzen oder in direktem Zusammenhang mit dem MAB-Programm stehen (z.B. GLORIA, ALTERNET). Der naturwissenschaftlichen Ausrichtung steht aktuell das Fehlen interdisziplinärer Forschung gegenüber. Die Forschungsleitfragen sind Fragen nach dem Druck, den verschiedene Landnutzungen auf alpine Landschaften ausüben können, wobei auch sozio-ökonomische Druckpunkte nicht außer Acht gelassen verden sollen, Fragen des Klimawandels und die Entwicklung von Monitoring-Methoden.

- Implement the Biosphere Reserve concept: Die Empfehlungen in der Sevilla-Strategie zur Implementienung des Biosphärenparkkonzeptes ist nur ansatzweise umgesetzt.

Handlungsbedarf

Die obige Ausfühnung lässt Defizite bei fast allen Zielen erkennen. Handlungsbedarf ist in vieledei Hinsicht gegeben. Bevor detailliente Aspekte entsprechend der SevillaRichtlinie diskutient werden können, sollten zunächst gnundsätzliche Fragen, die die Weichenstellung für die Zukunft betreffen, im Vordergnund stehen

- Biosphärenpark-Kategonie: Wenn das Biosphärenparkabel beibehalten werden soll, ist eine Vergrößenung der Biosphärenparkfläche zu überlegen, die auch eine entsprechende Zonienung zulässt. Der Umgang mit der stetigen Expansion des Skitourismus (Skilifte, Seilbahnen, Beschneiungsanlagen, Speicherseen) im derzeitigen Biosphärenparkareal ist zu hinterfragen. Seit kurzem werden auch seitens der Umweltschutzabteilung des Amtes der Tiroler Landesregienung Überlegungen zur Zukunft des Biosphärenparks angestellt.

- Managementstruktur. Ein Biosphärenparkmanagement mit entsprechender Ressourcenausstattung ist einzusetzen, um die
Umsetzung der Sevilla-Strategie voranzutreiben.

- Rahmenkonzept: Das einzunichtende Biosphärenparkmanagement muss ein Rahmenkonzept erstellen.

\subsubsection{Neusiedler See}

Vor dem Hintergnund der im Kapitel 4.3 beschniebenen Ausschlusskniterien stellt Abbildung 45 die gutachtliche Einschätzung für den Neusiedler See dar. In der Bewertung emeichen die beiden Kniterien "Natur- und kulturräumliche Repräsentativität" und "Adäquate Flächengröße" den Schwellenwert. Im Gesamten gesehen wird der Biosphärenpark Neusiedler See den grundsätzlichen Anfordenungen an das Biosphärenparklabel jedoch nur in eingeschränktem Maße gerecht. Die Beurteilung ist jedoch vor dem Hintergnund der von der aktuellen Sevilla-Strategie abweichenden Zielsetzungen bei der Entstehung des Biosphärenparks im Jahr 1977 entsprechend zu relativieren.

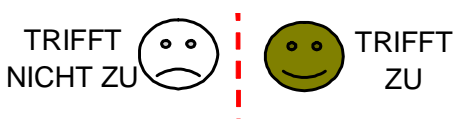

Natur- und kulturräuml. Repräsentativität

Adäquate Flächengröße

Angepasste Zonierung

Leistungsfähige Verwaltungsstruktur

Abgestimmtes Rahmenkonzept
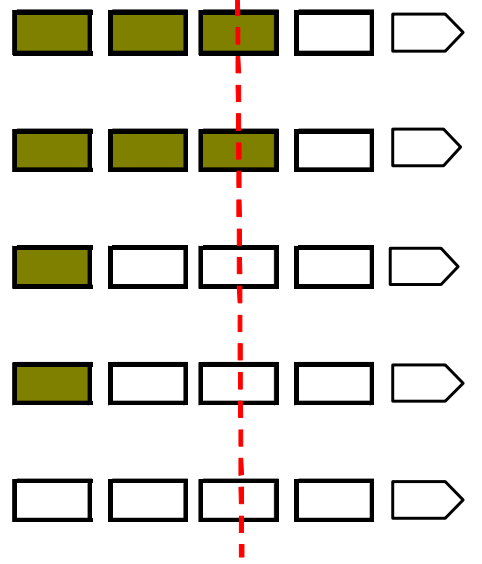

Abbildung45: GrundzätzlicheBiosphärenpark-EignungNevieder See

Im Detail ist anzumerken:

- Natur- und kulturäumliche Repräsentativität: Der Biosphärenpark 
repräsentient den für Österreich einzigartigen Landschaftstyp der außeralpinen Einbruchs- und Seebecken. Er nimmt die gesamte Wasser- und Schilffläche des Neusiedler Sees ein, nicht jedoch seine Umgebung. Er bietet daher nur wenige Anknüpfungspunkte (Fischereiwirtschaft, Schilfnutzung, etc.) zur kultumäumlichen Dimension.

- Adäquate Flächengröße: Mit 25.000 Hektar besitzt der Biosphärenpark eine ansehnliche Größe. Die Enfüllung der drei Leitfunktionen ist dennoch nur eingeschränkt möglich, da die Biosphärenparkfläche, die sich ja auf die Wassenfläche beschränkt, kaum anthropogene Nutzung zulässt.

- Angepasste Zonienung: Es existient keine abgestufte Zonienung. Die gesamte Fläche ist als Kemzone ausgeviesen.

- Leistungsfähige Verwaltungsstruktur. Es gibt zwar einen offiziell beauftragten Zuständigen für den Biosphärenpark Neusiedler See, ein Biosphärenparkmanagement im engeren Sinne existiest aber nicht. Wesentliche Aufgaben werden vom Nationalparkmanagement wahrgenommen.

- Abgestimmtes Rahmenkonzept: Der Biosphärenpark Neusiedler See besitzt kein Rahmenkonzept. Er ist jedoch in alle wesentlichen Planungen und Aktivitäten im Rahmen der Nationalparkmanagements eingebunden.

\section{Implementierungsgrad der Sevilla-Strategie}

Mit Bezug auf die in Kapitel 4.3 angeführte Methode visualisiert Abbildung 46 die SevillaTauglichkeit des Biosphärenparks Neusiedler See. Da fast alle Agenden des Biosphärenparks vom Nationalpark wahrgenommen werden, wird die Emeichung der Ziele auch unter diesem Aspekt betrachtet und in einer eigenen Darstellung festgehalten (vergl. Abbildung 47). Diese Betrachtung kann jedoch "lediglich" einen interessanten Vergleichswent darstellen, da die Zielsetzungen der beiden Schutzkategorien in wesentlichen Punkten voneinander abweichen und eine wertende Aussage daher nicht zulassen.

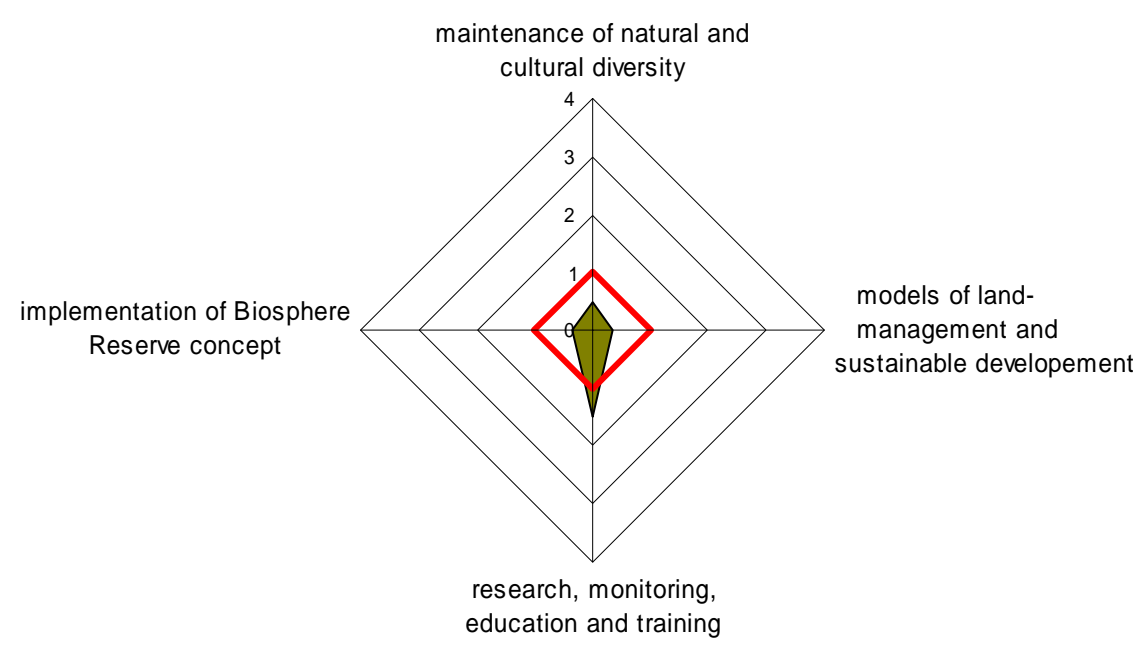

Abbildung46: Enridungder SeillaZideNerieder See

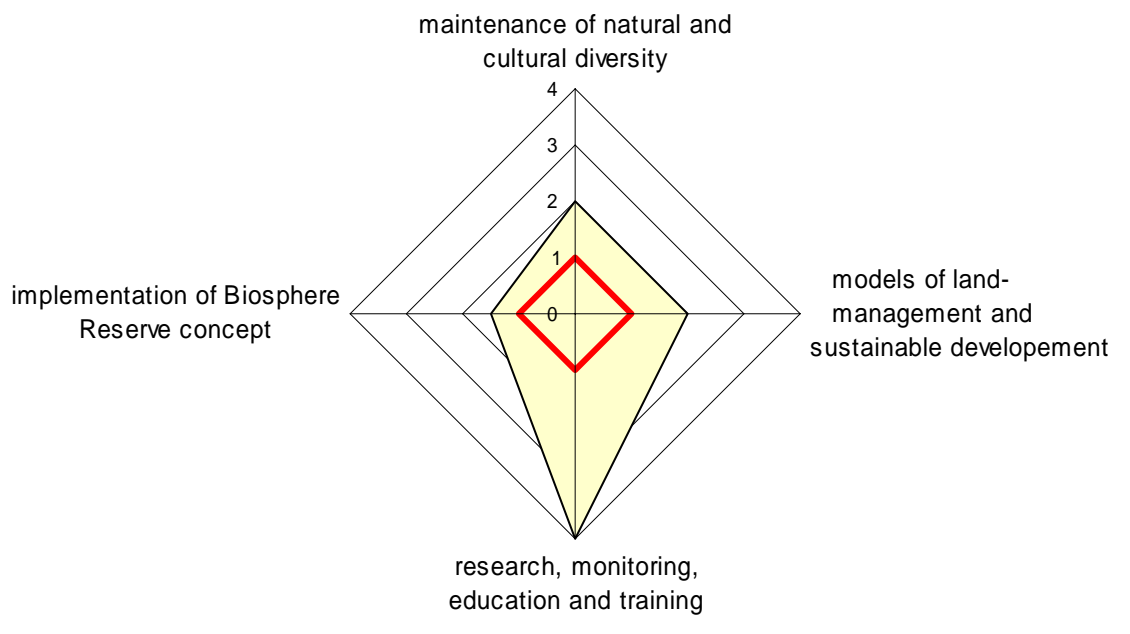

Abbildung47: Erreichungder SeillaZideNarieder Seebë Einbezihungder Nationalperkaktivitäten

- Use Biosphere Reserves to conserve natural and cultural diversity 
Der Biosphärenpark ist mit 25.000 Hektar relativ groß und kann dieses Kniterium trotzdem nur teilweise enfüllen. Der Biosphärenpark liegt am Schnittpunkt der sich überlagemden Schutzkategonien Nationalpark, Ramsar Site, World Heritage Site, Naturschutzgebiet, Landschaftsschutzgebiet und Natura 2000-Gebiet. Indirekt wird das Ziel dadurch zwar eneicht (vor allem unter dem Nationalparklabel), es finden jedoch keinedei dezidient auf den Biosphärenpark bezogene Aktivitäten statt

- Utilise Biosphere Reserves as models of land management and of approaches to sustainable development: Da der gesamte Biosphärenpark sich als geschlossene Wasser- und Schilffläche darstellt, ist die Enfüllung dieser Zielsetzung nicht möglich.

- Use Biosphere Reserve for research, monitoning, education and training: Abgesehen vom MAB5-Projekt „Der Einfluß des diffusen Nährstoffeintrags auf die Eutrophienung von Seen - Teil 2) hat keine MAB-Forschung hier stattgefunden. Es treten jedoch thematische Bezüge zu relevanten MAB-Forschungsschwerpunkten auf (MAB5 Wetlands).

- Implement the Biosphere Reserve concept: Die Empfehlungen in der Sevilla-Strategie zur Implementienung des Biosphärenparkkonzeptes wird nur ansatzweise nachgekommen.

\section{Handlungsbedarf}

Die obige Ausfühnung lässt Defizite bei fast allen Zielen erkennen Handlungsbedarf ist in vieledei Hinsicht gegeben. Bevor detaillierte Aspekte entsprechend der Sevilla-Richtlinie diskutiert werden können, sollten zunächst grundsätzliche Fragen, die die Weichenstellung für die Zukunft betreffen, im Vordergnund stehen.

- Biosphärenpark-Prädikat: Die Rolle des Biosphärenparks in der Region - als eine der vielen sich überschneidenden Schutzgebietskategonien - ist zu definieren. Der Biosphärenpark Neusiedler See steht vor allem im (Wind)Schatten (positiv oder negativ) des Nationalparks Neusiedler See. Der Umgang mit dieser speziellen Situation ist $\mathrm{zu}$ kären (Integration, Ausweitung Ausscheiden aus dem MAB-Programm, etc.)

- Adäquates Flächenausmaßs: Es ist zu überpnüfen, vie die angrenzende Kulturlandschaft einzubeziehen ist, um eine entsprechende Zonienung zu emöglichen.

- Managementstruktur. Ein Biosphärenparkmanagement mit entsprechender Ressourcenausstattung und entsprechenden Kompetenzen ist einzusetzen, um die Umsetzung der Sevilla-Strategie voranzutreiben. Es ist zu diskutieren, ob dies auch im Rahmen des Nationalparks möglich ist.

- Rahmenkonzept: Das einzurichtende Biosphärenparkmanagement muss ein Rahmenkonzept erstellen.

- Die Möglichkeit eines „gelebten“ transnationalen Biosphärenparks mit Fertö/ Ungam ist in Betracht zu ziehen.

\subsubsection{Untere Lobau}

Vor dem Hintergnund der im Kapitel 4.3 beschniebenen Ausschlusskniterien stellt Abbildung 48 die gutachtliche Einschätzung für die Untere Lobau dar. Zusammenfassend lässt sich feststellen, dass eines von fünf Kriterien enfüllt wird. Die Untere Lobau wird gesamtheitlich gesehen den grundsätzlichen Anfordenungen an das Biosphärenpark-Label nicht gerecht. Die Beurteilung ist jedoch vor dem Hintergnund der von der aktuellen Sevilla-Strategie abweichenden Zielsetzungen bei der Entstehung des Biosphärenparks im Jahr 1977 entsprechend zu relativieren. 


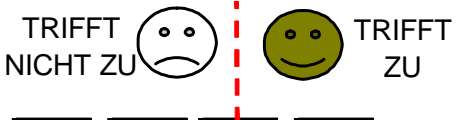

Natur- und kulturräuml. Repräsentativität

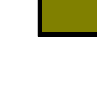

Adäquate Flächengröße

Angepasste Zonierung

Leistungsfähige Verwaltungsstruktur

Abgestimmtes Rahmenkonzept

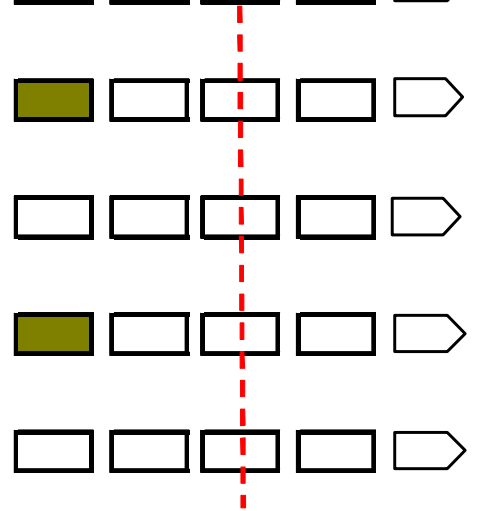

Abbildung48: GnumdätzlideBiosphärenperk-EignungL daul

Im Detail ist anzumerken:

- Natur- und kulturräumliche Repräsentativität: Die Untere Lobau gehört dem Landschaftstyp "Auwaldbänder entlang großer Flüsse“ an, der von Östemeichs Biosphärenparks nicht hinreichend repräsentient wird. Dieser Komplex ist aber bereits prionitäres Schutzobjekt des Nationalparks DonautAuen. Vor diesem Hintergnund und der aktuell eingeschränkten Interaktionsmöglichkeiten zwischen Mensch und Natur ist auch die Bewertung zu sehen.

- Adäquate Flächengröße: Die Lobau ist mit 1203 Hektar ein relativ kleiner Biosphärempark, der keinen Dauersiedlungsraum beinhaltet. Die Erfüllung der drei Leitfunktionen ist daher nur eingeschränkt möglich.

- Angepasste Zonienung: Es existient keine abgestufte Zonienung. Die gesamte Fläche ist als Kemzone ausgewiesen.

- Leistungsfähige Verwaltungsstruktur. Es gibt zwar eine von offizieller Seite nominiente Kontaktperson für den Biosphärenpark Untere
Lobau, ein eigenes Biosphärenparkmanagement existient aber nicht Wesentliche Aufgaben werden vom Nationalparkmanagement wahrgenommen

- Abgestimmtes Rahmenkonzept: Der Biosphärenpark Untere Lobau besitzt kein Rahmenkonzept. Er ist jedoch in alle wesentlichen Planungen und Aktivitäten im Rahmen der Nationalparkmanagements eingebunden.

\section{Implementierungsgrad der Sevilla-Strategie}

Mit Bezug auf die in Kapitel 4.3 angeführte Methode visualisiert Abbildung 49 die SevillaTauglichkeit des Biosphärenparks Unter Lobau. Da fast alle Agenden des Biosphärenparks vom Nationalpark wahrgenommen werden, wird die Emeichung der Ziele auch unter diesem Aspekt betrachtet und in einer eigenen Darstellung festgehalten (vergl. Abbildung 50). Diese Betrachtung kann jedoch ,lediglich" einen interessanten Vergleichswert darstellen, da die Zielsetzungen der beiden Schutzkategorien in wesentlichen Punkten voneinander abweichen und eine wertende Aussage daher nicht zulassen. 


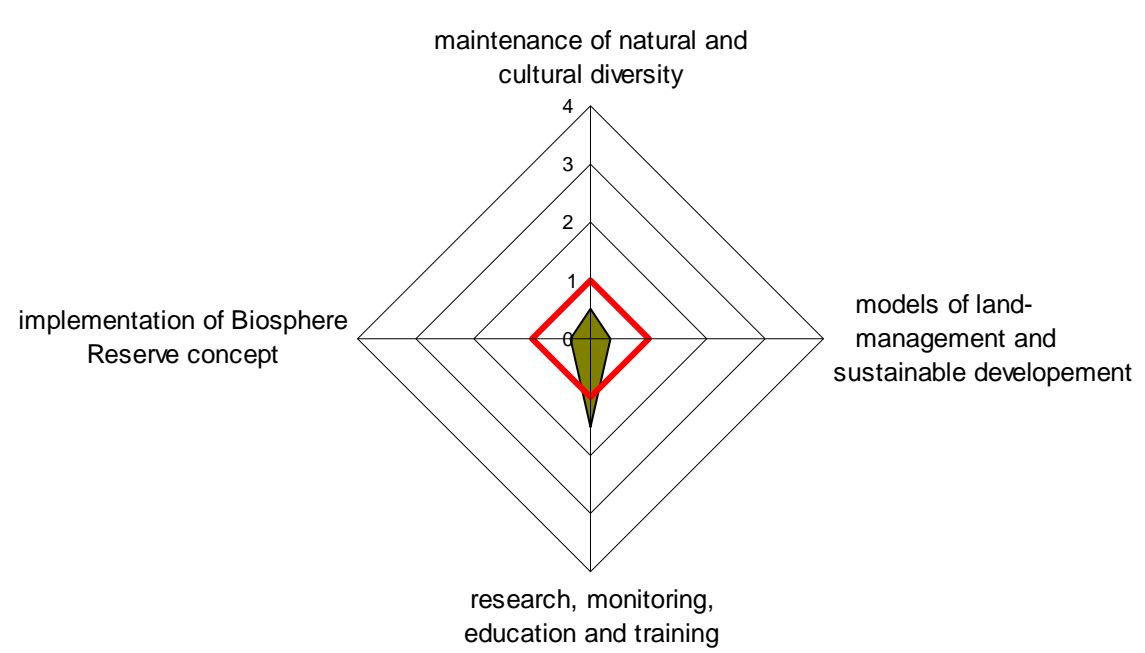

Abbildung49: Erreichung der SevillaZZideLdbau

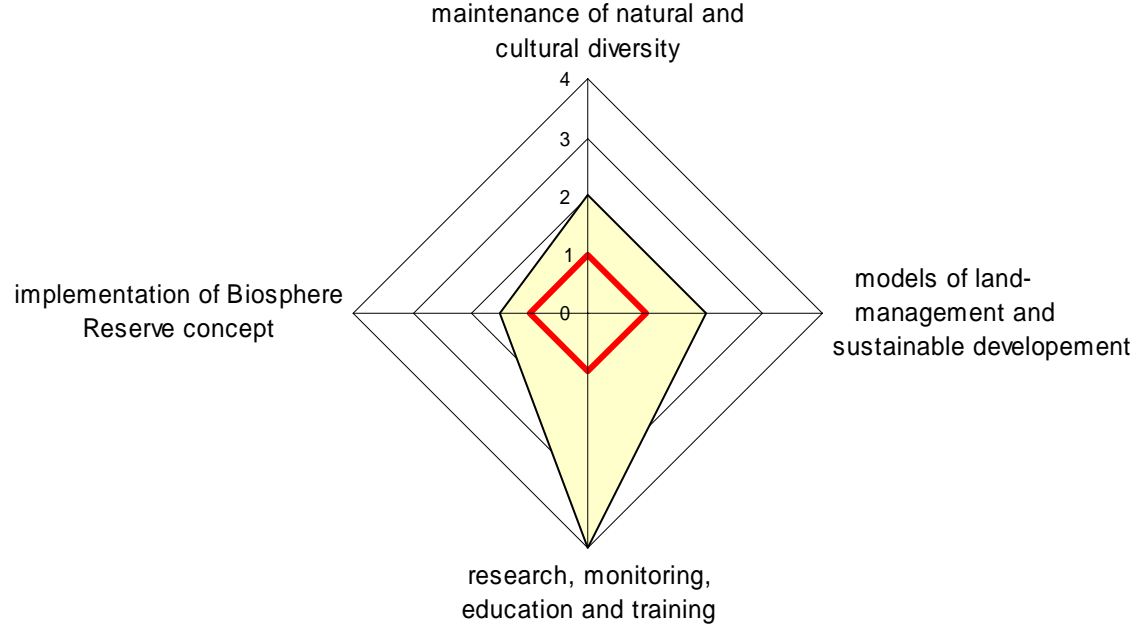

Abbildung50: Enėichungdar SeillaZideLdbau unter Einbezidungder Nationalparkaktivitäten

- Use Biosphere Reserves to conserve natural and cultural diversity:
Der Biosphärenpark ist mit 1203 Hektar relativ klein und kann daher dieses Kniterium nur teilweise enfüllen. Der Biosphärenpark liegt im Schnittpunkt weiterer, sich teilweise überlagemder Schutzkategorien wie Nationalpark, Ramsar site oder Naturschutzgebiet. Unter dem Label des Nationalparks würde das Ziel dadurch auch erreicht werden.

- Utilise Biosphere Reserves as models of land management and of approaches to sustainable development: Da der Biosphärenpark keinen Dauersiedlungsraum einbezieht, ist die Enfüllung dieser Zielsetzung nicht möglich.

- Use Biosphere Reserve for research, monitoning, education and training: Es finden keine MAB-Projekte statt. Es treten jedoch im Zuge der Nationalparkforschung und anderer freier Forschungsaktivitäten thematische Bezüge zu relevanten MABForschungsschwerpunkten auf (MAB5 - Wetlands, UNESCO's year of freshwater, etc.). Umweltbildungsaktivitäten verden vom Nationalpark und der Forstverwaltung Lobau angeboten (vor allem in der Oberen, eingeschränkt in der Unteren Lobau).

- Implement the Biosphere Reserve conoept: Den Empfehlungen in der Sevilla-Strategie zur Implementienung des Biosphärenparkkonzeptes wird nur ansatzweise nachgekommen.

\section{Handlungsbedarf}

Die obige Ausfühnung lässt Defizite bei fast allen Zielen erkennen. Handlungsbedarf ist in vieledei Hinsicht gegeben. Bevor jedoch detaillierte Aspekte entsprechend der Sevilla-Richtlinie diskutiert werden können, sollten zunächst gnundsätzliche Fragen, die die Weichenstellung für die Zukunft betreffen, im Vordergnund stehen.

- Biosphärenpark-Prädikat: Der Biosphärenpark Lobau wird vom Nationalpark Donau-Auen übedagent. Der Umgang mit dieser speziellen Situation ist zu klären (Biosphärenpark als „Klammer" um den Nationalpark, Gebietserweitenung außerhalb des Nationalparkareals, Aufgabe des Biosphärenparkprädikats, etc.), vor 
allem auch hinsichtlich der teilweise divergierenden Zielsetzungen der beiden Schutzgebietskategonien. Eine große Chance zur Belebung des Biosphärenpark-Prädikates könnte in der bereits jetzt anerkannten intemationalen Bedeutung der Lobau als Demonstrationsobjekt zur Renaturierbarkeit abgedämmter Auen liegen (vergl. 5.3.2.5). Da auch im Biosphärenparkkonzept die Rehabilitation/ Sanienung degradierter Ökosysteme in verschiedenen Regionen der Erde als modellhafte Vorzeigeprojekte angedacht sind, sollte dieser für Österreich spezielle Sachverhalt genauer überprüft werden

- Adäquates Flächenausmaß: Es ist zu überprüfen, vie angrenzende Auenökosysteme und Kulturlandschaften oder Schutzgebiete einzubeziehen sind, um unter anderem auch eine entsprechende Zonienung vomehmen zu können.

- Managementstruktur. Die Ressourcen und Kompetenzen des Biosphärenparkmanagements sind entsprechend auszuweiten, um die Umsetzung der Sevilla-Strategie voranzutreiben.

- Rahmenkonzept: Das einzurichtende Biosphärenparkmanagement sollte versuchen, ein Rahmenkonzept zu erstellen.

\section{Anmerkungen:}

Die Kurzdarstellung der Implementienung der Sevilla Strategie im Biosphärenpark Lobau entspricht der Einschätzung des Bearbeiterteams. Aus Sicht des Biosphärenparkbeauftragten, DI Haubenberger sind jedoch einige Aspekte differenzierter darzustellen:

Zur Beurteilung: Hier stellt sich die gnundsätzliche Frage, ob die mit Sevilla gesetzten Ziele absolut und auch rückwirkend in dieser Art angewendet werden sollen! Man könnte annehmen, dass mit dem Nationalpark-Gesetz für die Donau-Auen auch die Voraussetzungen geschaffen wurden, die Ziele eines Biosphären-Reservats zu erfüllen.

Zur Biosphärenparkeignung: Im Bericht zur Lobau wird festgestellt, dass die Lobau den gnundsätzlichen Anfordenungen an das BiosphärenparkLabel nicht gerecht wird. Aus Sicht des Biosphärenparkmanagements ist die Aussage so nicht richtig v.a. angesichts der langfristigen Sichenung durch eine höchstrangige Unterschutzstellung - wenn auch unter dem Etikett „Nationalpark“. Daher ist auch die Zuteilung der „Smilies“ in den Kästchen zur Eignung fragwürdig. 